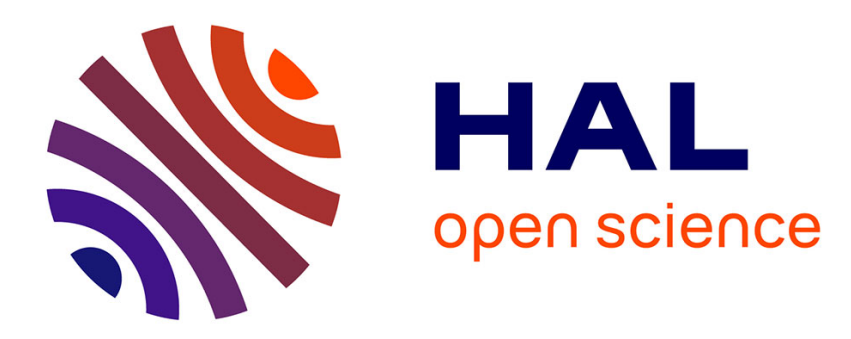

\title{
Adaptive motor control in crayfish
}

Daniel Cattaert, Didier Le Ray

\section{To cite this version:}

Daniel Cattaert, Didier Le Ray. Adaptive motor control in crayfish. Progress in Neurobiology, 2001, 10.1016/S0301-0082(00)00030-7 . hal-02346993

\section{HAL Id: hal-02346993 \\ https://hal.science/hal-02346993}

Submitted on 7 Nov 2019

HAL is a multi-disciplinary open access archive for the deposit and dissemination of scientific research documents, whether they are published or not. The documents may come from teaching and research institutions in France or abroad, or from public or private research centers.
L'archive ouverte pluridisciplinaire HAL, est destinée au dépôt et à la diffusion de documents scientifiques de niveau recherche, publiés ou non, émanant des établissements d'enseignement et de recherche français ou étrangers, des laboratoires publics ou privés. 


\title{
Adaptive motor control in Crayfish
}

\author{
Daniel CATTAERT ${ }^{1}$ and Didier LE RAY ${ }^{2}$
}

(1) Laboratoire Neurobiologie des Réseaux, CNRS, UMR 5816, Université BORDEAUX I, Biologie Animale, Bât B2, Avenue des Facultés, 33405 TALENCE CEDEX, France.

(2) CRSN - Université de Montréal, Département de Physiologie, 2960 chemin de la tour, Montréal (Qc), H3T 1J4, Canada.

Author for correspondence: D. Cattaert; Laboratoire Neurobiologie des Réseaux, CNRS, UMR 5816, Université BORDEAUX I, Biologie Animale, Bât B2, Avenue des Facultés, 33405 TALENCE CEDEX, France. 
ABSTRACT

This article reviews the principles that rule the organization of motor commands that have been described over the past five decades in crayfish. The adaptation of motor behaviors requires the integration of sensory cues into the motor command. The respective roles of central neural networks and sensory feedback are presented in an order of increasing complexity. The simplest circuits described are those involved in the control of a single joint during posture (negative feedback - resistance reflex) and movement (modulation of sensory feedback and reversal of the reflex into an assistance reflex). More complex integration is required to solve problems of coordination of joint movements in a pluri-segmental appendage, and coordination of different limbs and different motor systems. In addition, beyond the question of mechanical fitting, the motor command must be appropriate to the behavioral context. Therefore sensory information is used also to select adequate motor programs. A last aspect of adaptability concerns the possibility of neural networks to change their properties either temporarily (such on-line modulation exerted, for example, by presynaptic mechanisms) or more permanently (such as plastic changes that modify the synaptic efficacy). Finally, the question of how "automatic" local component networks are controlled by descending pathways in order to achieve behaviors is discussed. 


\section{CONTENTS}

2. Motor systems in crayfish

2.1 Abdomen and tail flip

8

2.2 Swimmerets

2.3 Walking

3. Sensory structures involved in motor control

3.1 Chordotonal organs

3.1.1 Structure

3.1.2 Coding

12

3.1.3 Involvement in motor control

3.2 Non-spiking stretch-receptors

3.3 Muscle Receptor Organs

3.3.1 Abdominal Stretch Receptor 16

3.3.2 TCMRO

3.4 Force receptors

3.4.1 Funnel Canal Organs

3.4.2 Cuticular Stress Detectors

3.5 Modulation of sensory coding

\section{Controlling a joint}

4.1 Maintaining a position

4.1.1 Tonic postural activity

4.1.2 Resistance reflex in Abdomen

4.1.3 Resistance reflex in walking legs

4.2 Controlling joint movement 25

4.2.1 Joint rhythmic movements 25

4.2.2 Role of motoneurons (swimmeret, walking legs) 26

4.2.3 Role of proprioception: negative and positive feedback $\quad 27$

$\begin{array}{ll}\text { 4.2.3.1 Proprioceptive control of swimmeret beating } & 28\end{array}$

$\begin{array}{ll}\text { 4.2.3.2 Proprioceptive control of leg joint rhythm } & 28\end{array}$

\section{Coordinating different joints}

5.1 Central control by coordinating interneurons in the leg 30

5.2 Peripheral contribution 31

5.2.1 Basal proprioceptive control of rami motoneuron in swimmeret 31

5.2.2 $\mathrm{CBCO}$ in the leg 32

5.2.3 Force receptors in the leg 33

6. Coordinating different limbs 33

6.1 Swimmerets 34

6.1.1 Bilateral synchronization 34

6.1.2 Metachronal wave $\quad 35$

6.2 Walking legs 36

6.2.1 Coordination during walking 36

6.2.2 Central coordination 'in vitro' 36 
$\begin{array}{ll}\text { 6.2.3 Role of sensory neurons } & 37\end{array}$

$\begin{array}{ll}\text { 6.2.3.1 Movement coding proprioceptors } & 37\end{array}$

$\begin{array}{ll}\text { 6.2.3.2 Force coding sensory neurons } & 37\end{array}$

\section{Coordinating different motor systems}

8.1 The "command neuron" concept

8.2 Example of the giant tail flip program 42

8.3 Example of the non-giant tail flip program 43

8.4 Sensory information gating motor program 43

$\begin{array}{ll}\text { 9. Sensory-motor integration } & 44\end{array}$

9.1 Primary afferent depolarization $\quad 44$

9.2 Mechanisms of presynaptic inhibition $\quad 45$

9.2.1 Mechanisms of presynaptic inhibition in CBCO terminals 46

9.2.2 Other mechanisms of presynaptic inhibition in crayfish sensory afferents 48

$\begin{array}{ll}\text { 9.2.2.1 Histaminergic PADs in CBCO terminals } & 49\end{array}$

9.2.2.2 Glutamatergic PADs in CBCO terminals $\quad 49$

$\begin{array}{lr}9.3 \text { Function of presynaptic inhibition } & 50\end{array}$

$\begin{array}{ll}\text { 9.3.1 Sensory processing - lateral inhibition } & 50\end{array}$

$\begin{array}{ll}\text { 9.3.2 Protection of the synapse (during Tail Flip) } & 51\end{array}$

$\begin{array}{ll}\text { 9.3.3 Automatic gain adjustment in sensory-motor circuits } & 51\end{array}$

$\begin{array}{ll}\text { 9.3.3.1 Protection of the postsynaptic motoneuron } & 51\end{array}$

$\begin{array}{ll}\text { 9.3.3.2 Adjusting gain of the negative feedback } & 51\end{array}$

$\begin{array}{ll}\text { 9.3.4 Control of afferent input by central pattern generators } & 52\end{array}$

$\begin{array}{ll}\text { 9.3.5 Mechanism of reflex reversal in the CB joint } & 53\end{array}$

10. Plastic changes in motor control $\quad 5$

$\begin{array}{ll}\text { 10.1 Habituation } & 56\end{array}$

10.1.1 Habituation of the giant escape reaction $\quad 56$

$\begin{array}{ll}\text { 10.1.2 Habituation of the reflex leg levation } & 57\end{array}$

$\begin{array}{ll}\text { 10.2 LTP at Neuromuscular junctions } & 57\end{array}$

10.3 LTP in sensory-motor synapses $\quad 59$

11. Conclusion

60

12. Acknowledgments

13. References 


\section{ABBREVIATIONS}

$\begin{array}{ll}\text { ARIN } & \text { Assistance reflex interneuron } \\ \text { ARCIN } & \text { Assistance reflex controlling interneuron } \\ \text { CO } & \text { Chordotonal organ } \\ \text { CB } & \text { Coxo-basal } \\ \text { CBCO } & \text { Coxo-basipodite chordotonal organ } \\ \text { CPG } & \text { Central pattern generator } \\ \text { CSD } & \text { Cuticular stress detector } \\ \text { DSA } & \text { Dactyl sensory afferent } \\ \text { EECO } & \text { Exopodite-endopodite chordotonal organ } \\ \text { EMG } & \text { Electromyogram } \\ \text { EPSP } & \text { Excitatory postsynaptic potentials } \\ \text { FCO } & \text { Funnel canal organ } \\ \text { GABA } & \text { Gamma aminobutyric acid } \\ \text { GF } & \text { Giant fiber } \\ \text { LTP } & \text { Long term potentiation } \\ \text { MoG } & \text { Motor giant motoneuron } \\ \text { MRO } & \text { Muscle receptor organ } \\ \text { NSSR } & \text { Non-spiking stretch receptor } \\ \text { PAD } & \text { Primary afferent depolarization } \\ \text { sdPAD } & \text { slowly developing primary afferent depolarization } \\ \text { SR } & \text { Stretch receptor } \\ \text { TC } & \text { Thoraco-coxal } \\ \text { TCCO } & \text { Thoraco-coxal chordotonal organ } \\ \text { TCMRO } & \text { Thoraco-coxal muscle receptor organ }\end{array}$




\section{Introduction}

The study of the neural bases of behaviors has largely been carried out on simple invertebrate models. The crayfish was one of the earliest and most studied models, because specific motor behaviors can be related to identified neuronal circuits. For example in 1947, Wiersma demonstrated that a single action potential in one of the giant fibers was able to elicit the escape behavior. Later, during the 60 's, it was established that in the central nervous system of various animal models such as insects (Wilson, 1961) and crustaceans (Ikeda and Wiersma, 1964), neural networks could elaborate motor patterns in the absence of any sensory feedback. However, the necessary adaptation of the command to the actual mechanical situation (such as irregularity of the substrate, or changes in the biomechanical apparatus) requires the participation of sensory feedback. It is therefore not surprising that an amount of sensory neurons coding for parameters of movements and forces exist in each motor system. For example, in a crayfish leg, there exist more than 2000 sensory neurons, for less than 100 motoneurons and 200-300 interneurons. Since the 60's, invertebrate nervous systems have proved to be excellent models for studying how sensory cues are integrated into the central neural networks commanding movements. In some cases, sensory and central neurons are so intermingled that the concept of a "central pattern generator" was balanced by the idea that "motor pattern for walking and flight systems in the insect are generated by neuronal systems in which sensory and central elements cannot be clearly distinguished functionally" (Pearson, 1985).

In this review, we address the question of how adaptive motor control is achieved in the crayfish. In fact, we do not pretend to be exhaustive owing to the amount of work made in the different motor systems of the crayfish (walking, escape swimming, swimmeret beating, scaphognathite rhythmic movements, etc.). We have rather tried to present the different problems raised by motor control (and their solutions) in an increasing order of complexity. Three main questions are thereby illustrated:

1) How are achieved posture and movement controls at a single joint? 
2) How is achieved movement coordination (of different joints in a multisegmental limb, different limbs, and different motor systems)?

3) How adapted behaviors are triggered in response to external situations?

In addition, we illustrate how, at all these levels, sensory-motor integration is exerted in both directions. On one hand, sensory information adaptively remodels the motor command elaborated by central neural networks. On the other hand, the central neural network reshapes its sensory cues at the presynaptic level (i.e. the sensory neuron itself), depending on the motor command being performed.

Finally, at a slower time scale, adaptive motor control requires the involved neural circuits to be capable of adapting themselves to the changes of constraints (for example the geometry of the limbs may change due to growing between successive molts, or accidents). Therefore plasticity must exist in the various components that participate to the motor control. This point is illustrated in the last part of the review.

\section{Motor systems in crayfish}

Several motor systems exist in the crayfish (Fig. 1A), and the motor command of most of them has been studied. Crayfishes use their four pairs of thoracic legs for walking, and their four pairs of abdominal appendages (swimmerets) to produce additional thrust. When in danger, they can rapidly escape by fast flexion of their abdomen (tail-flip). In addition, they use their claws in defense reaction and in agonist behaviors (fighting against another crayfish), or for walking on dry land. In this review, we have considered only locomotor systems. Therefore, although several other motor systems, such as the scaphognathite involved in the ventilation of the gill chamber, the stomatogastric system controlling the movements of the stomach, the antennae, antennulae and eye-talks used in active perception procedures have been described and analyzed, they will not be reviewed here. 


\subsection{Abdomen and tail flip}

In crayfish, lobsters and rock lobsters, fast escape reaction involves the rapid contraction of abdominal flexor muscles (Fig. 1B). It results in the closing of the abdomen (tail-flip response), and subsequently to the body of the animal being propelled either backward or upward, depending on the source of the mechanical stimulation. These rapid stereotyped reactions are triggered by single action potentials in any of the four large axons ("giant fibers") lying dorsally in the nerve cord of the crayfish from the circum-oesophageal ganglion to the last abdominal ganglion (Fig. 1C). These command neurons were extensively studied in the past five decades (for a review see Edwards et al., 1999). In addition to the fast giant fibertriggered escape reaction, non-giant fiber-triggered escape reaction also exists that consist in a series of smaller amplitude tail flips. Contrary to the giant fiber-triggered tail flip, this non-giant escape reaction allows a more precise control of direction of escape.

The adaptation of movements is achieved by sensory neurons such as sensory hair afferents and segmental stretch receptor neurons in the abdomen (Leise et al., 1987), and hair afferents and chordotonal organs (Newland and Nagayama, 1993) in the uropods (tail-fans of the last abdominal segment). In addition, statocysts (Schöne and Steinbrecht, 1968) that are equilibrium sensory organs located in the base of the antennulae, are involved in the fine control of abdominal and uropod posture and in non-giant tail-flips (Yoshino et al., 1980; Takahata, 1981; Takahata and Hisada, 1982a; Takahata and Hisada, 1982b; Miyan, 1984; Takahata and Hisada, 1986; Takahata and Murayama, 1992).

\section{$2.2 \quad$ Swimmerets}

The swimmerets are composed of four pairs of biramous appendages disposed on the $2^{\text {nd }}, 3^{\text {rd }}, 4^{\text {th }}$ and $5^{\text {th }}$ abdominal segments (Fig. 2A,B). A local neural network located in the corresponding hemi-ganglion of the abdominal nerve cord (Fig. $2 \mathrm{C}$ ) 
commands each swimmeret. Their motor program (Fig. 2D,E) consists in forward (returnstroke) and backward (powerstroke) rhythmic alternated movements of each swimmeret that can be recorded from anterior (la) and posterior (lb) nerve roots, respectively (Fig. 2C,D). The two swimmerets of a pair are synchronous, and each beating cycle involves the different pairs successively from the most posterior to the more anterior (metachronal wave, Fig. 2E). The organization of the motor program(s) has been largely studied in the lobster in vivo (Davis, 1968a; Davis, 1968b; Davis, 1968c; Davis, 1969a; Davis, 1969b; Davis, 1969c), and in the crayfish in vivo and in vitro (Hughes and Wiersma, 1960; Wiersma and Ikeda, 1964; Heitler, 1978; Heitler and Pearson, 1980; Paul and Mulloney, 1985a; Paul and Mulloney, 1985b; Mulloney et al., 1990; Skinner et al., 1997). Swimmeret beating is involved in different behavioral contexts such as burrowing, walking, agonist behavior, and egg aeration (in the female). Each of these motor tasks is achieved through a specific pattern of motor activity.

Several sensory structures such as swimmeret sensilla, and non-spiking stretch receptors have also been described and their effects on swimmeret motor control have been studied (West et al., 1979; Heitler, 1982; Heitler, 1986; Paul, 1989). In addition, swimmeret motor activities are also controlled by sensory neurons extrinsic to the swimmerets such as statocysts (Tatsumi et al., 1985; Knox and Neil, 1991), or leg proprioceptors coding for upward and downward movements (Cattaert et al., 1992a). Finally, swimmeret motor activity is also controlled by central connections between different neural networks commanding walking and abdominal posture (Barthe et al., 1991).

\section{$2.3 \quad$ Walking}

Crayfish and lobster possess four pairs of thoracic legs (Fig. 1A), used in locomotion. The first pair of thoracic appendages is transformed in forceps and generally not used in walking, except in crayfish (Procambarus clarkii) when the animal walks on dry land (Jamon, personal communication). Three main joints are involved in locomotion (Fig. 3A): the thoraco-coxopodite joint allows forward and 
backward movements of the leg (Fig. 3B); the coxo-basipodite joint is responsible for upward and downward movements (Fig. 3B); the mero-carpopodite joint is responsible for extension and flexion of the leg. The walking system was intensively studied in the crayfish after an in vitro preparation (Fig. 3C) was developed (Sillar and Skorupski, 1986; Chrachri and Clarac, 1989). The possibility to obtain tonic postural activity or fictive locomotion in this in vitro preparation (Fig. 3D) allowed an amount of data to be obtained on the central organization of the neural networks controlling walking (Sillar et al., 1987; Chrachri and Clarac, 1989; Chrachri and Clarac, 1990; Clarac et al., 1991; Cattaert et al., 1994a; Cattaert et al., 1994b; Cattaert et al., 1995; Pearlstein et al., 1998).

Interestingly, in each leg there exists a diversity of proprioceptors and exteroceptors such as stress cuticular detectors (Barnes, 1977; Klärner and Barnes, 1986), muscle receptor organs (Sillar and Elson, 1986; Sillar and Skorupski, 1986; Sillar et al., 1986; Skorupski and Sillar, 1988; Elson et al., 1992; Skorupski, 1992), chordotonal organs (Sillar and Elson, 1986; Sillar and Skorupski, 1986; Sillar et al., 1986; Skorupski and Sillar, 1988; El Manira et al., 1991a; El Manira et al., 1991b; Elson et al., 1992), the central projections of which, and their interactions with the walking activity have been studied (see below).

\section{Sensory structures involved in motor control}

Arthropods possess an external skeleton that allows movements only at the level of the various joints. As a consequence, most of the proprioceptors are preferentially located at those joints, where they are directly involved in the monitoring of joint movements. Scolopidial, such as chordotonal organs and cuticular stress detectors, multipolar and neuromuscular receptors are the three main types of structures that play a key role in motor control as sources of the proprioceptive information in crayfish. In many species, proprioceptive information has been described to largely influence the motor pattern, during active motion or reflexively induced movement (for reviews see: Grillner, 1981; Rossignol et al., 1988; Pearson, 1993). However, studies in arthropod motor systems (Burrows, 1992; Burrows, 1996; 
Bässler and Büschges, 1998), and especially in crustacea (Barnes et al., 1972; Clarac et al., 1978; Clarac and Chasserat, 1979; Le Ray and Cattaert, 1997; Le Ray et al., 1997a; Le Ray et al., 1997b), provided a more complete understanding of how proprioceptive information interact with the motor system.

\subsection{Chordotonal organs}

Located exclusively at the joint, chordotonal organs (COs) generally monitor both senses of the movements of unidirectional joints. However, more complex forms may be encountered at joints with several degrees of freedom, such as described in the locust (Hustert, 1982), or spread over several joints, for example in the antennae of rock lobsters (Rossi-Durand and Vedel, 1982). In the following, we will consider only the simple form of $\mathrm{CO}$, which function can be compared to that of joint receptors of mammals (Clarac et al., 2000).

\subsubsection{Structure}

The receptive element of COs consists of an elastic strand of conjunctive tissues in which are inserted from tens to hundreds sensilla (see Fig. 4A,B). Each sensillum may contain a variable number of sensitive neurons that will project their axons to the ipsilateral hemi-ganglion, through the $\mathrm{CO}$ sensory nerve. For example in crayfish, the sensory equipment of the leg proprioceptor coxopodite-basipodite chordotonal organ (CBCO) is composed of forty neurons, while the tailfan exopodite-endopodite chordotonal organ equipment consists of only twelve sensory neurons (Nagayama and Newland, 1993). However, all neurons in a given sensillum possess the same coding property, but their thresholds for spiking are distinct (Mill, 1976).

Detection of a joint movement is imputed to micro-tensions that are created between the conjunctive cells of the strand and the dendrites of sensory neurons, as demonstrated in the locust (Usherwood et al., 1968), which induces the depolarization of sensory neurons. Joint movements differently modify the organization of the tissues that compose the strand according to the kind of 
movement that is produced. In crustacea, the heterogeneity along the strand of the tissues that surround the sensilla accounts for the specificity of coding of sensory neurons, especially concerning their sensibility to dynamic changes (Mill, 1976).

\subsubsection{Coding}

All the sensory neurons innervating COs were classically described as monitoring unidirectional movements - except in the antennae (Rossi-Durand and Vedel, 1982). However, all the sensory neurons do not possess the same coding properties, since they can be more or less excited by movement. In early studies (Wiersma and Boettiger, 1959; Mendelson, 1963; Bush, 1965a; Bush, 1965b), sensory afferents were divided into two groups, one consisting of movementsensitive neurons, and the other consisting of position-sensitive neurons. Because sensory afferents are unidirectional, both groups were sub-divided into two subgroups according to the direction of the movement. Then, the sensory equipment of a given $\mathrm{CO}$ would comprise four types of coding neurons, opening or closing movement-sensitive afferents, and open or close position-sensitive cells. However, recent studies tended to demonstrate that such a simple division of $\mathrm{CO}$ sensory afferents may not reflect reality, and in crayfish, more complex coding properties have been described, in which all parameters of the movement were taken into account (Le Ray et al., 1997a).

In crayfish, the forty CBCO afferents are equally distributed in twenty stretchsensitive and twenty release-sensitive neurons that code depression and levation movement of the leg, respectively. However, the simplification in the sub-division of the afferents stops here. When sine wave stretch-release stimulation were applied to the CBCO strand in a range that corresponds to the angular sector covered by the joint during locomotor or postural behavior, only one half of the afferents were activated (Le Ray et al., 1997a) and no clear angular specificity emerged. The afferents fired action potentials for wide angular sectors and never any neuron coding specifically for a small sector was recorded. Nevertheless, within these large angular ranges, peaks of firing frequency are distinct among the CBCO sensory neurons, indicating distinct sensibility to position although each is movementsensitive. It is also noticeable that, in the angular range mimicked by the imposed 
stimulation, the number of release-sensitive afferents activated is larger than the number of stretch-sensitive afferents activated. In consequence, because their coding properties generally seem to take into account both the dynamic and static components of the joint movement, sensory afferents can no more be distinguished only on the basis of their directional sensibility. Intracellular recordings performed from release-sensitive CBCO sensory axons within the ganglion (Fig. 4C) revealed three distinct patterns of discharge in response to the same mechanical stimulation imposed to the strand (Le Ray et al., 1997a). When ramps-and-plateaus stimulation were applied to the CBCO strand, some of the afferents displayed constant highfrequency bursts of action potentials limited to the release-movement ramps while they remained silent during the maintained position plateaus (Fig. 4D, left). If faster release ramps were applied, the firing frequency of these phasic afferents increased significantly, demonstrating their sensitivity to movement velocity. Purely phasic afferents may play a key role in the fast adaptation of the limb movement to external disturbances. However, such phasic coding only accounts for changes in joint position, without any information concerning the initial position of the joint. Such a corrective system only based on movement detection would result in position gliding. The two other types of afferents that combine position detection solve this problem. First, phaso-tonic afferents (Fig. 4D, middle) are characterized by both a phasic firing that occurs during release ramps and a tonic discharge during the plateaus consecutive to release ramps. The instantaneous frequency of both the phasic and the tonic discharges is linearly correlated with the initial position from which the release ramp is applied. The more released position, the more intense firing frequency. As was the case for the purely phasic sensory neurons, the instantaneous frequency of the phasic firing of phaso-tonic afferents is also largely dependent on movement velocity. Phaso-tonic afferents combining movement and position coding may thus play a substantial role in the determination of the joint movement relative to the limb and the body. The third kind of release-sensitive CBCO afferents was continuously firing whatever the angular position of the joint (Fig. 4D, right). However, the firing frequency was largely increased during release ramps and correlated with the initial position from which the release movement is performed. In the same way, frequency of discharge of the continuous tonic firing was largely increased during the plateaus that followed release ramps. This latter group of sensory neurons may provide permanent information on the angular position of the joint, as a tonic 
background discharge. Nevertheless, when a movement is imposed, these afferents are able to change their function into a powerful angular movement- and positiondetector.

The sensory equipment of the CBCO, composed of an almost equal proportion of each afferent type, provides a complete information on CBCO release. Of course, the same three patterns were found in stretch-sensitive neurons allowing the CBCO to monitor very efficiently the whole range of $\mathrm{CB}$ joint angular movements, including both dynamic and static parameters. Such coding properties seem to be a common feature of crayfish COs since they have also been observed in the sensory neurons innervating the exopodite-endopodite $\mathrm{CO}$ of the tailfan where most of the afferents are exclusively movement-sensitive units and tonic fibers are affected by movement (Nagayama and Newland, 1993). In other arthropods such as the locust (Matheson, 1990) and the crab (Bush, 1965b), purely position-sensitive units have been described. In crayfish CBCO, such neurons could not be found. Moreover in CBCO afferents, firing frequency during movements was always higher than during plateaus, indicating that the major information conveyed by CBCO sensory afferents is dynamic rather than static. This supposes a different «philosophy» of movement control. When a perturbation occurs, a system only based on position coding would require an incompressible integration time to measure the position changes and compare with a precise pre-determined scheme, before counteracting the perturbation. In opposite, a motor system in which detection is based essentially on joint movement will be able to adjust faster the ongoing movement or the posture to counteract the perturbation.

\subsubsection{Involvement in motor control}

In many vertebrates (Lennard, 1985; Cheng et al., 1998) and invertebrates (Head and Bush, 1991; Elson et al., 1994), proprioceptive feedback has been shown to dramatically affect the motor output in accordance with the locomotor program in which the system is engaged. As proprioceptors located at the joints and excited by both movement directions, COs play a pivotal role in the control of movements. In crayfish motor system, COs have been found to interact with the abdominal motile appendages, e.g. swimmerets and uropods, as well as with the cephalothoracic 
ones, e.g. legs and antenna. Reflex responses elicited by these COs have been described first to antagonize the movement imposed to the joint (Clarac et al., 1978; Zill, 1985). But it rapidly appeared that the sign of the reflex response was closely dependent on the state of the animal, i.e. the motor program in which the central nervous system was involved (Cattaert et al., 1992b; Skorupski, 1996; Le Ray and Cattaert, 1997).

\subsection{Non-spiking stretch-receptors}

Most of crustacean mechanoreceptors have their cell bodies in the periphery, and convey sensory information in the form of actively propagated action potentials. In contrast, a particular class of proprioceptors is located at the base of limbs: they have their cell bodies located in the central nervous system and conduct graded electrotonic potentials rather than propagated action potentials. These groups of non-spiking receptors are the thoraco-coxal muscle receptor organs (TCMRO) which span the basal joint of the thoracic legs (Alexandrowicz and Whitear, 1957) (see next paragraph), the receptor at the base of the uropods of the anomura Emerita (Paul and Bruner, 1999), and a receptor complex at the base of crayfish swimmerets (Heitler, 1982). This latter, the non-spiking stretch receptor (NSSR) is composed of an elastic strand (S1) spanning the base of the swimmeret between the posterior rim of the swimmeret socket in the sternal rib of the abdomen and the anterior attach in the swimmeret near the coxopodite (see Fig. 5A,B). The strand is stretched by retraction or lateral extension of the swimmeret. The proximal part of this strand is innervated by two large axons (Fig. 5C) that ramify within the strand. The cell bodies of these sensory neurons are located centrally: one (NSSR-A) in the anterior ipsilateral quadrant and one (NSSR-P) in the posterior ipsilateral quadrant of the ganglion (Fig. 5C). These neurons are depolarized by retraction imposed to the swimmeret (Fig. 5D). During a maintained retraction imposed to the swimmeret, after an initial dynamic response and adaptation they keep depolarized as long as the position is maintained (Fig. 5D right). The amplitude of the induced depolarization is correlated with the amplitude of the imposed movement. When depolarized, the NSSR sensory neurons cause the excitation of swimmeret motoneurons, and so, NSSRs are likely involved in the control of exopodite and endopodite (rami) activity 
during swimmeret beating (see chapter 5.2.1.). There exist a second strand (S2, see fig $5 \mathrm{~B}$ ) that joins the mid-point of $\mathrm{S} 1$ to the anterior rim of the swimmeret socket. It is innervated by several small diameter axons that do not seem to have cell bodies in the periphery. Its function remains unknown.

\subsection{Muscle Receptor Organs}

In parallel with chordotonal organs that encode angular changes in joint positions, muscle receptor organs (MROs) monitor the changes in tension and length of the muscles responsible for joint movements. Originally described in the lobster abdomen (Alexandrowicz, 1951), their functions have been more precisely described in crayfish abdomen and walking legs.

\subsubsection{Abdominal Stretch Receptor}

The stretch receptor organ consists of a receptor muscle and a sensory neuron which dendrites are inserted in the connective tissue in the receptor muscle (Fig. 6A,B). Along the abdomen, stretch receptors are localized laterally (SR1) and dorsally (SR2), disposed by pairs on each side of each abdominal segment (Fields and Kennedy, 1965; Fields, 1966). Both motor axons and an inhibitory nerve, which runs to the dendrites of the sensory neurons, innervate each muscle organ. The sensory neuron dendrite endings embedded in the connective tissue are susceptible to stretch when the abdomen is flexed, and generate a potential that travels through dendrites to the cell soma (Tao-Cheng et al., 1981). The activation of two cationic channels when dendrite membrane is deformed are supposed to be responsible for the transduction of the signal and the generation of the potential in dendrites (Erxleben, 1989). Two kinds of sensory neurons innervate the receptor muscles (Eyzaguirre and Kuffler, 1955). One fast adapting neuron innervate SR1 (Fig. 6C), and one slow adapting neuron (Fig. 6D) innervate SR2 (Fields and Kennedy, 1965; Fields, 1966), a potassium conductance activated by calcium entrance during the membrane deformation being responsible for the fast adaptation (Erxleben, 1993). Coding properties of SRs are strongly modified by MRO inhibitory innervation. The 
presence of the inhibitory control allows a high-factor exponential increase in the firing frequency of the slow adapting $S R$ in response to increasing joint angle (Fig. 6E; Nja and Walloe, 1973). In contrast, when the inhibitory nerve is cut the amplification factor of the exponential is strongly reduced. Involved in postural control, each of the twenty stretch receptor sensory afferents project through the connective bundles to the brain and to the last $\left(6^{\text {th }}\right)$ abdominal ganglion, sending many short lateral branches as they traverse each of the abdominal ganglia (Bastiani and Mulloney, 1988). These inter-ganglion connections are responsible for lateral inhibition between SRs, through the thick inhibitory nerve, that tunes the response of the whole abdominal musculature (Fig. 6F; Jansen et al., 1970). Interestingly, some MRO-like receptors have also been found in crayfish thoracic segments. The $\mathrm{N}$-cells are mechanosensory neurons, which processes ramify in target muscles. They monitor thorax micro-torsion by sensing muscle passive stretch and active contraction (MacMillan and Field, 1994). According to its sensibility to muscle length, stretch receptor has first been supposed to play the role of the vertebrate muscle spindle. However, the recent observation of a complete cessation of stretch receptor firing with the starting of an abdominal extension tends to contradict this hypothesis (McCarthy and MacMillan, 1999).

\subsubsection{TCMRO}

At the first joint of crustacean walking legs, the thoracico-coxal (TC) joint, a specialized MRO, monitors forward and backward movements of the leg (Fig. 7A,B). First described in the crab (Alexandrowicz and Whitear, 1957; Bush and Roberts, 1971), it is composed of a muscle bundle that lays in parallel with the protractor muscle, to which two large diameter non-spiking sensory fibers are associated (Fig. 7C; Cannone and Bush, 1981b). The T-fiber was proposed to sense muscle tension, and the S-fiber to monitor changes in muscle length. Actually, a third fiber, the P-fiber has been recently described in the crab that performs both graded and spiking transmission (Wildman and Cannone, 1990; Wildman and Cannone, 1996). In crayfish, these fibers have been classified as dynamic velocity-sensitive and static sensory neurons, respectively (Skorupski and Sillar, 1986). TCMRO is stretched during backward movements of the leg, which results in a resistance reflex activation of promotor motoneurons in an inactive preparation, while in active preparation it will 
produce an assistance reflex activation of remotor motoneurons (Sillar and Skorupski, 1986). Central phase-locked depolarizations of both S- and T-fibers have been shown to underlay such activity-dependent changes in reflex actions from the TCMRO. When fictive locomotion is produced, the S-fiber is depolarized during promotor phase and consequently excites this pool of motoneurons while the T-fiber is depolarized during remotor phase and excites remotor motoneurons (Sillar and Skorupski, 1986). Intracellular studies revealed that both S- and T-fibers monosynaptically connected promotor motoneurons, but that in active preparation, T-fiber was also responsible for the polysynaptic inhibition of those motoneurons. Because the T-fiber also monosynaptically connects some of the remotor motoneurons, this connection being active only when the preparation produces spontaneous alternate locomotor activities, promotor motoneuron inhibition is likely to be due to inhibitory connections between remotor and promotor motoneurons (Skorupski, 1992). The efferent innervation of the TCMRO is achieved by receptor motoneurons, rm1 and rm2 (Cannone and Bush, 1981a). The stimulation of $r m 1$ and $r m 2(10 \mathrm{~Hz})$ results in the progressive contraction of the receptor muscle and the subsequent depolarization of the $\mathrm{T}$ fiber (Fig. 7D). $R m 1$ is excited by stretching the receptor during the promotor phase and inhibited by the same stimulus during remotor phase because of the T-fiber properties. When the receptor is almost maximally stretched, $r m 1$ receives a tonic inhibition from the S-fiber. During forward movements, rm1 being excited by another proprioceptor, the thoracico-coxal chordotonal organ TCCO (Skorupski and Bush, 1992), prevents the slackening of the TCMRO.

\subsection{Force receptors}

Force receptors represent another group of proprioceptors which role in motor control is particularly well established. Located on the various parts of the animal body, they may encode strains imposed to the cuticle, as well as contact with the substrate, and thus any body loading, as substrate or milieu vibrations (Wiese, 1976; Libersat et al., 1987a). 


\subsubsection{Funnel Canal Organs}

Funnel canal organs (FCOs) are sensory receptors that possess features of both mechanosensory scolopidia and chemoreceptors. Present in all the crustacean legs, they were more largely studied in crabs (Schmidt and Gnatzy, 1984; Zill et al., 1985; Libersat et al., 1987a; Libersat et al., 1987b). FCOs are innervated by 3-24 sensory cells, with 500-1400 $\mu \mathrm{m}$-long unique dendrite, which sheathed end passes through a canal in the cuticle. Two types of dendrites were described that differed essentially from the length of their ciliary segment, and every FCOs comprise two type-I sensory neurons and 1-22 type-II sensory neurons (Schmidt and Gnatzy, 1984). Both externally and internally applied forces are encoded by FCOs since the receptors are excited by both cuticular strains and strains engendered by muscle contractions (Zill et al., 1985; Libersat et al., 1987b). More distal FCOs, i.e. those located at the tip of the dactyl (the last leg segment), only respond phasically when bending forces are applied to the receptor. They likely code the contact with substrate and are also probably vibration-sensitive. In contrast, FCOs located more proximal on the dactyl express phasic firing for low amplitude bending and phasotonic responses for higher levels of stimulation. Proximal receptors also encode the direction and the velocity of the force applied (Schmidt and Gnatzy, 1984; Zill et al., 1985). In the crab, all FCO afferents discharge during the stance phase of locomotion while they remain silent during the swing phase (Libersat et al., 1987a) and during swimming (Bévengut et al., 1986).

In Crayfish, recordings from the dactyl afferent nerve during freely walking display phasic sensory activities correlated to the contact of the leg on the substrate (Cattaert, unpublished). Moreover, in vitro, mechanical bending applied to the dactyl cuticle evokes sensory discharges (Marchand et al., 1997) in the dactyl sensory nerve. The electrical stimulation of this nerve evokes reflexes that are similar to the ones obtained in the crab. Namely, these reflexes consist in the activation of levator motoneurons of the corresponding leg and depressor motoneurons of the adjacent legs in vivo (Cattaert, unpublished) and in vitro (Cattaert et al., 1994c).

\subsubsection{Cuticular Stress Detectors}


In crayfish legs, two different cuticular stress detectors (CSD1 and CSD2) have been described (Fig. 8A,B). CSD1 is located on the basipodite and CSD2 on the ischiopodite (Wales et al., 1971; Clarac, 1976). CSD2 is composed of an elastic strand containing sensory neurons, and attached to a soft cuticle area (Fig. 8C) that is stressed when force is applied to the leg. During walking, CSD2 sensory neurons fire rhythmically in phase with the locomotor rhythm (Fig. 8D). The afferent neurons of CSD2 make monosynaptic (at least $32 \%$ ) and polysynaptic connections on both levator and depressor motoneurons. Stimulation of CSD afferents elicit both excitatory and inhibitory responses in postsynaptic motoneurons. According to this characteristic, a CSD mechanical stimulation may evoke either a levation or a depression response, i.e. either a negative feedback reflex or a positive feedback reflex, respectively (Leibrock et al., 1996b). However, the sign of the postsynaptic neuron response is subdued to the intensity of the mechanical stimulation applied to the receptor. Indeed, low-threshold CSD1 afferents evoke inhibitory responses in levator motoneurons while high-threshold afferents elicit excitatory postsynaptic potentials in the same motoneurons (Leibrock et al., 1996a). The mechanism of such force-dependent reflex reversal remains unknown. However, it could be related to the observation of electrical couplings between CSD afferents within the thoracic ganglion (Marchand and Leibrock, 1994), which may spread the high-intensity stimulation-evoked sensory signal to neighboring CSD afferents that are specialized in levator motoneuron excitation.

\subsection{Modulation of sensory coding}

In many species, coding properties of proprioceptors are not constant but may vary according to the neuromodulatory environment. In crayfish, CBCO sensory afferents are subjected to a dose-dependent serotonin (5-HT) control at the level of the sensory organ. Local or bath application of low concentration $\left(10^{-6} \mathrm{M}\right)$ of $5-\mathrm{HT}$ on the CBCO strand induces a significant increase in firing of both dynamic and more static afferents (Fig. 9A,B). In contrast, at higher concentration $\left(10^{-4} \mathrm{M}\right)$ it induces the opposite effect in $20 \%$ of the sensory afferents (Rossi-Durand, 1993). Consequently in the walking animal, by modifying the coding properties of the proprioceptor, a local action of $5-\mathrm{HT}$ onto the sensory organ would change the locomotor pattern. In the 
same way, 5-HT and octopamine have been shown to dramatically modulate the reflex pathway involving the TCMRO and the promotor and remotor motoneurons by enhancing the resistance reflexes and suppressing assistance ones (Skorupski et al., 1991; Gill and Skorupski, 1996; Skorupski, 1996). Nevertheless, it is not known at which level these neuromodulators act, the sensory afferents or the motoneurons. Similar observations were done on the stick insect (Büschges et al., 1993).

Proprioceptors may also be involved in more complex regulations. In the crab, CBCO stretch and release is able to directly control the TCMRO coding properties (Head and Bush, 1991). In quiescent preparation (see Fig. 7E), stretch and release ramps applied to the $\mathrm{CBCO}$ strand evoke an increase in the firing frequency of $r m 1$ as well as $r m 2$, the other TCMRO motoneuron that also innervates the promotor muscle (performing an «extrafusal» command). In turn, activation of these motoneurons modifies the sensibility of the receptor muscle. However, during active promotor bursts, muscle receptor motoneurons are co-activated with promotor motoneurons, what strongly limits the control CBCO afferents exert on the TCMRO (Head and Bush, 1991). In the locust, similar proprioceptive control of muscle receptor sensibility has been shown in the MRO located at the coxa-trochanter joint (Bräunig and Hustert, 1983). At last, as described in insect (e.g. Burrows and Matheson, 1994), proprioceptive information may exert direct presynaptic inhibition of other afferent signal, in crayfish abdomen (Newland et al., 1996) as well as in the thoracic locomotor system (Marchand et al., 1997).

\section{Controlling a joint}

\subsection{Maintaining a position}

\subsubsection{Tonic postural activity}

During postural task, some motoneurons display continuous firing. Such tonic activity was observed in vivo (revealed by EMG recordings) and in vitro in 
motoneurons acting against gravity (depressor leg muscles, swimmeret promotor muscles, etc.). Generally, crustacean motoneurons involved in tonic firing have smaller axon diameters and, therefore, appear as smaller amplitude extracellular units in neurograms and EMGs. In addition, tonic motoneurons produce slow but highly facilitating excitatory junction potentials in the muscle fibers they innervate (Rathmayer and Erxleben, 1983). In some motor systems, different types of muscle fibers with fatigue-resistant or fatigue-sensitive characteristics have been described (Mykles, 1988). However, in most motor systems of the crayfish, there is no strict relationship between the characteristics of a motoneuron discharge and the type of muscles it innervates. Therefore, it appears that the same muscle fibers may be involved in both postural tonic and movement phasic tasks. This dual role raises the problem of the ability of such motor systems to achieve fast movements. If posture is mainly maintained by the activation of tonic muscle fibers, and active movements by the activation of phasic muscle fibers (Rathmayer and Erxleben, 1983), rapid movements are, however, not compatible with the relaxation rate of the slow muscle fibers. This problem is solved by the existence of inhibitory motoneurons (Atwood, 1965; Atwood and Morin, 1970). Among these, the common inhibitory motoneuron innervates every leg muscle (Rathmayer and Erxleben, 1983; Rathmayer and Bévengut, 1986). During locomotion in the crab, the common inhibitory motoneuron promotes phasic contractions in the limb muscles by eliminating the slow build-up of tension in tonic muscle fibers (Ballantyne and Rathmayer, 1981).

With such properties, the neuromuscular apparatus can easily switch between maintaining a tonic postural activity for a long period of time, and producing rapid movements. However, maintaining a position not only requires special characteristics of the neuromuscular system. Unexpected perturbations, due to either external events or modification of limb geometry or alteration of neuromuscular system properties, would require a different motor command to achieve the maintaining of the position. It is not surprising that in most animal groups the motor command is completed by a negative feedback providing sensory information on the movement and position of the commanded joint. This negative feedback system is termed stretch reflex in vertebrate and resistance reflex in arthropods. Its principle is simple: any movement imposed to a joint activates the motoneurons that oppose this unintended movement. It is striking that such negative feedback reflexes involve 
monosynaptic connection between the involved proprioceptive afferents and motoneurons (Clarac et al., 2000). In the next paragraphs, we review some examples of such resistance reflex that have been studied in different motor systems of the crayfish.

\subsubsection{Resistance reflex in Abdomen}

Abdominal stretch receptors are excited during abdominal flexion and code by a change in firing frequency the amplitude of the flexion (Fields, 1966). However, both types of stretch receptors do not play the same role (Fig. 10A). Stretching SR1 activates mainly the slow superficial extensor muscles that are involved in the control of postural adjustments (Fields and Kennedy, 1965). Flexion of one abdominal joint excites the SR1 of that joint, which results in the reflex activation of superficial extensors (Fig. 10A), and inhibits those of the neighboring joints ( $\mathrm{Nja}$ and Walloe, 1975). In contrast, SR2 effects are associated with the activation of the fast deep extensors that are involved specifically in the escape behavior (Fields and Kennedy, 1965). Although basic reflex activities evoked by both kinds of SR seem to be well defined, there exist however some interneurons in abdominal ganglia that respond to the electrical stimulation of the afferents originating from both sensory receptors (Fig. 10B), suggesting other more complex functions for stretch receptor proprioceptive feedback.

Afferents from the exopodite-endopodite chordotonal organ (EECO), which code movements of the endopodite versus the exopodite, produce a negative feedback onto the motoneurons that command these movements (Newland and Nagayama, 1993). However, this polysynaptic reflex remains very weak and does not represent the principal role of the EECO in motor control. EECO afferents make both electrical and chemical synapses directly onto ascending interneurons that are involved in either postural control or escape behavior (Nagayama et al., 1997; Aonuma et al., 1999). Actually, ascending interneurons integrate sensory information from various modalities, the result of which may trigger the firing of the concerned interneuron. According to the motor behavior it controls, the ascending interneuron thus couples the EECO sensory 
information to either a postural extension of the abdomen or an escape powerful tail flip (Aonuma et al., 1999).

\subsubsection{Resistance reflex in walking legs}

In walking legs, TCMRO exerts a powerful control onto promotor and remotor motoneuron activities. Applying alternate stretch and release stimulation to the receptor (Fig. 11A-C) evokes the alternate bursting of remotor and promotor motoneurons, respectively (Elson et al., 1992). Promotor motoneuron bursts could also be obtained by depolarizing the S-fiber or hyperpolarizing the T-fiber. Converse stimulation evokes remotor motoneuron bursts. During walking or postural activities, the TCMRO exerts a complex control onto motoneurons. Actually, the TC joint movements are monitored by two proprioceptors, the TCMRO and the TCCO, the first being innervated by stretch-sensitive afferents excited during leg remotion, the second by release-sensitive afferents excited during leg promotion. Parallel stimulation of both proprioceptors in an otherwise isolated preparation leads the reflex responses of promotor and remotor motoneurons to occur on both stretch and release, which indicates that stretch-evoked reflexes are imputable to the TCMRO while release-evoked ones are due to the TCCO (Skorupski et al., 1992).

In crayfish, CO proprioceptive effects on the locomotor command have been largely elucidated owing to in vitro investigations on the second leg joint proprioceptor, the $\mathrm{CBCO}$ on which we will focus in this chapter. Imposing stretch and release stimulation to the CBCO strand (Fig. 11D) generally results in the reflex activation of sets of motoneurons that are antagonistic to the imposed movement: stretch activates levator motoneurons while release stimulates the depressor motoneurons (Fig. 11E,F) (El Manira et al., 1991a). This reflex has been termed resistance reflex because it counteracts the imposed movement of the leg in the intact animal (Clarac et al., 1978). Monosynaptic connections between CBCO sensory afferents and motoneurons have been demonstrated to generate the resistance reflex originating from the CBCO (EI Manira et al., 1991a).

However, intracellular recordings of the whole set of depressor motoneurons established that their monosynaptic responses to stretch-release stimulation of the 
CBCO strand were not stereotyped. First, some depressor motoneurons were not monosynaptically activated within the studied range of stimulation (Le Ray and Cattaert, 1997). Second, while most of the motoneurons are monosynaptically connected by release-sensitive sensory afferents, some stretch-sensitive sensory afferents project directly onto one specific "assistance" depressor motoneuron (Le Ray and Cattaert, 1997; Le Ray et al., 1997b). In consequence, such activation of an agonist depressor motoneuron would reinforce, or assist, an ongoing depression of the leg. This indicates that within the same functional group some specialized subsets of motoneurons exist, as it has been previously shown in crayfish promotor and remotor motoneuron groups (Skorupski, 1992; Skorupski et al., 1992). Moreover, among the depressor motoneurons activated by the release of the CBCO strand, various shapes of monosynaptic responses to ramp-and-plateau imposed movements were observed (Le Ray et al., 1997a). Some motoneurons display purely phasic responses characterized by bursts of large excitatory postsynaptic potentials (EPSPs) during the release ramps interrupted by silences during maintained plateaus (Fig. 11E). In addition to these phasic-response motoneurons, another group of depressor motoneurons shows a sustained depolarization increasing with the release of the strand, on which phasic bursts of large EPSPs were superimposed during release ramps (Fig. 11F). Nevertheless, the response to movement remains the major monosynaptic response of motoneurons that allows fast correction of the imposed movement. The role of the sustained depolarization observed in phasotonic motoneurons would be thus to modulate the global response and prevent the motor response to shift or to be saccadic. This dual motor response organization reflects the organization in phasic and more or less tonic sensory fiber of the CBCO (see chapter 3.1.2). It emphasizes that the resistance reflex originating from this proprioceptor is essentially based on dynamic parameters, the static ones playing the role of an intrinsic modulator of the sensory-motor loop.

\subsection{Controlling joint movement}

4.2.1 Joint rhythmic movements 
The simplest rhythmic motor movements may concern rhythmic alternating activities of antagonistic muscles at a given joint. This is the case of alternating forward and backward movements of the swimmerets. Note that, in multi-joint appendages such as legs, the analysis of the controlling neural networks has demonstrated that any given joint is commanded by an elementary oscillator (Cattaert et al., 1995). These neural networks produce rhythmic activities in the absence of any proprioceptive feedback, and, therefore, can be considered as central pattern generators (CPGs). Two conditions are necessary for a neuron belongs to a CPG: (i) it must present rhythmic activities related to the network rhythm; (ii) experimental change of its activity (by injection of depolarizing or hyperpolarizing current in the neuron) must affect the rhythmic activity of the whole CPG (accelerating, slowing down, or resetting the rhythm). Except in very simple networks such as the stomatogastric pyloric network in which motoneurons are almost the exclusive components (for example the pyloric network comprises a unique interneuron $A B$ ), most networks controlling motor activity include mainly interneurons. Those interneurons can be elements of the rhythm generator, or determine which groups of motoneurons will be activated in which temporal sequence.

In each local network (located in an hemi-ganglion) commanding swimmeret beating activity, a single non-spiking interneuron (IA interneuron) is essential to the generation of a cyclic motor pattern (Paul and Mulloney, 1985b). This conclusion is supported by two observations: (i) the membrane potential of IA interneurons oscillates in phase with the swimmeret rhythm; (ii) injection of hyperpolarizing or depolarizing current in IA interneurons respectively initiates or stops the swimmeret rhythm. Such interneurons were also recorded in the walking system.

\subsubsection{Role of motoneurons (swimmeret, walking legs)}

In crustacea, motoneurons actively participate to the rhythm and pattern generation. This was first demonstrated in the crayfish abdominal ganglion for the swimmeret motoneurons (Heitler, 1978). The injection of current into these motoneurons modifies the rhythm generated by the swimmeret CPG. This property was then demonstrated for the walking system (Chrachri and Clarac, 1989; Chrachri 
and Clarac, 1990). The motoneuron membrane displays active electrical properties such as plateau potentials (Fig. 12A; Chrachri and Clarac, 1990), and, at least in some motoneurons, pacemaker potentials (Fig. 12B; Cattaert et al., 1994a). However, active properties are not always spontaneously present in motoneurons. They may require the presence of neuromodulators such as acetylcholine acting through muscarinic receptors (Chrachri and Clarac, 1990; Cattaert et al., 1994a) and other neuromodulators such as octopamine, serotonin, and proctolin (Mulloney et al., 1987; Arnesen and Olivo, 1988; Gill and Skorupski, 1996).

In addition, electrical connections exist between motoneurons belonging to the same group. This was demonstrated for swimmeret motoneurons (Heitler, 1986), and walking leg motoneurons (Chrachri and Clarac, 1989). Due to these electrical connections, and because at least some motoneurons of a given group possess conditional oscillator properties, it is possible to consider a 'half center' organization for each joint. In leg joints, alternating activities of antagonistic motoneurons involves direct inhibitory connections between these motoneurons (Chrachri and Clarac, 1989; Pearlstein et al., 1994; Pearlstein et al., 1998). Therefore, it was proposed that each joint is commanded by an elementary oscillator (Cattaert et al., 1995).

Due to the presence of active properties, motoneurons have an important role in the shaping of the motor message sent to the muscles. Moreover, motoneurons receive an amount of proprioceptive and exteroceptive sensory inputs, via monosynaptic and polysynaptic pathways, which confer to the motoneurons an important role in the adaptation of the motor control.

\subsubsection{Role of proprioception: negative and positive feedback}

During rhythmic movements, proprioceptors convey rhythmic sensory inputs to the CPG. This sensory feedback interacts with the central network, and allows the CPG to adapt to any perturbation of the biomechanical apparatus. However, proprioceptive feedback integration during active movements will depend on the phase considered. In forward walking, during powerstroke, when a leg exerts a propulsive force onto the substrate, any backward slipping will immediately activate a 
resistance reflex (Barnes, 1977). At the contrary during the returnstroke, a similar forward movement results in the activation of an assistance reflex.

The sensory structures responsible for such online adaptation may be chordotonal organs present in various appendage joints (El Manira et al., 1991a), non-spiking muscle receptor organs (such as TCMRO coding for forward and backward movements of the leg; Skorupski, 1992) or non-spiking stretch receptors (such as NSSRs spanning the base of the swimmeret and coding for retraction; Heitler, 1982).

\subsubsection{Proprioceptive control of swimmeret beating}

When the swimmeret is held in a fixed protracted position, the NSSRs exert a static negative feedback (resistance reflex) that increases the amplitude of the depolarization phase of the oscillations in powerstroke motoneurons during swimmeret beating activity (Heitler, 1986). The NSSRs, which are the only proprioceptors that do not eventually adapt to a maintained position, are likely to be responsible for steady state reflex. In addition, a dynamic effect consisting in modulation of amplitude and frequency of motoneuron activity and resetting the period of the rhythm, was also observed when a swimmeret is moved in either directions (protraction or retraction). NSSRs, which present a dynamic response to movement, could be involved in such a dynamic motor control (Heitler, 1986). However, other receptors such as spiking neurons innervating strands in the base of the swimmeret and stress receptors in the cuticle may also be involved (Heitler, 1986).

\subsubsection{Proprioceptive control of leg joint rhythm}

In walking legs, the intensity of the negative feedback depends on the state of the central network. In intact animal, a series of imposed movements to a given leg joint produces responses variable in intensity. The reflex intensity is deeply changed when the animal exhibits spontaneous movements. In such occurrences, the reflex not only changes in intensity but also in sign when it reverts from negative to positive feedback. Such reflex reversals were observed in vivo and in vitro for the two first leg joints: in the first leg joint between TCMRO and promotor and remotor motoneurons 
(Skorupski and Sillar, 1986; Skorupski, 1992; Skorupski et al., 1992; Skorupski et al., 1994), and in the second leg joint in the reflex between the CBCO and the levator and depressor motoneurons governing the coxo-basal joint (El Manira et al., 1990; Le Ray and Cattaert, 1997).

TC JOINT: When the in vitro preparation of the thoracic nerve cord is activated by muscarinic agonists of acetylcholine, the locomotor network produces fictive locomotor activity (Fig. 13A, left). On such a rhythmic preparation, a phasic stimulation of the TCMRO induces a complete resetting of the ongoing rhythm (Fig. $13 \mathrm{~A}$, right). Note that contrary to the case of a tonic preparation, in which movements applied to the TCMRO result in a resistance reflex (see Fig. 11B), phasic stimulation applied to a rhythmic preparation evokes an assistance reflex: forward movement activate promotor motoneurons, and backward movements activate remotor motoneurons (Fig. 13A, right). Rhythm entrainment by TCMRO has been proposed to result in part from the potentials that occur temporally staggered in both $\mathrm{S}$ - and T-fibers when the receptor is stimulated (Elson et al., 1992). As already mentioned above for the TCMRO, reflexes evoked by the TCCO release are phase-dependent when the preparation is active, while in quiescent preparation, only resistance reflexes are induced. In active state, both proprioceptor afferents make phasedependent connections with distinct subgroups of promotor and remotor motoneurons (see illustration of phase-dependent reflex in a promotor motoneuron in Fig. 13B). A subgroup of promotor motoneurons is excited in resistance by TCMRO stretch and a second group is excited in assistance mode by TCCO shortening. In remotor motoneurons, a comparable subdivision is observed between motoneurons that are activated in resistance by TCCO release and motoneurons activated in assistance by TCMRO stretch (Skorupski et al., 1992; Skorupski et al., 1994).

CB JOINT: The proprioceptive control exerted by the CBCO onto the motor system of the leg is not limited to a «simple» balance between resistance and assistance reflex activation of the motoneurons. In the absence of central rhythmic activity generated by the walking network, sine wave movements applied to the $C B$ joint results in alternated levator and depressor bursts in phase with the imposed rhythm corresponding to resistance reflexes (see Fig. 11E). In an active preparation displaying fictive locomotion (Fig. 13C, left), sine wave stretch-release stimulation 
applied to the CBCO strand can entrain the rhythmic activity recorded from both levator and depressor neurograms. However, phase relationship is characteristic of assistance reflex (Fig. 13C, right), with a slight delay corresponding to the forcing of an oscillator (the CPG) by another (the imposed movement). Therefore, as was described in vertebrates (Pearson et al., 1992; Schomburg et al., 1998) and insects (Hess and Büschges, 1999), crayfish sensory-motor connections are strong enough to entrain or even reset the central rhythm (El Manira and Cattaert, unpublished). The reversal of the reflex from resistance to assistance has been analyzed. It involves cyclic modulation of synaptic transmission at sensory-motor synapses (presynaptic inhibition of the CBCO sensory neurons; see chapter 9.3.4) and activation of assistance reflex interneurons (see chapter 9.3.5). In addition, during walking activity, motoneuron active properties contribute to reinforce positive feedback efficacy (see chapter 9.3.5).

\section{Coordinating different joints}

\subsection{Central control by coordinating interneurons in the leg}

The increasing number of segments and degrees of freedom in walking legs compared to swimmerets rises the problem of how to coordinate the different joints. This question is important from two points of view: (i) the same muscles may be involved in different phase relations in the walking cycle, depending on the type of walking (forward, or backward); (ii) the analysis of the rhythmic activities elicited in vitro demonstrated that, in some conditions, the different joints could display different rhythms without any coupling between consecutive joints (Cattaert et al., 1995). Therefore, a modular schema for the organization of the neural network commanding walking leg movements was proposed (Cattaert et al., 1995), in which the leg is commanded by a series of oscillators each of which governing a single leg joint. The coordination between joints is achieved by "coordinating interneurons" (Fig. 14A). Four types of such coordinating interneurons for walking activity have been described 
(Chrachri and Clarac, 1989), commanding respectively forward stance, forward swing, backward stance and backward swing (Fig. 14B).

\subsection{Peripheral contribution}

\subsubsection{Basal proprioceptive control of rami motoneuron in swimmeret}

During swimmeret powerstroke, the rami (composed of the exopodite and the endopodite in each swimmeret) are rigid as a result of their muscular contraction, and thus exert a propulsive force against the water (Fig. 15A1). At the onset of the returnstroke when the basipodite protracts due to promotor muscle contraction, the rami are bent as a result of two summed actions: the contraction of rami muscles and the resistance of water against the rami. The latter passive force accounts for the time lag between the movement of the proximal joint and the curling of the rami. It suggests that the difference between rami muscle EMGs and other muscle EMGs (Protractor and Remotor) reflects the involvement of the rami muscles in both powerstroke and returnstroke movements. This aspect of rami muscle functioning seems to be due to the fact that the innervation of these muscles is mixed; some rami muscle fibers are active in powerstroke while others are active in returnstroke (Fig. 15A1). It thus emerges that the central command is quite stereotyped and that movements result from a combination of muscle contractions and fluid resistance. Indeed, in isolated preparations, it was demonstrated that rami motoneurons are activated by a central drive (Cattaert and Clarac, 1987), and that rami motoneuron activity is closely dependent on a proprioceptor located at the basis of the swimmeret.

By comparison with unrestrained swimmeret beating (Fig. 15A1), the rami EMGs are completely abolished during swimming activity if the basipodite is maintained in a forward position, although the promotor and remotor activities are 
unchanged (Fig. 15A2). If on the contrary the basipodite is maintained in a backward position, the rami muscle activities increase conspicuously (Fig. 15A3). Moreover, in the absence of rhythmic activity (Fig. 15B), imposed movements of the basipodite result in the firing of the rami motoneurons in backward positions, and the absence of firing in forward positions. This control is very powerful, as indicated by the perfect correlation found to exist between the firing frequency of the rami motoneurons and the imposed basal angle. In fact, the basal proprioceptor that codes angle positions and movements has dual effects on the rami motoneurons: excitatory during retraction, and inhibitory during protraction. Lastly, during real movements, the rami motoneurons summate the inputs from both the central command and the basal proprioceptor. This organization allows passive forces to interact with the central output through the proximal proprioceptors. We are therefore dealing here with a quite simple mechanism where the fine distal movements are achieved on the basis of a combination of central and peripheral information.

\subsubsection{CBCO in the leg}

CBCO afferents are capable of activating motoneurons that command movements of other joint (Fig. 16). Sine wave stimulation of the CBCO strand also evokes reflex responses that spread to promotor and remotor motoneurons (El Manira et al., 1991b). In the absence of fictive locomotion, stretching or releasing the CBCO strand (equivalent to a downward or upward movement of the leg, respectively) produces depolarizing responses in promotor (Fig. 16A1) and remotor (Fig. 16A2) motoneurons. These inter-joint reflexes were demonstrated to involve monosynaptic connections between CBCO sensory afferents and promotor and remotor motoneurons (El Manira et al., 1991b). When the preparation displays fictive locomotion activities, the same movements applied to the CBCO strand evoke large and complex responses in promotor and remotor motoneurons (Fig.16B). Similar inter-joint reflexes originating form a $\mathrm{CO}$ were described at the various joints of rock lobster walking legs (Clarac et al., 1978) and, recently, in the stick insect (Hess and Büschges, 1999). Proprioceptive influences from the legs were also found to exert a 
direct modulation on the swimmeret rhythm (Cattaert et al., 1992a). At last, a recent study in crayfish clearly demonstrated that leg proprioceptive information directly exerted a transient control of the activity of uropods in postural adjustment during walking or active standing (Murayama and Takahata, 1998).

\subsubsection{Force receptors in the leg}

One major difference between the walking and swimming appendages centers on the presence in the former case of contact with a rigid substrate. It provides a firm resistive support for the propulsive force of the mobile segment and facilitates the postural adjustments necessary to preserve the overall body orientation in the field of gravity forces. This component involves additional regulatory mechanisms as compared to the swimming systems. Here, position coding and especially force coding proprioceptors, informing the central nervous system about the relative positions of the leg and the substrate play a leading role. In other words, the proprioceptive information about the geometry of the leg touching the substrate is essential to ensure efficient inter-leg coordination when walking on irregular ground. Therefore, stimulation of force receptors appears to have dramatic effects on the motor pattern.

In the mero-carpopodite joint of the crayfish cheliped, stimulation of CSD2 afferents evokes a strong increase in the discharge of flexor nerves (Vedel et al., 1975). Moreover during fictive locomotion, a powerful entrainment of the rhythmic alternation between levator and depressor motoneurons is provoked by CSD phasic stimulation (Leibrock et al., 1996b). In the same way, mechanical or electrical stimulation of the FCO afferents induces the resetting of motoneuron activities in the corresponding leg but also in adjacent legs in vivo (Schmidt and Gnatzy, 1984; Libersat et al., 1987a).

\section{Coordinating different limbs}


Crayfish locomotor systems (swimmerets and walking legs) are composed of several limbs. The coordination of these appendages is a prerequisite for efficacy of the motor system concerned. This is true for the swimmeret system, and even more crucial for the walking system, which deals with equilibrium and force distribution problems. A lot of studies have been performed in vivo and in vitro to analyze the mechanisms involved in inter-appendage coordination. If we compare walking system with the swimmeret system, the latter seems to be more stereotyped and more centrally organized than the former.

\subsection{Swimmerets}

Right and left swimmerets are very strongly coupled, and their movements are always synchronized (Hughes and Wiersma, 1960; Ikeda and Wiersma, 1964; Mulloney et al., 1990). Despite this bilateral synchronization, it was demonstrated that separate pattern generators in each hemi-ganglion govern each swimmeret (Murchison et al., 1993).

\subsubsection{Bilateral synchronization}

The bilateral synchronization is due to the existence of central coupling mechanisms involving bilateral spiking interneurons between the right and left swimmerets of a given abdominal segment (Murchison et al., 1993). In the in vitro preparation of the abdominal nerve cord, simultaneous intracellular recordings from both a left side and right side powerstroke motoneurons display synchronous oscillations of the membrane potential during proctolin-induced fictive beating activity of swimmerets (Fig. 17A). This bilateral synchrony involves spiking interneurons because it is disrupted in the presence of tetrodotoxin that suppresses spiking activity (Fig. 17B). Therefore the two segmental hemi-ganglionic networks can be considered as a unit segmental CPG. However, right and left swimmerets may display changes in their pattern of activation when the animal is tilted on one side. In this case, only the swimmerets on the lifted side are activated (Davis, 1969c; Neil and Miyan, 1986) and produce movements directed outside, that would produce a 
propulsive force helping to restore the horizontal orientation of the body. The sensory organs responsible for this equilibrium reaction, are the statocysts located at the basis of the antennulae (Schöne, 1971; Paul and Mulloney, 1986). Note that statocysts not only control swimmerets but, when the animal is rolled, they are also responsible for several other motor responses in different systems. Hence, eyestalk compensatory movements consisting in the eyestalk on the elevated side being lowered (Nakagawa and Hisada, 1992), abdominal postural adjustments (Takahata and Hisada, 1985), and uropod steering behavior consisting in the closing of the uropod on the lowered side (Yoshino et al., 1980) may be triggered by statocyst stimulation.

\subsubsection{Metachronal wave}

The coordination of the swimmeret in the different segments is maintained when the abdominal nerve cord is isolated. This clearly implies the existence of central coordinating inter-ganglionic connections between the segmental CPGs. Such interneurons were first demonstrated by Stein (1971) in the ventral nerve cord of the crayfish. Discharge in these interneurons is synchronized with motor activity of the immediately posterior ganglion, or, more rarely, the immediately anterior ganglion (Stein, 1971). Their suppression (by sectioning the medial tract) results in the abolition of the inter-ganglionic coordination. Conversely, if the entire connective is sectioned except the medial tract (containing the so-called "coordinating neurons"), the anterior ganglion may synchronize to the posterior, or vice versa. This shows that coordinating information travels in both directions within the inter-ganglionic connectives. Such interneurons were intracellularly recorded ten years later (Paul and Mulloney, 1986) in the crayfish. In fact, several types of inter-ganglionic interneurons originate in each abdominal ganglion. They receive synaptic input in the ganglion of origin and project to other ganglia. Although these interneurons were stained with the fluorescent dye Lucifer Yellow, it was not possible to follow them on their entire length. However, several lines of evidence suggest that such interneurons do not extend the entire length of the abdominal nerve cord: (i) most of them arose or terminated in G2, G3 or G4; (ii) when the number of connected ganglia reduced from six to two, the motor pattern and phase relationship between connected ganglia is unchanged. The capacity of such interneurons to achieve the metachronal 
intersegmental coordination was tested using a model in which the four pairs of swimmerets were simulated using a chain of four oscillators, each coupled to its nearest neighbors (Skinner et al., 1997). This model was capable of reproducing experimentally observed changes in intersegmental phases and periods caused by differential excitation of selected abdominal ganglia.

\subsection{Walking legs}

\subsubsection{Coordination during walking}

Recent analysis of crayfish free walking in vivo demonstrated two preferred phase couplings between ipsilateral legs 4 and 5: in phase and out of phase. In the same situation, contralateral legs display large fluctuations in their phase relationship, with slight preferred out of phase and in phase patterns. It seems that the ipsilateral antiphase pattern between adjacent legs is mainly achieved by force sensory cues. Particularly, the force receptors located at the tip of each walking leg seem to be involved in ipsilateral coupling (see section 6.2.3.2). Whether or not they are involved in contralateral coupling remains to be determined.

\subsubsection{Central coordination 'in vitro'}

Contrary to the swimmeret system, when the thoracic nerve cord is isolated in the Petri dish, the coordination of the walking legs observed during rhythmic activities, is deeply changed. Ipsilateral legs tend to be synchronized (Fig. 18A), while controlateral legs are generally not coordinated at all (Sillar et al., 1987).

The in phase coupling of central pattern generators of ipsilateral legs is very similar to the waving behavior observed in vivo in rock lobster (Pasztor and Clarac, 1983). In this spontaneously occurring behavior, all the legs of a given side display alternated forward and backward movements with the usual characteristics of a metachronal rhythm (movements of adjacent legs are slightly delayed; Barnes et al., 1972). 


\subsubsection{Role of sensory neurons}

\subsubsection{Movement coding proprioceptors}

The waving behavior described above can be triggered by autotomy of the legs (Barnes et al., 1972). Because the autotomy plane is located between the basipodite and the ischiopodite, the first joint (thoraco-coxal) keeps working and allows forward and backward movements. In this situation, all the coxopodites of the same side produce synchronized movements. A sensory organ (the thoraco-coxal muscle receptor organ - TCMRO; see section 3.3.2) may be partially responsible for this coordinating pattern. When the thoracic nerve cord is dissected out in the Petri dish, sinusoidal stimulation applied to the TCMRO of the fourth ganglion evokes a segmental assistance (positive) feedback activity in the remotor of the fourth ganglion (remotor motoneurons fire on TCMRO stretch and promotor motoneurons on release). In addition, this assistance feedback is synchronized with an interganglionic reflex response in the remotor motoneurons of the third ganglion (Fig. 18B). This result and the fact that the isolated thoracic nerve cord of the crayfish only display synchronized ipsilateral motor activities strongly suggest that central and peripheral mechanisms coexist for coordinating ipsilateral legs. Synchronization is achieved by central and sensory (TCMRO) in phase mechanisms, and out of phase adjacent leg pattern is mainly achieved by sensory mechanisms.

\subsubsection{Force coding sensory neurons}

In crustacea, force-coding receptors considerably influence the inter-leg coordination. During walking for example, the stability of the phase relationship between the left and right legs of a given segment is enhanced when the crayfish is loaded (weight increased by $25-50 \%$ ). Under these conditions, the phase histograms become unimodal, with mean phases of about 0.5 and lower standard deviations than in the case of unloaded animals (Clarac and Barnes, 1985). Among the force 
coding proprioceptors of the crayfish legs, two sensory structures seem to play a major role in leg movement coordination. The first is located at the tip of each leg (the dactyl sensory afferents, DSAs), and the other is situated in the proximal part of the leg (cuticular stress detectors, CSDs). The CSDs are mainly active during the stance phase and reinforce the activation of muscles involved in propulsive forces. The role of the DSAs, which are sensilla associated with cuticular structures in the dactyl, has been studied during locomotion in the crab (Libersat et al., 1987a; Libersat et al., 1987b). In intact animals, electrical stimulation of DSA sensory nerve results in levation of the proper leg and depression of adjacent ones. This reflex is phase dependent, since it is more effective at the end of the stance than at the beginning.

When stimulation were applied to the sensory nerve of DSA in vitro in the crayfish, while recording from motor nerves to the levator and depressor muscles, the responses were similar to those recorded in intact animals, and demonstrated that these receptors are involved in intra- and inter-leg reflexes. Fig. 19A gives two simultaneous recordings from the levator and depressor nerves of the $4^{\text {th }}$ leg, in an isolated preparation of the three last thoracic ganglia, with legs 4 and 5 attached. Electrical stimulation of the DSA nerve of the $4^{\text {th }}$ leg resulted in the activation of the levator 4 and the inhibition of the depressor 4 (Fig. 19A, left), while electrical stimulation of the DSA nerve of the $5^{\text {th }}$ leg had the opposite effect (Fig. 19A, right). These effects were observed at stimulation intensities just above the threshold, and were therefore assumed not to reflect a protective reflex.

Libersat et al. (1987b) have investigated the role of DSAs in inter-leg coordination in vivo, during free walking in the intact crab. Brief electrical stimuli delivered to the $3^{\text {rd }}$ leg DSA during walking modified the period of the ongoing cycle in a phase dependent manner. During the stance phase, the period was shortened, whereas it was increased during the swing phase. There exists a very narrow range 
of phase values (just at the end of the stance phase of leg 3, which corresponds to the onset of the stance of leg 4) during which the stimulation of DSA 3 does not change the period. Indeed, in the freely walking animal, DSA 3 are cyclically stimulated by the contact with the substrate, and these sensory cues are incorporated into the coordination process.

The coordinating role of these force-coding sensory cues was investigated in experiments where leg 3 was artificially maintained in the levated position during walking. Under these experimental walking conditions, leg 2 and leg 4 were antiphase locked, while leg 3 did not display any rhythmic activities but only a tonic firing in the depressor EMGs as the result of resistance reflexes (Fig. 19B, middle). This phase relationship between leg 2 and leg 4 is abnormal since these legs move in phase in natural walking (Fig. 19B, left). Nevertheless, when repetitive electrical stimulation of the DSA of leg 3 was delivered at the onset of each depressor 4 activity, it induced regular bursting in the depressor muscle of leg 3 (Fig. 19B, right). More importantly, these stimuli completely reset the depressor bursting phase relationships of leg 2 and leg 3 within leg 4 . With the electrical stimulation used, it was not possible of course to identify the sensory information involved. The sensilla may have been coding the loading of the leg, or the unloading of the leg since both occurred. In the latter case, the levation of the leg induced by DSA electrical stimulation would correspond to an assistance reflex reinforcing the levator motoneurons of this leg while activating the depressor motoneurons of adjacent legs. Although this hypothesis needs to be confirmed experimentally, the inter-leg resetting induced by stimulation of these mechanoreceptors might have involved sensorymotor pathways controlling inter-leg coordination, which normally control the walking program.

DSA reflexes are polysynaptic and involve central local interneurons and interganglionic coordinating interneurons (Cattaert, unpublished). This wiring of the reflex pathways differs from the central coupling responsible for the synchronous activities 
of all the legs shown in Fig. 18A. This central coupling is achieved through "in phase" inter-ganglionic coordinating interneurons that may be switched off during locomotion, whereas the "out of phase" interneurons that are responsible for the alternate walking pattern are facilitated by DSAs. This mechanism does not however involve a strict alternation between adjacent legs, but rather provides cyclical timing signals that are incorporated into the walking CPG of each leg. Depending upon the strength of these effects, a whole range of situations can be observed, from the total absence of coordination to strict alternation. Although the fundamental central relationships between ganglionic oscillators may be very similar in swimming and walking systems, a large part of the latter network seems to be devoted to sensorymotor integration, so that the sensory cues from the legs are predominantly involved in reshaping the inter-leg coordination.

\section{Coordinating different motor systems}

More generally, motor systems are not independent from each other. Instead, a motor behavior involves generally the participation of several parts of the body. For example during agonist behaviors in crayfish, claws, legs, abdomen, swimmerets and uropods are simultaneously activated in complex patterns. How are such complex behaviors controlled by the central nervous system? To which extent the superior centers (cerebroid ganglia, suboesophageal ganglia) exert a direct and separate control onto each of these motor systems? An answer to these questions was given in the 50's, with the discovery of "command neurons" in the crayfish circumoesophageal connectives (Wiersma, 1947), and led to the hypothesis that each behavior could be driven by a single command neuron or a small set of such neurons. Since this pioneering work, the concept of "command neuron" has evolved and it is now admitted that behaviors involve concomitant activation of several descending interneurons.

In addition, a number of interneurons involved in the coordination of different motor systems have been studied. These interneurons are coordinating interneurons rather than command neurons because they receive inputs from one motor system 
and they influence another motor system. For example during walking in the intact animal, a relative coordination exists between the walking leg system and the swimmeret system (Cattaert and Clarac, 1983). In the lobster Homarus gammarus, during walking on a treadmill, swimmerets generally display beating movements that can either be not coordinated with the walking rhythm, or slightly coordinated in a 2:1 pattern (Fig. 20A1), or even absolutely coordinated (1:1). In this later case (Fig. 20A2), swimmeret beating occurs when one of the fifth legs terminates its powerstroke (stance phase).

When swimmeret beating is such 1:1 coordinated to the walking leg rhythm, the metachronal wave duration is no more related to the swimmeret beating period. This result would indicate that walking disorganizes the swimmeret beating, and that each walking step activates a single swimmeret beating cycle, the metachronal wave duration of which is determined by the intensity of the coupling between the walking legs and the swimmeret system. The period of the swimmeret beating is then that of the walking system and is therefore not related to the metachronal wave duration. This coordination between walking system and swimmeret system may contribute to prolong the propulsive thrust of the more posterior legs during forward waking. The origin of such a coupling between the two systems seems to involve both intersegmental interneurons receiving their inputs directly from the central activity of the walking CPGs, and interneurons that convey sensory information from the CBCO to the swimmeret system (Cattaert et al., 1992a). In fact, in the crayfish in vitro preparation, rhythmic electrical stimulation delivered to the CBCO nerve from the 5th leg entrains the swimmeret rhythm in absolute coordination mode (Fig. 20B).

\section{Triggering a motor program}

\subsection{The "command neuron" concept}

A class of interneurons was very early defined by their ability to elicit a recognizable behavior when stimulated. For this reason such interneurons were 
named "command neurons". For example a single spike in one of the giant fibers of the ventral nerve cord of the crayfish, produces a tail-flip escape response (Wiersma, 1947). Likewise, "command neurons" were described for swimmeret beating (Wiersma and lkeda, 1964), forward and backward walking (Bowerman and Larimer, 1974b), and for postural reactions such as defense posture (Bowerman and Larimer, 1974a) or abdominal extension (Bowerman and Larimer, 1974a).

\subsection{Example of the giant tail flip program}

The best example of a motor program triggered by a "command neuron" in which the circuitry has been extensively studied remains the escape reaction. The neuronal organization of this system allows the production of an adapted motor behavior in response to a given external stimulation. In the escape reaction of the crayfish (for a review see Edwards et al., 1999), mechanical stimuli are processed by a series of sensory interneurons (Fig. 21). If the stimulus is sudden and large enough, they activate in turn giant fibers that command a single fast stereotyped tailflip (Mittenthal and Wine, 1973; Wine and Krasne, 1982). In contrast, when the stimulus is more progressive, the sensory interneurons activate a network of premotor interneurons that commands a series of finely adapted tail-flips (Kramer and Krasne, 1984).

In the giant fiber-mediated escape reaction, the command neurons (the giant fibers; GFs) directly connect to giant motoneurons (MoGs) specific of the GFmediated escape reaction, and to fast flexor motoneurons via a set of segmental giant interneurons (Kramer et al., 1981a; Kramer et al., 1981b). This design is likely the result of an evolutive adaptation that allows rapid responses (a few milliseconds). The only two possibilities are to produce either a backward or an upward/forward escape reaction depending on the source of mechanical stimulation. When the stimulation is delivered to the posterior part of the body, lateral giant fibers are excited, and because they only contact the abdominal MoGs of the most anterior abdominal segments ( 2 and 3 ), the movement of the tail propels the animal upward and forward (Fig. 21, left part). In contrast, when the stimulation is delivered to the anterior part of the body (either mechanical or visual), the medial giant fibers are 
activated. Because they contact MoGs of all abdominal segments (2, 3, 4 and 5), a backward escape movement is elicited due to the flexion of the most posterior segments (Fig. 21, left part). In these GF-mediated responses, interneurons are involved in the transmission of sensory inputs to the giant fibers, but once the behavioral choice is made, there is no online change in the execution.

\subsection{Example of the non-giant tail flip program}

Contrary to the GF-mediated escape reaction that elicits a single tail-flip, the non-giant responses consist in a series of extensions/flexions of the abdomen (Reichert and Wine, 1982). This reaction is produced when the stimulus is not sharp enough to elicit a GF-mediated reaction. In this case, a motor program is elaborated that produces an output more finely adapted to the stimulus, via a circuitry different from the GF-mediated escape reaction. Non-giant escape behavior is produced by the fast flexor motoneurons and does not involve the MoGs (Fig. 21, right part). Nongiant escape behavior results from the processing of many different sensory inputs by a population of premotor interneurons, each of which contributes modestly to the excitation of the fast flexor motoneurons. Depending on the localization of the stimulus, a set of premotor interneurons is activated in a combination that specifies the exact pattern of activation of the fast flexor motoneurons (Kramer and Krasne, 1984). The result of this slow computation, which lasts many tens of milliseconds (Reichert and Wine, 1982), is to produce an escape response exactly adapted to the stimulus source. Note that very often, non-giant tail-flips are elicited after a GFmediated tail-flip. This allows the animal, after an initial rapid stereotyped escape reaction to adapt more precisely the escape behavior.

\subsection{Sensory information gating motor program}

The force receptors (FCOs), located on the dactyl of each leg, seem to be essential for triggering motor program in which force is exerted on the substrate. For example, when a crayfish is held above the substrate without any contact with the 
substrate, lateral exploring movements are elicited. Similarly, in the crab, the simple loss of contact with the substrate, i.e. the complete cessation of firing of all of the FCOs, is sufficient to initiate the swim program (Bévengut et al., 1986).

\section{Sensory-motor integration}

As previously presented in this review, sensory afferents continuously feed the central neural networks during motor activities. However, sensory-motor interactions are not stereotyped and a number of mechanisms exist that allow the sensory inflow to be processed in a way specific to the ongoing activity. This activity-dependent treatment of the sensory afferent message may involve gating mechanisms on polysynaptic sensory-motor pathway interneurons, or directly involve the sensory axon by presynaptic mechanisms. In this chapter, we will present evidences of the earliest processing of sensory message at the level of the sensory axon itself. Presynaptic inhibition consists of a negative control of the synaptic efficacy exerted onto the presynaptic element of the synapse. It was described first in the crayfish neuromuscular junction (Dudel and Kuffler, 1961), and in primary afferents of the flexor muscles in the cat (Eccles et al., 1962). Since these pioneering works, presynaptic inhibition has been described in many neuronal systems from both invertebrates and vertebrates.

In the following chapters, the presentation of the characteristics of presynaptic inhibition will be based on the example of CBCO afferents. In addition, the mechanisms of presynaptic inhibition existing in the various systems of the crayfish in which it has been described will be reviewed.

\subsection{Primary afferent depolarization}

In the earliest studies in mammals, presynaptic inhibition of primary afferents has been associated with depolarization (Frank and Fuortes, 1957). Similarly, in 
crayfish, primary afferent depolarizations (PADs) were observed in intracellular recordings from the terminals of telson tactile hair neurons, in response to electrical stimulation of lateral and medial giant axons and tactile stimulation of corresponding receptive field (Kennedy et al., 1974; Kennedy et al., 1980). Later on, PADs have been demonstrated to exist in all crayfish sensory neurons that were recorded intracellularly. For example in walking legs of the crayfish, PADs have been observed in TCMRO (Sillar and Skorupski, 1986), in terminals of CBCO sensory neurons (Cattaert et al., 1992b), cuticular stress detectors (Barnes et al., 1995), and dactyl sensilla (Marchand et al., 1997).

The origin of PADs is diverse and depends on the sensory neuron considered. PADs can be produced in response to the activity of the sensory neurons themselves as is the case for tactile sensory neurons of the telson (Kennedy et al., 1974) and dactyl sensory afferents (Marchand et al., 1997). However, PADs may also be triggered by sensory neurons of a modality different from the sensory neurons in which they occur. For example, sensory neurons of exteroceptive hairs of the uropod receive PADs from sensory neurons innervating a proprioceptor that monitors movements of the endopodite and protopodite of the tailfan (Kennedy et al., 1974). Finally, PADs can be produced in response to a central command. For example, in tactile sensory neurons of the telson, PADs can be produced in response to lateral giant tail-flip (Kennedy et al., 1974) and medial giant tail-flip (Kennedy et al., 1980). Similarly, in leg proprioceptors, PADs related to the walking CPG activity have been demonstrated in the TCMRO (Sillar and Skorupski, 1986) and in the CBCO (Cattaert et al., 1992b).

As was the case in mammals, PADs recorded from primary afferents in crayfish were correlated with inhibition of synaptic transmission (Kennedy et al., 1974; Cattaert et al., 1992b).

\subsection{Mechanisms of presynaptic inhibition}

How do PADs produce presynaptic inhibition? This question addressed in sensory-motor systems of different animals received two (non-exclusive) 
explanations: (i) a shunting mechanism based on the fact that PADs are accompanied by a decrease of input resistance (Kennedy et al., 1974; Cattaert et al., 1992b); (ii) an inactivation of sodium channels based on the fact that PADs are depolarizing (Graham and Redman, 1994; Lamotte d'Incamps et al., 1998b). In this case, inactivated sodium channels can no more conduct action potentials that eventually can no more be propagated up to the synapse, which then results in a total blocking of synaptic transmission.

\subsubsection{Mechanisms of presynaptic inhibition in CBCO terminals}

Intracellular recordings performed from CBCO terminals in the thoracic ganglion revealed the presence of burst of PADs during in vitro fictive locomotion (Fig. 22A; Cattaert et al., 1992b). During PADs generated by the walking CPG, sensory spikes are smaller (Fig. 22B,C) as are the corresponding EPSPs simultaneously recorded from a postsynaptic motoneuron (Fig. 22C). These PADs, which reversal potential is about $-35 \mathrm{mV}$ (Fig. 22D), are blocked by the application of the GABA-A blocker picrotoxin and, therefore, are likely to involve a chloride conductance activated by the neurotransmitter GABA. The equilibrium potential for chloride ions is very depolarized $(-35 \mathrm{mV})$, and likely results from an active mechanism that increases chloride concentration inside the sensory neurons as was demonstrated in the frog dorsal root ganglion neurons (Alvarez-Leefmans et al., 1988). The local microapplication of GABA directly onto an intracellularly recorded CBCO terminal (Fig. 23A) results in the same effects as spontaneous PADs. It evokes a depolarization associated to a decrease of both the amplitude of sensory spikes (Fig. 23B,C) and the amplitude of EPSPs in a postsynaptic motoneuron (Cattaert et al., 1992b). In addition, such GABA local application produces a marked decrease in the input resistance (up to $67 \%$; Fig. 23B,D). As was the case for spontaneous PADs, the depolarizing response evoked by GABA micro-application reverses at a membrane potential of about $-35 \mathrm{mV}$ and involves a chloride conductance (Cattaert et al., 1992b).

Recently, the respective role of membrane shunting and sodium channel inactivation was directly tested in CBCO sensory terminals (Cattaert and El Manira, 1999). Immuno-histochemical techniques associated with confocal imaging 
(Fig. 24A) revealed the presence of abundant GABA boutons in close apposition with $\mathrm{CBCO}$ axons on the sensory axon before it branches in the ganglion. By using two intracellular recording electrodes in the same sensory terminal placed at various locations of the sensory terminal, the cellular mechanisms of presynaptic inhibition were demonstrated. (i) PADs of moderate amplitude $(<20 \mathrm{mV})$ result in a substantial decrease of sensory spike amplitude (Fig. 24B,D) without inactivation of sodium channels. (ii) Larger amplitude PADs (up to $35 \mathrm{mV}$ ) reach the threshold for sodium channel inactivation. Therefore, for such large PADs (as occurring during phasic bursts phase-locked with the locomotor rhythm), the two mechanisms coexist (Fig. 24C,D). (iii) The largest PADs generate spikes in the sensory terminal, which are conveyed antidromically to the CBCO (Fig. 25; Cattaert and El Manira, 1999). Interestingly, such antidromic volleys were demonstrated to exert a powerful inhibition of the sensitivity of CBCO sensory neurons, which may be silenced for hundreds of milliseconds (Bévengut et al., 1997), introducing a new level of presynaptic inhibition.

However, these three degrees in the efficacy of the control of sensory feedback within the sensory neuron itself require additional mechanisms to function properly.

The first question concerns the way spikes are propagated in the axon terminal. We know that once past the synaptic site were PADs are produced, if the shunting is not too large, active propagation would restore the amplitude of the sensory spike in the distal part of the sensory axon (Segev, 1990). This possibility was explored and it has been demonstrated that in the sensory arborization only passive conduction occurs (Fig. 26A; Cattaert et al., 1992b; Cattaert and El Manira, 1999). Therefore in CBCO terminals, once a spike has been partially shunted due to the activation of the GABA-associated chloride channels, it can no more be restored in more distal sites (Fig. 26B). This result is consistent with the finding that even small PADs $(<10 \mathrm{mV})$ which reduce spike amplitude of less than $10 \%$, also produce a decrease in the EPSP elicited by such shunted spikes (Fig. 26B).

Another question concerns the area on which shunting mechanism operates. Simulation studies (Lamotte d'Incamps et al., 1998b; Lamotte d'Incamps et al., 1999) demonstrated that the effect of shunting is very local, close to the GABA synaptic 
site, whereas the depolarization spread on much large distance from the synaptic site. Therefore, presynaptic inhibition based on inactivation of sodium channels exerts a much more powerful inhibitory effect onto spike propagation. Synapses that are at some distance the one from the other may therefore cooperate in inactivation process, whereas cooperation of several synaptic sites to shunting requires proximity of all concerned synapses. This seems to be the case in the CBCO terminals, were anti-GABA immunoreactive boutons were localized in a restricted area of the sensory arborization (see Fig. 24A). The situation seems to be different for lb afferents in the cat where presynaptic inhibition seems to be achieved via inactivation process (Lamotte d'Incamps et al., 1998a).

A last question concerns the way antidromic discharges are produced by PADs, and why such spikes do not elicit any EPSP in post-synaptic motoneurons (Fig. 25). Intracellular recordings from CBCO sensory terminals demonstrated that such antidromic spikes were not conveyed orthodromically and were, therefore, never associated with post-synaptic potentials (Cattaert and El Manira, in prep.). Indeed, when a PAD is large enough to trigger a spike, the spike is not generated at the GABA synaptic site because of the shunting effect that is maximum at this location, but spike generation occurs a few hundreds of $\mu$ m apart from GABA synaptic sites, in the sensory axon. Due to the absence of active propagation of spikes in the distal part of the sensory terminal, spikes cannot be produced at distal sites. In addition, the spike triggered in the axon cannot be conveyed electrotonically in the distal parts of axon terminals due to the massive shunt exerted at the GABA synaptic sites (Fig. 26C).

9.2.2 Other mechanisms of presynaptic inhibition in crayfish sensory afferents

The GABA-mediated PADs associated with the locomotor CPG activity are not the only presynaptic inhibitory mechanisms occurring in $\mathrm{CBCO}$ terminals. Two other mechanisms responsible for presynaptic inhibition have been described in the same sensory afferent terminals: some involve histamine, others involve glutamate. 


\subsubsection{Histaminergic PADs in CBCO terminals}

Electrical stimulation of medial giant fibers evokes PADs in CBCO terminals via a polysynaptic pathway (El Manira and Clarac, 1994). These PADs are partially blocked by the GABA antagonist picrotoxin, and by the histamine antagonist cimetidine. The local micro-application of histamine close to the CBCO terminal induces a depolarizing response, and a $50 \%$ decrease in input resistance. As was the case with GABA-mediated PADs, histamine-mediated PADs are carried by chloride ions, and reverse at a membrane potential of $-35 \mathrm{mV}$ (EI Manira and Clarac, 1994). Therefore, the mechanisms involved in histamine-mediated presynaptic inhibition in CBCO terminals are very similar to that of GABA-mediated presynaptic inhibition in the same terminals.

\subsubsection{Glutamatergic PADs in CBCO terminals}

A third mechanism of presynaptic inhibition was recently demonstrated in CBCO terminals, involving glutamate (Cattaert and Le Ray, 1998). Contrary to GABA- and histamine-mediated presynaptic inhibition, glutamate-mediated presynaptic inhibition is not based on large depolarizing PADs. Instead, this last category of inhibitory mechanism involves only small amplitude and slowly developing PADs (sdPADs) occurring during bursts of spikes in motoneurons (Fig. 27A). Actually, it was demonstrated that sdPADs are due to a retrograde glutamate action from the motoneurons postsynaptic to the sensory terminal (Cattaert and Le Ray, 1998). Contrary to GABA- and histamine-mediated PADs, glutamate-mediated PADs do not involve chloride ions, since they are not blocked by perfusion of picrotoxin (Fig. 27B), but a mixed $\mathrm{Na}^{+}$and $\mathrm{K}^{+}$conductance, with an equilibrium potential of $-55 \mathrm{mV}$. In addition, glutamate micro-application evoked a $>60 \%$ decrease of input resistance. Therefore sdPADs mainly, if not exclusively, achieve presynaptic inhibition via a shunting mechanism (Fig. 27C). Additionally, it seems that sdPADs are produced at more distal sites than GABA-mediated PADs. Therefore, it would represent a local mechanism (Cattaert and Le Ray, 1998), whereas GABA-mediated PADs, which are produced on the main axon before it branches in the ganglion, would affect the sensory arborization as a whole. 


\subsection{Function of presynaptic inhibition}

\subsubsection{Sensory processing - lateral inhibition}

Presynaptic inhibition may exist between exteroceptive mechanosensory neurons of the same or neighboring receptive fields. In such cases, it may represent a mechanism of lateral inhibition that contributes to sharpen the localization of the stimulus.

Lateral inhibition is especially interesting when both high sensitivity and high precision are required. Hair sensilla neurons are generally very sensitive, and would saturate the postsynaptic neurons each time a mechanical stimulation is applied. In such a case, the precise localization of the stimulus is lost. However, if each sensory neuron of the receptive field inhibits its neighbors, only the first and more intensely activated sensory neuron will transmit its sensory input. Thereby a correspondence between sensory neurons and postsynaptic network neurons is preserved. This correspondence is a prerequisite for building spatial sensory representation in interneuronal networks. This could be the case of the non-giant tail-flip sensory organization (see chapter 8.3). The same principles may be true for the PADs occurring in dactyl sensory afferents (Marchand et al., 1997). In DSAs that display large amplitude spikes, large PADs are often recorded (Fig. 28B). Because an afferent spike in another DSA always precedes them, these PADs are of sensory origin (Fig. 28C) and are likely resulting from a disynaptic central connection between DSAs (Fig. 28D). It was suggested that such sensory PADs likely allowed the selection of the most reliable DSA input (Marchand et al., 1997).

Note that lateral inhibition may also be achieved at the level of sensory interneurons as was demonstrated in crayfish telson exteroceptive inputs (Reichert et al., 1982). An identified, non-spiking local interneuron mediates lateral inhibition (across the midline) of a highly restricted set of projecting sensory interneurons. The lateral inhibition between right and left sides is responsible for stimuli that are 
common to both sides to be attenuated, and conversely the difference signal produced by partially lateralized input to be enhanced.

\subsubsection{Protection of the synapse (during Tail Flip)}

In the escape neural circuits of the crayfish, the synapses from primary afferent to mechanosensory interneurons are the site of activity-dependent reductions in synaptic efficacy, what contribute to habituation of the tail-flip response (Wine and Krasne, 1982) (see section 10.1.1). During tail-flip, a use-dependent habituation should therefore occur. However, presynaptic inhibition of mechanosensory afferents (Fig. 29; Kirk, 1985) greatly reduces the extent to which activity-dependent synaptic depression develops, and thereby protects the reflex from habituating to the stimulation produced by rapid movement through the water (Bryan and Krasne, 1977a; Bryan and Krasne, 1977b). These results demonstrated for the first time that central neural networks can not only regulate their own input, but moreover they can helpfully modulate their own plastic mechanisms.

\subsubsection{Automatic gain adjustment in sensory-motor circuits}

\subsubsection{Protection of the postsynaptic motoneuron}

In CBCO proprioceptive afferents, a class of PAD is related to the activity of postsynaptic motoneurons (Cattaert and Le Ray, 1998). When motoneurons are very active, slow depolarizing wave develops in CBCO terminals, and such sdPADs mediate presynaptic inhibition. The fact that sdPADs are only observed during high level of motoneuron activity was interpreted as a mechanism that protects the motoneuron from saturation. However, a possible role in normal locomotor activity may also apply, as an «assistant» to the locomotor-related presynaptic inhibition mediated by GABA.

9.3.3.2 Adjusting the gain of the negative feedback 
Adjusting the gain of the sensory-motor negative feedback is also important to keep the response of motoneurons adapted to the situation, whatever the level of the motor activity. In other systems, for example in locust primary afferents, proprioceptive afferents exert presynaptic inhibition on themselves (Burrows and Matheson, 1994). This presynaptic inhibition was interpreted as a mechanism of presynaptic gain control. In situations where more and more proprioceptive inputs occur, proprioceptive-based self-presynaptic inhibition contributes to extend the dynamic range of the sensory-motor relationship. And, thereby, it allows this sensorymotor system to operate on an extended range of proprioceptive activity. In the case of CBCO proprioceptive afferents in crayfish, such an "auto inhibition" does not seem to exist. Consequently, the regulation of the gain of the sensory input synapses is devoted to the other element of sensory-motor loop, the motoneuron itself.

\subsubsection{Control of afferent input by central pattern generators}

The relationship between central pattern generator and proprioceptive feedback is rather complex, and proprioceptive feedback may change not only in intensity but also in sign when negative feedback reverses into positive feedback. Such positive feedback exists during locomotion. For example, spinal-sectioned cats walking on a treadmill adjust their gait as well as the cadence of their steps to the speed of the belt by shortening the stance phase duration when the belt speed is higher (for a review see Wetzel and Stuart, 1976). Similar results were obtained in the rock lobster walking on a treadmill (Chasserat and Clarac, 1983). These observations demonstrate that afferent signals are able to modify the timing of the central pattern generator.

In biological systems, proprioceptive reflexes are not fixed, but rather depend on the ongoing activity. This is particularly true for negative feedback systems (resistance reflex) that are useful to maintain a given position (MROs in the abdomen, chordotonal organs at the various limb joints). Such reflex organization is therefore mainly devoted to postural control. However, as soon as an active movement is required, the negative feedback loop becomes rapidly inappropriate as the required movement speed increases. In this case, the negative feedback reflexes would contract the muscles that oppose the movement. Therefore, to avoid this 
"movement blockade" effect, a number of mechanisms are present in sensory-motor circuits. Because negative feedback reflexes are partly based on monosynaptic contacts between proprioceptive afferents and motoneurons, presynaptic inhibition of the sensory afferent represents the most effective way to open the control loop. There exist many examples of such presynaptic inhibition directly controlled by central networks to avoid undesired negative reflex effects.

Eckert (1961), on the abdominal stretch receptors, provided one of the first demonstrations of such central control exerted on a proprioceptor. MROs, the extensor stretch receptors are inhibited during the powerful abdominal flexion of the tail-flip (Eckert, 1961), and this inhibition is released at the end of the flexion, which allows these MROs to be activated and to stimulate strongly the extensor motoneurons. But the MROs are not the only receptors that are inhibited by the tailflip system. In most of the proprioceptive neurons studied so far, similar effects were demonstrated. For example, electrical stimulation of the giant fibers produces a mixed GABAergic and histaminergic presynaptic inhibition in CBCO afferents. This is related to the fast movements of the legs that are actively directed forward during the tail-flip. During such fast protraction, the other segments are moved and CBCO neurons are activated. The presynaptic inhibition in CBCO neurons thereby avoids any inappropriate reflex actions.

More generally, during rhythmic movements such as walking activities, phasic presynaptic inhibition allows the central command to avoid inappropriate negative feedback effects during active movement phases. Such phase-dependent reflexes were demonstrated during locomotion in both vertebrates and invertebrates. Indeed, a large part of this phasic modulation results from presynaptic inhibition in primary afferent axons. For example during fictive locomotion in the cat, group I afferent fibers display rhythmic bursts of PADs phase-locked with the locomotor rhythm (Gossard et al., 1991). During fictive walking activity in crayfish, similar PADs of central origin have been reported in CBCO axons (Cattaert et al., 1992b), and in TCMRO axons (Sillar and Skorupski, 1986).

\subsubsection{Mechanism of reflex reversal in the CB joint}


In the locomotor system, when the central neural network is inactive, stretches and releases of the $\mathrm{CBCO}$ strand evoke resistance reflexes: levator motoneurons are excited by stretching the strand while depressor motoneurons are activated during the release of the $\mathrm{CBCO}$ strand (Fig. 30A). In contrast, when the central neural network produces fictive locomotor activity, the same stretch-release mechanical stimulation of the CBCO strand evokes reversed responses. Levator motoneurons are activated during release while stretch stimulates the depressor motoneurons (Le Ray and Cattaert, 1997), both groups being therefore utilized in an assistance mode (Fig. 30B). Mechanisms of reflex reversal have been recently discovered in the CBCO-depressor motoneuron loop. It involves a specialized interneuron that relays information between stretch-sensitive afferents and depressor motoneurons. This assistance reflex interneuron, ARIN, is a non-spiking interneuron that integrates much convergent stretch-sensitive inputs to produce transient currents that elicit graded EPSPs in the postsynaptic depressor motoneurons (Le Ray and Cattaert, 1997). The ARIN being such a center of sensory convergence, it is likely alone responsible for the reflex activation of all depressor motoneurons in assistance mode.

In response to fast ramp stimulation, the ARIN receives both fast excitatory and long latency inhibitory influences. Sensory afferent monosynaptic connections achieve the fast excitation while the inhibitory influence is likely due to an assistance reflex controlling interneuron, $\mathrm{ARCIN}$, that negatively relays sensory inputs to depressor motoneurons (Le Ray and Cattaert, 1997). ARCIN would then perform an automatic control of the gain of the disynaptic assistance reflex pathway by inhibiting the non-spiking ARIN (Fig. 30B), thus preventing any exaggeratedly long activation of motoneurons. Crayfish sensory-motor system appears very simple, especially by comparison with insects (Burrows, 1992; Bässler, 1993; Bässler and Büschges, 1998) and vertebrates (for a review see Shik and Orlovsky, 1976) where more complex interneuronal interactions and/or a greater number of neurons are involved in reflexes and reflex reversal. Systematic study of the organization of the wiring between sensory afferents and depressor motoneurons demonstrated that from three to seven CBCO afferents connected one single depressor motoneuron. Direct convergence of sensory inputs onto motoneurons is a common characteristic of crayfish and vertebrates (Eccles et al., 1957). However, contrary to vertebrates, sensibilities of $\mathrm{CBCO}$ afferents are not exactly the same and so, the motoneuron 
integrates various spatial informations that define its major angular sector of activation. Because every motoneurons are not connected by the same afferents, each motoneuron is activated preferentially in a restricted and perfectly defined angular range, what leads every motoneurons to be sequentially activated in resistance reflex during the imposed movement (Le Ray et al., 1997b). And, because depressor motoneurons may share common afferents from the CBCO, their sequence of reflex activation partly overlap each other, allowing a supple motor response. In contrast, in the assistance mode where motoneurons already command the ongoing movement, the activity of the whole depressor motoneurons is reflexively reinforced at the same time because of their shared input neuron, the ARIN.

Note that the switch from posture-oriented resistance reflex to active movement-associated assistance reflex is not a simple change in the sign of the feedback. Besides the fact that ARIN are activated by the locomotor CPG, the motoneuron properties are also modified when the network produces a locomotor activity (see chapter 4.2.2, and Fig. 12). Particularly, motoneurons that were previously passive neurons, present active membrane properties such as plateau properties and, at least some of them, pacemaker potentials that confer to such motoneurons endogenous oscillator properties (Cattaert et al., 1994a; Cattaert et al., 1994b). Because electrical connections exist between motoneurons of the same group (Chrachri and Clarac, 1989), each group of motoneuron is therefore much more activated during locomotion than during resting postural activity. In addition, inhibitory connections between antagonistic motoneurons (Chrachri and Clarac, 1989; Pearlstein et al., 1998) contribute to inhibit antagonistic motoneurons during agonist burst. Together with the monosynaptic resistance reflex pathway being deeply inhibited by presynaptic inhibition (see chapter 9.3.4), the increased inhibition of antagonistic motoneurons by active ones would completely prevent the resistance reflex to occur. In contrast, the disynaptic assistance response would be enhanced in the active motoneuron group due to their active properties expressed during walking activity (Fig. 30B). 


\section{Plastic changes in motor control}

\subsection{Habituation}

One of the simplest models used for studying learning phenomena has been that of habituation. It is the reversible response decrement to a stimulus repeated at low frequency. Its study in central nervous systems has been greatly facilitated by the existence of monosynaptic reflex arcs which habituate, both in invertebrates (Castellucci et al., 1970) and vertebrates (Farel and Thompson, 1976). In such preparations, the synaptic mechanism for short-term habituation seems to involve a decrease in the amount of transmitter released from primary sensory endings (for a review see Zucker, 1989). In crayfish, a similar mechanism was demonstrated in the polysynaptic pathways supporting the escape response (Zucker, 1972b). Such mechanisms, however, were not demonstrated for habituation in other polysynaptic pathways such as defense response (Hawkins and Bruner, 1981) and leg levation reflex (Marchand and Barnes, 1992).

\subsubsection{Habituation of the giant escape reaction}

When lateral giant tail flips are elicited repetitively at low frequency, the response habituates and no escape is produced after some trials. The vanishing of the response is due to habituating phenomena in the neuronal circuit that controls the escape behavior (Fig. 31A). However, electrical excitation of the lateral giant axon at frequencies up to $5 \mathrm{~Hz}$ can elicit up to 50 apparently normal tail flips, indicating that the circuit efferent from the lateral giant cannot contribute importantly to the habituation of the escape behavior. The excitation of some mechanosensory interneurons by tactile afferents decreases with stimulus repetition (Zucker, 1972a). While tactile afferent do not fatigue to repeated stimulation, the amplitude of corresponding EPSPs recorded from the lateral giant neuron progressively decrease (Fig. 31B). A quantal analysis has demonstrated that, during habituation of the lateral giant-mediated escape, the synapses between cholinergic primary afferents and postsynaptic mechanosensory interneurons were presynaptically depressed (Zucker, $1972 b)$. This local segmental process, however, is not the only mechanism acting in 
behaving animals. More recently, habituation was demonstrated to result more from onset of tonic descending inhibition than to intrinsic depression of circuit synapses. Thus, the altered performance seems to depend at least as much on events in higher centers as on local plasticity (Krasne and Teshiba, 1995).

More generally, the inhibitory control exerted by higher centers onto of the lateral giant escape reaction by GABAergic tonic inhibition, allows the animal to avoid inappropriate "automatic" escape responses in circumstances such as feeding, defense against attack and agonistic interactions with other crayfish (Vu et al., 1993).

\subsubsection{Habituation of the reflex leg levation}

In intact crayfish, gentle pinching of the dactyl can elicit a brief levation of the leg. Such responses involve force-sensitive mechanoreceptors since, in vivo, the electrical stimulation (125-ms train at $100 \mathrm{~Hz}$ ) of dactyl sensory afferents reproduce the levation response (Marchand and Barnes, 1992). However, if this electrical stimulation is repeated at 2.5-s intervals, the response (movement amplitude and number of muscle potentials in levator EMG) progressively decreases. Similar results were obtained in an in vitro preparation of the ventral nerve cord with the considered leg attached. In this case, the compound EPSPs recorded from levator motoneurons and the compound inhibitory postsynaptic potentials recorded from depressor motoneurons progressively decreased (Marchand and Barnes, 1992).

Unlike the escape response habituation, when habituation is established in the levation reflex arc, a train of shocks to the telson can achieve a dishabituation (Marchand and Barnes, 1992).

\subsection{LTP at Neuromuscular junctions}

Motor control largely depends on the properties of the neuromuscular junction and excitation-contraction characteristics of muscle fibers. Therefore, it is not surprising that plastic changes are frequently observed at neuromuscular junctions to allow a fine control of the muscle tension (Bittner, 1989). 
Plasticity at the neuromuscular junction of the opener muscle that command dactyl in claws and in first walking legs was particularly studied. At this synapse, brief stimulation of the single excitor motor axon may enhance the amplitude of subsequent EPSPs for many hours (Baxter et al., 1985). Quantal analysis (Fig. 32A), using binomial models, examined the synaptic transmission before and after induction of long-term facilitation. After the induction protocol was applied, both the quantal content and the mean number of released quanta were increased, which demonstrated the occurrence of an entirely presynaptic mechanism (Baxter et al., 1985; Wojtowicz and Atwood, 1986). However, it was not associated with any persistent changes in presynaptic action potential (Bittner and Baxter, 1991) or membrane potential recorded in the terminal region of the excitatory axon. Instead, it has been proposed that long-term facilitation resulted from the recruitment of synapses to the active state. The synaptic transmission behavior during facilitation was simulated by a binomial model in which the number of active synapses was increased, while the probability of transmission for the population of responding units (i.e., the mean probability of release at a given synapse) was slightly reduced (Wojtowicz and Atwood, 1986). Provided that a pool of inactive synapses exists, such a model largely supported the hypothesis of silent synapse recruitment.

Similarly, many plastic modalities have been described at the neuromuscular junction between the phasic motor axon and the closer muscle of crayfish claws (Lnenicka and Atwood, 1985; Pahapill et al., 1986; Lnenicka and Atwood, 1988). For example, stimulation of this fast motor axon at relatively low frequency $(0.1 \mathrm{~Hz})$ leads to depression of the EPSP recorded from single muscle fibers. However, when the same stimulation is delivered following depression of the EPSP at a higher frequency $(5 \mathrm{~Hz})$, an EPSP that is more resistant to low frequency depression appears (Lnenicka and Atwood, 1985). When electrodes are implanted in situ and the phasic motoneuron stimulated at $5 \mathrm{~Hz}$ for $2 \mathrm{~h}$ each day, synaptic depression becomes less pronounced, and the initial EPSP amplitude becomes smaller over a period of several days. The former effect, i.e. the resistance to synaptic fatigue, may last for at least one day after one conditioning trial. It is attributable to local changes in terminal regions of the axon and does not require the cell body since it still occurs if stimulation is applied to decentralized axons in situ. The latter changes, which adapt 
the neuron to a more tonic activity pattern, usually require several days for completion but, once established, remain for many days without further superimposed activity (Lnenicka and Atwood, 1985). This long-term adaptation does not occur in decentralized axons.

Thus, long-term resistance to fatigue and long-term adaptation are different plastic responses of the neuron to enhanced activity. However, they do not represent the only plastic control that may occur at this neuromuscular junction since long-term potentiation (LTP) and high frequency depression have also been described (Pahapill et al., 1986).

\subsection{LTP in sensory-motor synapses}

Although plastic changes exist in central synapses of arthropods (Parker, 1995a; Parker, 1995b), nothing was known concerning the capacity of crayfish central synapses to express plastic properties. In a recent study, plastic changes were also demonstrated in sensory-motor pathways, between proprioceptive primary afferents and motoneurons (Le Ray and Cattaert, 1999). This finding is important since adaptive motor control is largely based on the processing and integration of proprioceptive feedback information.

In crayfish walking leg, many of these operations are carried out directly by the motoneurons, which are monosynaptically connected by proprioceptive sensory afferents. In vitro, paired intracellular recordings from $\mathrm{CBCO}$ afferents and motoneurons commanding the CB joint (levator and depressor) demonstrated that the sole spiking activity of a leg motoneuron is able to enhance long-lastingly the efficacy of the CBCO terminal-motoneuron synapses (Fig. 33A). Moreover, this effect is specific to the activated motoneuron because no changes were induced at the afferent synapses of neighboring silent motoneurons. Because this effect occurs even in the absence of any presynaptic sensory firing during the induction period, it confers to the motoneuron a pivotal role in the recruitment of its own sensory afferents. 
The long-term potentiation of monosynaptic EPSPs in crayfish involves a retrograde system of glutamate transmission from the postsynaptic motoneuron, which induces the activation of a metabotropic glutamate receptor located presynaptically on the CBCO terminals (Le Ray and Cattaert, 1999). Quantal analysis demonstrated that the increase in EPSP amplitude was related to an increase in the sole quantal content (Fig. 33B). Hence, the retrograde activation results exclusively in the long-lasting enhancement of acetylcholine release from presynaptic sensory afferent terminals, without inducing any modifications of the postsynaptic motoneuron properties. Taken together, these results strongly suggest the involvement of such plastic modifications in the organization of sensory-motor connections (Le Ray and Cattaert, 1999). Indeed, when the animal is quiet and does not make any movement (for example, when resting in its shelter), sensory-motor synapses are useless, and their strength decreases. In contrast, as soon as motoneurons are recruited in a motor task, sensory information becomes essential for adjusting the movement and, through this retrograde glutamatergic activation, sensory afferents are recruited together with their target, active motoneurons (Fig. 33C).

Synaptic plasticity in the sensory-motor system of crayfish thus represents another, higher level of adaptation of motor control that modeled the neuronal network in accordance to the behavioral task.

\section{Conclusion}

In this review we have tried to present the general principles that allow crayfish motor systems to perform adapted motor tasks. Crayfish motor systems have been extensively investigated, and an amazing amount of data is available. Consequently, it was not possible to present all of them in this review. Why is this animal so popular to neuroscientists? As many other invertebrates, its nervous system contains few neurons (compared to vertebrates), and very early these neurons became accessible due to the development of in vitro preparations of the ventral nerve cord. Small number of neurons and accessibility are not the only reasons for the success of the 
crayfish as a model preparation in neurophysiology. Very early, a repertoire of motor behaviors has been described, which could be triggered by stimulating a series of "command neurons". During the fifty past years, neurophysiologists analyzed the neural circuits that support motor commands in walking legs, abdomen, swimmerets and uropods. These motor systems express various degrees of variability, the rapid flexion of the abdomen during the giant fiber tail-flip being the most stereotyped motor program, the walking activity the most variable. Between these two extremes the motor program commanding swimmeret beating only allows variations of the period, and the swimmerets remain strongly coupled to each other.

The variety of motor performances displayed by the crayfish legs, makes this motor system a good model to understand how a nervous system manages to produce and control such a diversity of motor commands. However, the interest of this kind of study is not limited to the crayfish nervous system. As was recently reviewed for the comparison of the stretch reflex in vertebrates and the resistance reflex in arthropods (Clarac et al., 2000), animal's solution to problems of motor control share striking similarities, even in such distant animal groups. These similarities probably reflect general principles of motor control, that can be implemented by different components (muscles spindles are different from chordotonal organ) but achieving the same global task (negative feedback) with similar solutions (direct connection with motoneurons, reciprocal inhibition wiring, presynaptic inhibition, etc.). Therefore the understanding of the neural network controlling crayfish walking legs should be very useful to propose conceptual frameworks for analyzing the more complex neural organization of vertebrate limb movements.

Fifty years after the "command neuron" concept was established in the crayfish by Wiersma (1947), the neural mechanisms by which local networks for walking or swimmeret beating are controlled by these interneurons are still largely unknown. This question remains one of the challenges for the future, and will require more extensive analysis at the level of the local networks. More precisely, the relationship between postural activity and locomotion remains to be analyzed. The fine structure of the neurons is, also, still largely unknown and should be analyzed to better understand how modulation operates. Such studies would concern not only 
presynaptic inhibition in the various branches of neurons, but also modulation of integration properties of the component neurons, and control of their active properties.

\section{Acknowledgments}

This work was supported by the Centre National de la Recherche Scientifique.

\section{References}

Alexandrowicz, J. S. (1951) Muscle receptor organs in the abdomen of Homarus vulgaris and Palinurus vulgaris. Quart. J. Micr. Sci. 92, 163-199.

Alexandrowicz, J. S. and Whitear, M. (1957) Receptor elements in the coxal region of decapoda crustacea. J. Mar. Biol. Ass. UK. 36, 603-628.

Alvarez-Leefmans, F. J., Gamino, S. M., Giraldez, F. and Nogueron, I. (1988) Intracellular chloride regulation in amphibian dorsal root ganglion neurones studies with ionselective microelectrodes. J. Physiol. (Lond.) 406, 225-246.

Aonuma, H., Newland, P. L. and Nagayama, T. (1999) Processing of proprioceptive signals by ascending interneurones in the terminal abdominal ganglion of the crayfish. J. Exp. Biol. 202, 2975-2984.

Arnesen, S. and Olivo, R. (1988) The effect of serotonin and octopamine on behavioral arousal in the crayfish. Comp. Biochem. Physiol. 91C, 259-263.

Atwood, H. L. (1965) Excitation and inhibition in crab muscle fibres. Comp. Biochem. Physiol. 16, 409-426.

Atwood, H. L. and Morin, W. A. (1970) Neuromuscular and axoaxonal synapses of the crayfish opener muscle. J. Ultrastruct. Res. 32, 351-369.

Ballantyne, D. and Rathmayer, W. (1981) On the function of the common inhibitory neurone in the walking legs of the crab, Eriphia spinifrons. J. Comp. Physiol. 143 , 111-122.

Barnes, W. J. P. (1977) Proprioceptive influences on motor output during walking in the crayfish. J. Physiol. (Paris) 73, 543-564.

Barnes, W. J. P., Cattaert, D., Leibrock, C. S. and Marchand, A. R. (1995) Functional roles for presynaptic inhibition in crayfish mechanoreceptors. In: Nervous systems and behaviour. Proceedings of the 4th International Congress of Neuroethology, pp -237 Eds M. Burrows, T. Matheson, P. L. Newland, H. Schuppe. Georg Thieme Verlag: Stuttgart, New York.

Barnes, W. J. P., Spirito, C. P. and Evoy, W. H. (1972) Nervous control of walking in the crab, Cardisoma guanhumi. II. Role of resistance reflexes in walking. J. Comp. Physiol. 76, 16-31. 
Barthe, J. Y., Bévengut, M. and Clarac, F. (1991) The swimmeret rhythm and its relationships with postural and locomotor activity in the isolated nervous system of the crayfish Procambarus clarkii. J. Exp. Biol. 157, 207-226.

Bastiani, M. J. and Mulloney, B. (1988) The central projections of the stretch receptor neurons of crayfish: structure, variation, and postembryonic growth. J. Neurosci. 8, 1254-1263.

Baxter, D. A., Bittner, G. D. and Brown, T. H. (1985) Quantal mechanism of long-term synaptic potentiation. Proc. Natl. Acad. Sci. U. S. A 82, 5978-5982.

Bässler, U. (1993) The femur-tibia control system of stick insects - a model system for the study of the neural basis of joint control. Brain Res. Rev. 18, 207-226.

Bässler, U. and Büschges, A. (1998) Pattern generation for stick insect walking movements multisensory control of a locomotor program. Brain Res. Rev. 27, 65-88.

Bévengut, M., Clarac, F. and Cattaert, D. (1997) Antidromic modulation of a proprioceptor sensory discharge in crayfish. J. Neurophysiol. 78, 1180-1183.

Bévengut, M., Libersat, F. and Clarac, F. (1986) Dual locomotor activity selectively controlled by force- and contact-sensitive mechanoreceptors. Neurosci. Lett. 66, 323-327.

Bittner, G. D. (1989) Synaptic plasticity at the crayfish opener neuromuscular preparation. $J$. Neurobiol. 20, 386-408.

Bittner, G. D. and Baxter, D. A. (1991) Synaptic plasticity at crayfish neuromuscular junctions: facilitation and augmentation. Synapse 7, 235-243.

Bowerman, R. F. and Larimer, J. L. (1974a) Command fibres in circumoesophageal connectives of crayfish. I. Tonic fibres. J. Exp. Biol. 60, 95-117.

Bowerman, R. F. and Larimer, J. L. (1974b) Command fibres in circumoesophageal connectives of crayfish. II. Phasic fibres. J. Exp. Biol. 60, 119-134.

Bräunig, P. and Hustert, R. (1983) Proprioceptive control of a muscle receptor organ in the locust leg. Brain Res. 274, 341-343.

Bryan, J. S. and Krasne, F. B. (1977a) Presynaptic inhibition : the mechanism of protection from habituation of the crayfish lateral giant fibre escape response. J. Physiol. (Lond.) 271, 369-390.

Bryan, J. S. and Krasne, F. B. (1977b) Protection from habituation of the crayfish lateral giant fibre escape response. J. Physiol. (Lond.) 271, 351-368.

Burrows, M. (1992) Local circuits for the control of leg movements in an insect. Trends Neurosci. 15, 226-232.

Burrows, M. (1996) The neurobiology of an insect brain. Oxford University Press: Oxford.

Burrows, M. and Matheson, T. (1994) A presynaptic gain control mechanism among sensory neurons of a locust leg proprioceptor. J. Neurosci. 14, 272-282. 
Bush, B. M. and Roberts, A. (1971) Coxal muscle receptors in the crab: the receptor potentials of $\mathrm{S}$ and $\mathrm{T}$ fibers in response to ramp stretches. J. Exp. Biol. 55, 813-832.

Bush, B. M. H. (1965a) Leg reflexes from chordotonal organs in the crab, Carcinus maenas. Comp. Biochem. Physiol. 15, 567-587.

Bush, B. M. H. (1965b) Proprioception by the coxo-basal chordotonal organ, CB, in legs of the crab, Carcinus maenas. J. Exp. Biol. 42, 285-297.

Büschges, A., Kittmann, R. and Ramirez, J. M. (1993) Octopamine effects mimick statedependent changes in a proprioceptive feedback system. J. Neurobiol. 24, 598-610.

Cannone, A. J. and Bush, B. M. H. (1981a) Reflexes mediated by non-impulsive afferent neurones of the thoracic-coxal muscle receptor organs in the crab, Carcinus maenas. III. Positive feedback to the receptor muscle. J. Comp. Physiol. 142, 103-112.

Cannone, A. J. and Bush, B. M. H. (1981b) Reflexes mediated by non-impulsive afferent neurones of the thoracic-coxal muscle receptor organs in the crab, Carcinus maenas. IV. Motor activation of the receptor muscle. J. Comp. Physiol. 142, 113-125.

Castellucci, V. F., Pinsker, H. M., Kupfermann, I. and Kandel, E. R. (1970) Neuronal mechanisms of habituation and dishabituation in the gill-withdrawal reflex in Aplysia. Science 167, 1745-1748.

Cattaert, D., Araque, A., Buño, W. and Clarac, F. (1994a) Motor neurones of the crayfish walking system possess $\mathrm{TEA}^{+}$-revealed regenerative electrical properties. J. Exp. Biol. 188, 339-345.

Cattaert, D., Araque, A., Buño, W. and Clarac, F. (1994b) Nicotinic and muscarinic activation of motoneurons in the crayfish locomotor network. J. Neurophysiol. 72, 1622-1633.

Cattaert, D., Barthe, J.-Y. and Clarac, F. (1994c) Sensory-motor coordination in crustacean limbs during locomotion. In: Interlimb Coordination: Neural, Dynamical, and Cognitive Constraints, pp. 49-73. Eds S. Swinnen, H. Heuer, J. Massion, P. Casaer. Academic Press, Inc: San Diego.

Cattaert, D., Barthe, J.-Y., Neil, D. M. and Clarac, F. (1992a) Remote control of the swimmeret central pattern generator in crayfish (Procambarus clarkii and Pacifastacus leniusculus): effect of a walking leg proprioceptor. J. Exp. Biol. 169, 181-206.

Cattaert, D. and Clarac, F. (1983) Influence of walking on swimmeret beating in the lobster Homarus gammarus. J. Neurobiol. 14, 421-439.

Cattaert, D. and Clarac, F. (1987) Rami motor neurons and motor control of the swimmeret system of Homarus gammarus. J. Comp. Physiol. [A] 160, 55-68.

Cattaert, D. and El Manira, A. (1999) Shunting versus inactivation: analysis of presynaptic inhibitory mechanisms in primary afferents of the crayfish. J. Neurosci. 19, 60796089.

Cattaert, D., El Manira, A. and Clarac, F. (1992b) Direct evidence for presynaptic inhibitory mechanisms in crayfish sensory afferents. J. Neurophysiol. 67, 610-624. 
Cattaert, D. and Le Ray, D. (1998) Direct glutamate-mediated presynaptic inhibition of sensory afferents by the postsynaptic motor neurons. Eur. J. Neurosci. 10, 3737-3746.

Cattaert, D., Pearlstein, E. and Clarac, F. (1995) Cholinergic control of the walking network in the crayfish Procambarus clarkii. J. Physiol. (Paris) 89(4-6), 209-220.

Chasserat, C. and Clarac, F. (1983) Quantitative analysis of walking in a decapod crustacean, the rock lobster Jasus lalandii. II Spatial and temporal regulation of stepping in driven walking. J. Exp. Biol. 107, 219-243.

Cheng, J., Stein, R. B., Jovanovic, K., Yoshida, K., Bennett, D. J. and Han, Y. (1998) Identification, localization, and modulation of neural networks for walking in the mudpuppy (Necturus maculatus) spinal cord. J. Neurosci. 18, 4295-4304.

Chrachri, A. and Clarac, F. (1989) Synaptic connections between motor neurons and interneurons in the fourth thoracic ganglion of the crayfish, Procambarus clarkii. $J$. Neurophysiol. 62, 1237-1250.

Chrachri, A. and Clarac, F. (1990) Fictive locomotion in the fourth thoracic ganglion of the crayfish, Procambarus clarkii. J. Neurosci. 10, 707-719.

Clarac, F. (1976) Crustacean cuticular stress detectors. In: Structure and function of proprioceptors in the invertebrates., pp. 299-321. Ed P. J. Mill. Chapman \& Hall: London.

Clarac, F. and Barnes, W. J. P. (1985) Peripheral influences on the coordination of the legs during walking in decapod crustaceans. In: Coordination in Motor Behaviour. SEB seminar series 24, pp. 249-269. Eds B. M. H. Bush, F. Clarac. Cambridge University Press: Cambridge.

Clarac F, Cattaert D, Le Ray D (2000) Central control components of a 'simple' stretch reflex. Trends Neurosci. 23: (in press).

Clarac, F. and Chasserat, C. (1979) Experimental modification of interlimb coordination during locomotion of a crustacea. Neurosci. Lett. 12, 271-276.

Clarac, F., Chrachri, A. and Cattaert, D. (1991) Interneuronal control of a walking leg reflex in an in vitro crayfish preparation. In: Locomotor neural mechanisms in Arthropods and Vertebrates, pp. 707-719. Eds D. M. Armstrong, B. M. H. Bush. Manchester University Press: Manchester.

Clarac, F., Vedel, J. P. and Bush, B. M. H. (1978) Intersegmental reflex coordination by a single joint receptor organ (CB) in rock lobster walking legs. J. Exp. Biol. 73, 29-46.

Davis, W. J. (1968a) Quantitative analysis of swimmeret beating in the lobster. J. Exp. Biol. 48, 643-662.

Davis, W. J. (1968b) The integrative action of the nervous system in crustacean equilibrium reactions. In: Gravity and the Organism., pp. 237-249. Eds S. A. Gordon, M. J. Cohen. University of Chicago: Chicago. 
Davis, W. J. (1968c) The neuromuscular basis of lobster swimmeret beating. J. Exp. Zool. 48, 643-662.

Davis, W. J. (1969a) Reflex organization in the swimmeret system of the lobster. I. Intrasegmental reflexes. J. Exp. Biol. 51, 547-563.

Davis, W. J. (1969b) Reflex organization in the swimmeret system of the lobster. II. Reflex dynamics. J. Exp. Biol. 51, 565-573.

Davis, W. J. (1969c) The neural control of swimmeret beating in the lobster. J. Exp. Biol. 50, 99-117.

Dudel, J. and Kuffler, S. W. (1961) Presynaptic inhibition at the crayfish neuromuscular junction. J. Physiol. (Lond.) 155, 543-562.

Eccles, J. C., Eccles, R. M. and Lundberg, A. (1957) The convergence of monosynaptic excitatory on to many different species of alpha motoneurones. J. Physiol. (Lond.) 2250.

Eccles, J. C., Kostyuk, P. G. and Schmidt, R. F. (1962) Presynaptic inhibition of the central actions of flexor reflex afferents. J. Physiol. (Lond.) 161, 258-281.

Eckert, R. O. (1961) Reflex relationships of the abdominal stretch receptors of the crayfish. I. Feedback inhibition of the receptors. J. Cell. Comp. Physiol. 57, 149-162.

Edwards, D. H., Heitler, W. J. and Krasne, F. B. (1999) Fifty years of a command neuron: the neurobiology of escape behavior in the crayfish. Trends Neurosci. 22, 153-161.

El Manira, A., Cattaert, D. and Clarac, F. (1990) Reflex reversal and presynaptic control of sensory afferents in crustacea. Eur. J. Neurosci. S3, 183-183.

El Manira, A., Cattaert, D. and Clarac, F. (1991a) Monosynaptic connections mediate resistance reflex in crayfish (Procambarus clarkii) walking legs. J. Comp. Physiol. [A] 168, 337-349.

El Manira, A. and Clarac, F. (1994) Presynaptic inhibition is mediated by histamine and GABA in the crustacean escape reaction. J. Neurophysiol. 71, 1088-1095.

El Manira, A., DiCaprio, R. A., Cattaert, D. and Clarac, F. (1991b) Monosynaptic interjoint reflexes and their central modulation during fictive locomotion in crayfish. Eur. J. Neurosci. 3, 1219-1231.

Elson, R. C., Panchin, Y. V., Arshavsky, Y. I. and Selverston, A. I. (1994) Multiple effects of an identified proprioceptor upon gastric pattern generation in spiny lobsters. J. Comp. Physiol. [A] 174, 317-329.

Elson, R. C., Sillar, K. T. and Bush, B. M. H. (1992) Identified proprioceptive afferents and motor rhythm entrainment in the crayfish walking system. J. Neurophysiol. 67, 530546.

Erxleben, C. (1989) Stretch-activated current through single ion channels in the abdominal stretch receptor organ of the crayfish. J. Gen. Physiol. 94, 1071-1083. 
Erxleben, C. F. (1993) Calcium influx through stretch-activated cation channels mediates adaptation by potassium current activation. Neuroreport 4, 616-618.

Eyzaguirre, C. and Kuffler, S. W. (1955) Processes of excitation in the dendrite and in the soma of single isolated sensory nerve cells of the lobster and crayfish. J. Gen. Physiol. 39, 87-153.

Farel, P. B. and Thompson, R. F. (1976) Habituation of a monosynaptic response in frog spinal cord: evidence for a presynaptic mechanism. J. Neurophysiol. 39, 661-666.

Fields, H. L. (1966) Proprioceptive control of posture in the crayfish abdomen. J. Exp. Biol. 44, 455-468.

Fields, H. L. and Kennedy, D. (1965) Functional role of muscle receptor organs in crayfish. Nature 206, 1235-1237.

Frank, K. and Fuortes, M. G. F. (1957) Presynaptic and postsynaptic inhibition of monosynaptic reflexes. Fed. Proc. Fed. Am. Soc. Exp. Biol. 16, 39-40.

Gill, M. D. and Skorupski, P. (1996) Modulation of spontaneous and reflex activity of crayfish leg motor neurons by octopamine and serotonin. J. Neurophysiol. 76, 3535-3549.

Gossard, J.-P., Cabelguen, J.-M. and Rossignol, S. (1991) An intracellular study of muscle primary afferents during fictive locomotion in the cat. J. Neurophysiol. 65, 914-926.

Graham, B. and Redman, S. (1994) A simulation of action potentials in synaptic boutons during presynaptic inhibition. J. Neurophysiol. 71, 538-549.

Grillner, S. (1981) Control of locomotion in bipeds, tetrapods and fish. In: Handbook of physiology, pp. 1179-1236. Ed V. B. Brooks.

Hawkins, R. D. and Bruner, J. (1981) Activity of excitor and inhibitor claw motor neurones during habituation and dishabituation of the crayfish defense response. J. Exp. Biol. 91, 145-164.

Head, S. I. and Bush, B. M. (1991) Reflex actions of one proprioceptor on the motoneurones of a muscle receptor and their central modulation in the shore crab. J. Physiol. (Lond) 437, 49-62.

Heitler, W. J. (1978) Coupled motoneurones are part of the crayfish swimmeret central oscillator. Nature 275, 231-234.

Heitler, W. J. (1982) Non-spiking stretch receptors in the crayfish swimmeret system. J. Exp. Biol. 96, 355-366.

Heitler, W. J. (1986) Aspects of sensory integration in the crayfish swimmeret system. J. Exp. Biol. 120, 387-402.

Heitler, W. J. and Pearson, K. G. (1980) Non-spiking interactions and local interneurones in the central pattern generator of the crayfish swimmeret system. Brain Res. 187, 206211. 
Hess, D. and Büschges, A. (1999) Role of proprioceptive signals from an insect femur-tibia joint in patterning motoneuronal activity of an adjacent leg joint. J. Neurophysiol. 81, 1856-1865.

Hughes, G. M. and Wiersma, C. A. G. (1960) The coordination of swimmeret movements in the crayfish, Procambarus clarkii. J. Exp. Biol. 37, 657-670.

Hustert, R. (1982) The proprioceptive function of a complex chordotonal organ associated with the mesothoracic coxa in locusts. J. Comp. Physiol. [A] 147, 389-399.

Ikeda, K. and Wiersma, C. A. G. (1964) Autogenic rhythmicity in the abdominal ganglia of the crayfish; the control of swimmeret movements. Comp. Biochem. Physiol. 12, 107115.

Jansen, J. K., Nja, A. and Walloe, L. (1970) Inhibitory control of the abdominal stretch receptors of the crayfish. II. Reflex input, segmental distribution, and output relations. Acta Physiol. Scand. 80, 443-449.

Kennedy, D., Calabrese, R. L. and Wine, J. J. (1974) Presynaptic inhibition: primary afferent depolarization in crayfish neurons. Science 186, 451-454.

Kennedy, D., MacVittie, J., Calabrese, R., Fricke, R. A., Craelius, W. and Chiapella, P. (1980) Inhibition of mechanosensory interneurons in the crayfish. I. Presynaptic inhibition from giant fibers. J. Neurophysiol. 43, 1495-1509.

Kirk, M. D. (1985) Presynaptic inhibition in the crayfish CNS: pathways and synaptic mechanisms. J. Neurophysiol. 54, 1305-1325.

Klärner, D. and Barnes, W. J. P. (1986) The cuticular stress detector (CSD2) of the crayfish. II. Activity during walking and influences on leg coordination. J. Exp. Biol. 122, 161175.

Knox, P. C. and Neil, D. M. (1991) The coordinated action of abdominal postural and swimmeret motor systems in relation to body tilt in the pitch plane in the Norway lobster Nephrops norvegidus. J. Exp. Biol. 155, 605-627.

Kramer, A. P. and Krasne, F. B. (1984) Crayfish escape behavior: production of tailflips without giant fiber activity. J. Neurophysiol. 52, 189-211.

Kramer, A. P., Krasne, F. B. and Bellman, K. L. (1981a) Different command neurons select different outputs from a shared premotor interneuron of crayfish tail-flip circuitry. Science 214, 810-812.

Kramer, A. P., Krasne, F. B. and Wine, J. J. (1981b) Interneurons between giant axons and motoneurons in crayfish escape circuitry. J. Neurophysiol. 45, 550-573.

Krasne, F. B. and Teshiba, T. M. (1995) Habituation of an invertebrate escape reflex due to modulation by higher centers rather than local events. Proc. Natl. Acad. Sci. U. S. A 92, 3362-3366.

Lamotte d'Incamps, B., Destombes, J., Thiesson, D., Hellio, R., Lasserre, X., KouchtirDevanne, N., Jami, L. and Zytnicki, D. (1998a) Indications for GABA-immunoreactive 
axo-axonic contacts on the intraspinal arborization of a Ib fiber in cat: a confocal microscope study. J. Neurosci. 18, 10030-10036.

Lamotte d'Incamps, B., Meunier, C., Monnet, M. L., Jami, L. and Zytnicki, D. (1998b) Reduction of presynaptic action potentials by PAD: model and experimental study. $J$. Comput. Neurosci. 5, 141-156.

Lamotte d'Incamps, B., Meunier, C., Zytnicki, D. and Jami, L. (1999) Flexible processing of sensory information induced by axo-axonic synapses on afferent fibers [In Process Citation]. J. Physiol. Paris 93, 369-377.

Le Ray, D. and Cattaert, D. (1997) Neural mechanisms of reflex reversal in coxo-basipodite depressor motor neurons of the crayfish. J. Neurophysiol. 77(4), 1963-1978.

Le Ray, D. and Cattaert, D. (1999) Active motor neurons potentiate their own sensory inputs via glutamate- induced long-term potentiation. J. Neurosci. 19, 1473-1483.

Le Ray, D., Clarac, F. and Cattaert, D. (1997a) Functional analysis of the sensory motor pathway of resistance reflex in crayfish. I. Multisensory coding and motor neuron monosynaptic responses. J. Neurophysiol. 78, 3133-3143.

Le Ray, D., Clarac, F. and Cattaert, D. (1997b) Functional analysis of the sensory motor pathway of resistance reflex in crayfish. II. Integration Of sensory inputs in motor neurons. J. Neurophysiol. 78, 3144-3153.

Leibrock, C. S., Marchand, A. R. and Barnes, W. J. (1996a) Force dependent response reversal mediated by low- and high-threshold afferents from the same mechanoreceptor in a crayfish leg. J. Neurophysiol. 76, 1540-1544.

Leibrock, C. S., Marchand, A. R., Barnes, W. J. P. and Clarac, F. (1996b) Synaptic connections of the cuticular stress detectors in crayfish: mono-and polysynaptic reflexes and the entrainment of fictive locomotion in an in vitro preparation. J. Comp. Physiol. [A] 178, 711-725.

Leise, E. M., Hall, W. M. and Mulloney, B. (1987) Functional organization of crayfish abdominal ganglia: II. Sensory afferents and extensor motor neurons. J. Comp. Neurol. 266, 495-518.

Lennard, P. R. (1985) Afferent perturbations during "monopodal" swimming movements in the turtle: phase-dependent cutaneous modulation and proprioceptive resetting of the locomotor rhythm. J. Neurosci. 5, 1434-1445.

Libersat, F., Clarac, F. and Zill, S. N. (1987a) Force-sensitive mechanoreceptors of the dactyl of the crab: single-unit responses during walking and evaluation of function. $J$. Neurophysiol. 57, 1618-1637.

Libersat, F., Zill, S. and Clarac, F. (1987b) Single-unit responses and reflex effects of forcesensitive mechanoreceptors of the dactyl of the crab. J. Neurophysiol. 57, 1601-1617.

Lnenicka, G. A. and Atwood, H. L. (1985) Long-term facilitation and long-term adaptation at synapses of a crayfish phasic motoneuron. J. Neurobiol. 16, 97-110. 
Lnenicka, G. A. and Atwood, H. L. (1988) Long-term changes in neuromuscular synapses with altered sensory input to a crayfish motoneuron. Exp. Neurol. 100, 437-447.

MacMillan, D. L. and Field, L. H. (1994) Morphology, physiology, and homology of the Ncell and muscle receptor organs in the thorax of the crayfish Cherax destructor. $J$. Comp. Neurol. 350, 573-586.

Marchand, A. R. and Barnes, W. J. P. (1992) Correlates of habituation of a polysynaptic reflex in crayfish in vivo and in vitro. Eur. J. Neurosci. 4, 521-532.

Marchand, A. R., Barnes, W. J. P. and Cattaert, D. (1997) Primary afferent depolarizations of sensory origin within contact- sensitive mechanoreceptive afferents of a crayfish leg. $J$. Neurophysiol. 77(6), 3340-3354.

Marchand, A. R. and Leibrock, C. S. (1994) Functional aspects of central electrical coupling in mechanoreceptor afferents of crayfish. Brain Res. 667, 98-106.

Matheson, T. (1990) Responses and locations of neurones in the locust metathoracic femoral chordotonal organ. J. Comp. Physiol. [A] 166, 915-927.

McCarthy, B. J. and MacMillan, D. L. (1999) Control of abdominal extension in the freely moving intact crayfish Cherax destructor. I. Activity Of the tonic stretch receptor. J. Exp. Biol. 202 (Pt 2), 183-191.

Mendelson, M. (1963) Some factors in the activation of crab movement receptors. J. Exp. Biol. 40, 157-169.

Mill, P. J. (1976) Chordotonal organs of crustacean appendages. In: Structure and Function of Proprioceptors in the Invertebrates, pp. 243-297. Ed P. J. Mill. Chapman and Hall Ltd.: London.

Mittenthal JE, Wine JJ (1973) Connectivity patterns of crayfish giant interneurons: visualization of synaptic regions with cobalt dye. Science 179:182-184.

Miyan, J. A. (1984) A method for the neurophysiological study of reflexes elicited by natural statocyst stimulation in lobsters. J. Exp. Biol. 108, 465-469.

Mulloney, B., Acevado, L. D. and Bradbury, A. G. (1987) Modulation of the crayfish swimmeret rhythm by octopamine and the neuropeptide proctolin. J. Neurophysiol. 58, 584-597.

Mulloney, B., Acevedo, L. D., Chrachri, A., Hall, W. M. and Sherff, C. M. (1990) A confederation of neuronal circuits: control of swimmeret movements by a modular system of pattern generators. In: Frontiers in Crustacean Neurobiology, pp. 439-441. Eds K. Wiese, W.-D. Krenz, J. Tautz, H. Reichert, D. Mulloney. Birkhäuser Verlag: Basel.

Murayama, M. and Takahata, M. (1998) Neuronal mechanisms underlying the facilitatory control of uropod steering behaviour during treadmill walking in crayfish. I. Antagonistically regulated background excitability of uropod motoneurones. J. Exp. Biol. 201 (Pt 9), 1295-1305. 
Murchison, D., Chrachri, A. and Mulloney, B. (1993) A separate local pattern-generating circuit controls the movements of each swimmeret in crayfish. J. Neurophysiol. 70, 2620-2631.

Mykles, D. L. (1988) Histochemical and biochemical characterization of two slow fiber types in decapod crustacean muscles. J. Exp. Zool. 245, 232-243.

Nagayama, T., Aonuma, H. and Newland, P. L. (1997) Convergent chemical and electrical synaptic inputs from proprioceptive afferents onto an identified intersegmental interneuron in the crayfish. J. Neurophysiol. 77, 2826-2830.

Nagayama, T. and Newland, P. L. (1993) A sensory map based on velocity threshold of sensory neurones from a chordotonal organ in the tailfan of the crayfish. J. Comp. Physiol. [A] 172, 7-15.

Nakagawa, H. and Hisada, M. (1992) Local spiking interneurons controlling the equilibrium response in the crayfish Procambarus clarkii. J. Comp. Physiol. [A] 170, 291-302.

Neil, D. M. and Miyan, J. A. (1986) Phase-dependent modulation of auxiliary swimmeret muscle activity in the equilibrium reactions of the norway lobster, Nephrops norvegicus L. J. Exp. Biol. 126, 157-179.

Newland, P. L., Aonuma, H., Sato, M. and Nagayama, T. (1996) Presynaptic inhibition of exteroceptive afferents by proprioceptive afferents in the terminal abdominal ganglion of the crayfish. J. Neurophysiol. 76, 1047-1058.

Newland, P. L. and Nagayama, T. (1993) Parallel processing of proprioceptive information in the terminal abdominal ganglion of the crayfish. J. Comp. Physiol. [A] 172, 389-400.

Nja, A. and Walloe, L. (1973) In situ performance of slowly adapting stretch receptor of the crayfish. J. Neurophysiol. 36, 1062-1070.

Nja, A. and Walloe, L. (1975) Reflex inhibition of the slowly adapting stretch receptors in the intact abdomen of the crayfish. Acta Physiol. Scand. 94, 177-183.

Pahapill, P. A., Lnenicka, G. A. and Atwood, H. L. (1986) Neuronal experience modifies synaptic long-term facilitation. Can. J. Physiol. Pharmacol. 64, 1052-1054.

Parker, D. (1995a) Depression of synaptic connections between identified motor neurons in the locust. J. Neurophysiol. 74, 529-538.

Parker, D. (1995b) Long-lasting potentiation of a direct central connection between identified motor neurons in the locust. Eur. J. Neurosci. 7, 1097-1106.

Pasztor, V. M. and Clarac, F. (1983) An analysis of waving behaviour: an alternative motor program for the thoracic appendages of decapod Crustacea. J. Exp. Biol. 102, 59-77.

Paul, D. H. (1989) Nonspiking stretch receptors of the crayfish swimmeret receive an efference copy of the central motor pattern for the swimmeret. J. Exp. Biol. 141, 256264. 
Paul, D. H. and Bruner, J. (1999) Receptor potentials and electrical properties of nonspiking stretch- receptive neurons in the sand crab Emerita analoga (Anomura, Hippidae). $J$. Neurophysiol. 81, 2493-2500.

Paul, D. H. and Mulloney, B. (1985a) Local interneurons in the swimmeret system of the crayfish. J. Comp. Physiol. [A] 156, 489-502.

Paul, D. H. and Mulloney, B. (1985b) Non-spiking local interneuron in the motor pattern generator for the crayfish swimmeret. J. Neurophysiol. 54, 28-39.

Paul, D. H. and Mulloney, B. (1986) Intersegmental coordination of the swimmeret rhythms in isolated nerve cords of crayfish. J. Comp. Physiol. [A] 158, 215-224.

Pearlstein, E., Marchand, A. R. and Clarac, F. (1994) Inhibitory effects of L-Glutamate on central processes of crustacean leg motoneurons. Eur. J. Neurosci. 6, 1445-1452.

Pearlstein, E., Watson, A. H., Bévengut, M. and Cattaert, D. (1998) Inhibitory connections between antagonistic motor neurones of the crayfish walking legs. J. Comp. Neurol. 399, 241-254.

Pearson, K. G. (1985) Are there central pattern generators for walking and flight in insects? In: Feedback and motor control in invertebrates and vertebrates., pp. 307-315. Eds W. J. P. Barnes, M. H. Gladden. Croom Helm: London.

Pearson, K. G. (1993) Common principles of motor control in vertebrates and invertebrates. Annu. Rev. Neurosci. 16, 265-297.

Pearson, K. G., Ramirez, J. M. and Jiang, W. (1992) Entrainment of the locomotor rhythm by group Ib afferents from ankle extensor muscles in spinal cats. Exp. Brain Res. 90, 557566.

Rathmayer, W. and Bévengut, M. (1986) The common inhibitory neuron innervates every leg muscle in crabs. J. Comp. Physiol. [A] 158, 665-668.

Rathmayer, W. and Erxleben, C. (1983) Identified muscle fibers in a crab. I. Characteristics of excitatory and inhibitory neuromuscular transmission. J. Comp. Physiol. 152, 411-420.

Reichert, H., Plummer, M. R. and Wine, J. J. (1982) Lateral inhibition mediated by a nonspiking interneuron: circuit properties and consequences for behavior. J. Physiol. (Paris.) 78, 786-792.

Reichert, H. and Wine, J. J. (1982) Neural mechanisms for serial order in a stereotyped behaviour sequence. Nature 296, 86-87.

Rossi-Durand, C. (1993) Peripheral proprioceptive modulation in crayfish walking leg by serotonin. Brain Res. 632, 1-15.

Rossi-Durand, C. and Vedel, J. P. (1982) Antennal proprioception in the rock lobster Palinurus vulgaris: anatomy and physiology of a bi-articular chordotonal organ. $J$. Comp. Physiol. [A] 145, 505-516. 
Rossignol, S., Lund, J. P. and Drew, T. (1988) The role of sensory inputs in regulating patterns of rhythmical movements in higher vertebrates. In: Neural control of rhythmic movements in vertebrates, pp. 201-283. Eds A. H. Cohen, S. Rossignol, S. Grillner. John Wiley and Sons: New-York.

Schmidt, M. and Gnatzy, W. (1984) Are the funnel-canal organs the 'campaniform sensilla' of the shore crab Carcinus maenas (Decapoda Crustacea) ? II. Ultrastructure. Cell Tissue Res. 237, 81-93.

Schomburg, E. D., Petersen, N., Barajon, I. and Hultborn, H. (1998) Flexor reflex afferents reset the step cycle during fictive locomotion in the cat. Exp. Brain Res. 122, 339-350.

Schöne, H. (1971) Gravity receptors and gravity orientation in Crustacea. In: Gravity and the Organism, pp. 223-235. Anonymous. The University of Chicago Press: Chicago.

Schöne, H. and Steinbrecht, R. A. (1968) Fine structure of statocyst receptor of Astacus fluviatilis. Nature 220, 184-186.

Segev, I. (1990) Computer study of presynaptic inhibition controlling the spread of action potentials into axonal terminals. J. Neurophysiol. 63, 987-998.

Shik, M. L. and Orlovsky, G. (1976) Neurophysiology of locomotor automatism. Physiological Review 55, 465-501.

Sillar, K. T., Clarac, F. and Bush, B. M. H. (1987) Intersegmental coordination of central neural oscillators for rhythmic movements of the walking legs in crayfish, Pacifastacus leniusculus. J. Exp. Biol. 131, 245-264.

Sillar, K. T. and Elson, R. C. (1986) Slow active potentials in walking-leg motor neurones triggered by non-spiking proprioceptive afferents in the crayfish. J. Exp. Biol. 126, 445-452.

Sillar, K. T. and Skorupski, P. (1986) Central input to primary afferent neurons in crayfish, Pacifastacus leniusculus, is correlated with rhythmic motor output of thoracic ganglia. J. Neurophysiol. 55, 678-688.

Sillar, K. T., Skorupski, P., Elson, R. C. and Bush, B. M. H. (1986) Two identified afferent neurones entrain a central locomotor rhythm generator. Nature 323, 440-443.

Skinner, F. K., Kopell, N. and Mulloney, B. (1997) How does the crayfish swimmeret system work? Insights from nearest- neighbor coupled oscillator models. J. Comput. Neurosci. 4, 151-160.

Skorupski, P. (1992) Synaptic connections between nonspiking afferent neurons and motor neurons underlying phase-dependent reflexes in crayfish. J. Neurophysiol. 67, 664679.

Skorupski, P. (1996) Octopamine induces steady-state reflex reversal in crayfish thoracic ganglia. J. Neurophysiol. 76, 93-108.

Skorupski, P. and Bush, B. M. H. (1992) Parallel reflex and central control of promotor and receptor motoneurons in crayfish. Proc. R. Soc. Lond. B. Biol. Sci. 249, 7-12. 
Skorupski, P., Rawat, B. M. and Bush, B. M. H. (1991) The effect of octopamine and the neuropeptide proctolin on centrally generated and reflex activity in crayfish thoracic ganglia. In: Locomotor neural mechanisms in Arthropods and Vertebrates., pp. 173179. Eds D. M. Armstrong, B. M. H. Bush. Manchester University Press: Manchester.

Skorupski, P., Rawat, B. M. and Bush, B. M. H. (1992) Heterogeneity and central modulation of feedback reflexes in crayfish motor pool. J. Neurophysiol. 67, 648-663.

Skorupski, P. and Sillar, K. T. (1986) Phase-dependent reversal of reflexes mediated by the thoracocoxal muscle receptor organ in the crayfish, Pacifastacus leniusculus. J. Neurophysiol. 55, 689-695.

Skorupski, P. and Sillar, K. T. (1988) Central synaptic coupling of walking leg motor neurones in the crayfish: implications for sensorimotor integration. J. Exp. Biol. 140, 355-379.

Skorupski, P., Vescovi, P. and Bush, B. M. H. (1994) Integration of positive and negative feedback loops in a crayfish muscle. J. Exp. Biol. 187, 305-313.

Stein, P. S. G. (1971) Intersegmental coordination of swimmeret motoneuron activity in crayfish. J. Neurophysiol. 34, 310-318.

Takahata, M. (1981) Functional differentiation of crayfish statocyst receptors in sensory adaptation. Comp. Biochem. Physiol. A 68, 17-17.

Takahata, M. and Hisada, M. (1982a) Statocyst interneurons in the crayfish Procambarus clarkii Girard. II. Directional sensitivity and its mechanism. J. Comp. Physiol. 149, 301-306.

Takahata, M. and Hisada, M. (1982b) Statocyst interneurons in the crayfish Procambarus clarkii Girard. J. Comp. Physiol. 149, 287-300.

Takahata, M. and Hisada, M. (1985) Interactions between the motor systems controlling uropod steering and abdominal posture in crayfish. J. Comp. Physiol. [A] 157, 547554.

Takahata, M. and Hisada, M. (1986) Sustained membrane potential change of uropod motor neurons during the fictive abdominal posture movement in crayfish. J. Neurophysiol. 56, $702-717$.

Takahata, M. and Murayama, M. (1992) Multiple gate control of the descending statocystmotor pathway in the crayfish Procambarus clarkii Girard. J. Comp. Physiol. [A] 170, 463-477.

Tao-Cheng, J.-H., Hirosawa, K. and Nakajima, Y. (1981) Ultrastructure of the crayfish stretch receptor in relation to its function. J. Comp. Neurol. 200, 1-21.

Tatsumi, H., Haragashira, M. and Suzuki, R. (1985) Interrelations between posture and locomotion in response to body rotation in crayfish. J. Comp. Physiol. [A] 157, 509517. 
Usherwood, P. N. R., Runion, H. I. and Campbell, J. L. (1968) Structure and physiology of a chordotonal organ in the locust leg. J. Exp. Biol. 48, 305-323.

Vedel, J. P., Angaut-Petit, D. and Clarac, F. (1975) Reflex modulation of motoneurone activity in the cheliped of the crayfish Astacus leptodactylus. J. Exp. Biol. 63, 551-567.

Vu, E. T., Lee, S. C. and Krasne, F. B. (1993) The mechanism of tonic inhibition of crayfish escape behavior: distal inhibition and its functional significance. J. Neurosci. 13, 4379-4393.

Wales, W., Clarac, F. and Laverack, M. S. (1971) Stress detection at the autotomy plane in decapod crustacea. I. Comparative anatomy of the receptors of the basi-ischiopodite region. Z. vergl. Physiol. 73, 357-382.

West, L., Jacobs, G. and Mulloney, B. (1979) Intrasegmental proprioceptive influences on the period of the swimmeret rhythm in crayfish. J. Exp. Biol. 82, 281-288.

Wetzel, M. C. and Stuart, D. G. (1976) Ensemble characteristics of cat locomotion and its neural control. Prog. Neurobiol. 7, 1-98.

Wiersma, C. A. G. (1947) Giant nerve fiber system of the crayfish. A contribution to comparative physiology of synapse. J. Neurophysiol. 10, 23-38.

Wiersma, C. A. G. and Boettiger, E. G. (1959) Unidirectional movement fibres from a proprioceptive organ of the crab Carcinus maenas. J. Exp. Biol. 36, 102-112.

Wiersma, C. A. G. and Ikeda, K. (1964) Interneurones commanding swimmeret movements in the crayfish Procambarus clarkii (Girard). Comp. Biochem. Physiol. C 12, 509-525.

Wiese, K. (1976) Mechanoreceptors for near-field water displacements in crayfish. $J$. Neurophysiol. 39, 816-833.

Wildman, M. H. and Cannone, A. J. (1990) Action potentials in a "non-spiking" neurone : graded responses and spikes in the afferent $\mathrm{P}$ fibre of the crab thoracic-coxal muscle receptor organ. Brain Res. 509, 339-342.

Wildman, M. H. and Cannone, A. J. (1996) Sensory feedback and central afferent interaction in the muscle receptor organ of the crab, Carcinus maenas. J. Neurophysiol. 76, 788798.

Wilson, D. M. (1961) The central nervous control of flight in locust. J. Exp. Biol. 38, 471-490.

Wine, J. J. and Krasne, F. B. (1982) The cellular organization of crayfish escape behavior. In: The Biology of Crustacea, pp. 241-292. Ed D. E. Bliss. Academic Press: New-York.

Wojtowicz, J. M. and Atwood, H. L. (1986) Long-term facilitation alters transmitter releasing properties at the crayfish neuromuscular junction. J. Neurophysiol. 55, 484-498.

Yoshino, M., Takahata, M. and Hisada, M. (1980) Statocyst control of the uropod movement in response to body rolling in crayfish. J. Comp. Physiol. 139, 243-250. 
Zill, S. N. (1985) Plasticity and proprioception in insects. II. Modes of reflex action of the locust metathoracic femoral chordotonal organ. J. Exp. Biol. 116, 463-480.

Zill, S. N., Libersat, F. and Clarac, F. (1985) Single unit sensory activity in free walking crabs: force sensitive mechanoreceptor of the dactyl. Brain Res. 336, 337-341.

Zucker, R. S. (1972a) Crayfish escape behavior and central synapses. I. Neural circuit exciting lateral giant fiber. J. Neurophysiol. 35, 599-599.

Zucker, R. S. (1972b) Crayfish escape behavior and central synapses. II. Physiological mechanisms underlying behavioral habituation. J. Neurophysiol. 35, 621-637.

Zucker, R. S. (1989) Short-term synaptic plasticity. Annu. Rev. Neurosci. 12, 13-31.

FIGURE LEGENDS

Figure 1: Motor systems in crayfish. A: Organization of the thoracic and abdominal motor systems. The legs (for walking), the swimmerets disposed by pair under each of the abdominal segments (for swimming), and the abdomen itself with its last segment differentiated in a telson and two uropods (for escape reaction) represent the three main locomotor and equilibrium systems of the crayfish. B: Transversal view of the abdomen showing both its flexor (Flex) and extensor (Ext) musculature, as well as a pair of swimmerets (SW) and the ventral localization of the nerve cord. C: Isolated ventral nerve cord composed of five thoracic ( $\mathrm{TH} 1$ to $\mathrm{TH} 5$ ) and six abdominal (AB1 to AB6) ganglia. On TH5, the proximal innervation of the left $5^{\text {th }}$ leg is also shown.

Figure 2: The swimmeret motor system. A: Sub-abdominal localization of the swimmerets (SW2 to SW5) under segments 2, 3, 4, and 5 of the abdomen. B: Drawing of the infrastructure of a swimmeret. Two muscles, the promotor and the remotor command the forward/backward movements of the basipodite that entrains the rami (composed of both an endopodite and an exopodite). C: Detail of the abdominal nerve cord showing the motor (la and lb) and sensory (II) roots of each ganglion. D: Neurograms recorded from both la and lb roots showing the burst of motor activities that correspond to the returnstroke (RS) and the powerstroke (PS), respectively. Note that during the PS phase, rami motoneurons (MN) are co-activated with the promotor motoneurons. E: Neurograms recorded from four consecutive lb motor roots (SW2 to SW5) demonstrating the metachronal propagation of the motor wave (from SW5 to SW2). 
Figure 3: The thoracic walking leg system. A: Walking appendages are composed of seven segments. The $1^{\text {st }}$ (thoraco-coxal), $2^{\text {nd }}$ (coxo-basal) and $5^{\text {th }}$ (mero-carpal) joints are crucial for walking, allowing the leg to move forward/backward, upward/downward and to extend/flex, respectively. B: Detailed organization of the muscles that control the two firsts joints of the leg. Promotor (PRO) and remotor (REM) muscles control the thoraco-coxal joint movements, levator (LEV) and depressor (DEP) the coxo-basal joint movements. A mechanoreceptor, the coxobasipodite chordotonal organ ( $\mathrm{CBCO}$ ) spans the coxo-basal joint and monitors its movements. C: Detail of the isolated nervous system that controls the movements of the proximal leg joints. In vitro, every motor nerve commanding the two proximal joints are conserved, together with the $\mathrm{CBCO}$ and its sensory nerve that projects to levator and depressor motoneurons located in the ipsilateral hemi-ganglion. D: Neurograms recorded from each of the proximal motor nerves in a quiescent preparation, where only tonic postural activity is produced by the depressor motoneurons, and in active preparation, where fictive locomotion consists in alternate bursts of activity between antagonistic nerves. Note that a forward fictive walking is presented, levator motoneurons being co-activated with promotor ones.

Figure 4: The coxo-basal chordotonal organ mechanoreceptor (CBCO). A: Localization of the $\mathrm{CBCO}$ within the leg. $\mathrm{B}$ : Microphotography and drawing of the $\mathrm{CBCO}$ strand showing the localization of scolopidies. C: Spatial organization of the $\mathrm{CBCO}$ afferents (CBTs) within the ipsilateral hemi-ganglion. Intracellular recordings $(M E)$ are generally performed in the largest part of the sensory afferent bundle. $D$ : Sensory coding performed by $\mathrm{CBCO}$ afferents. Phasic fibers respond only when a movement occurs, while both phaso-tonic and continuously firing afferents code both the movement and the position of the CB joint.

Figure 5: Swimmerets sensory apparatus. A: Localized at the base of the basipodite, the non-spiking stretch receptor (NSSR) monitors the movements of the basipodite relative to its abdominal support. B: Detail of the organization of the NSSR. C: Ipsilateral localization of the anterior NSSR cell bodies within the anterior part of the abdominal ganglion. D: Retracting the basipodite (upward deflection of the movement (mvt) trace) elicits a depolarization of the membrane potential of NSSR 
(the example of the posterior NSSR (NSSR-P) is presented). Increasing the amplitude of retraction increases the amplitude of the depolarization in the NSSR (left traces). When retracted position is maintained, a persisting depolarization is recorded in the NSSR (right traces).

Figure 6: The abdominal muscle receptor organs (MROs). A: Drawing of the fast adapting $\mathrm{MRO}$, with its receptor muscle (RM1) and its afferent and efferent innervation. B: Drawing of the slow adapting MRO showing its receptor muscle (RM2) and its innervation. C: Coding properties of the afferent sensory neuron of MR1. The sensory neuron is activated by the stretch (s) of RM1 but rapidly adapts its response, a further stretch evoking a longer but still adapting firing response although the neuron remains depolarized. The sensory neuron repolarizes as soon as RM1 is released ( $r$ ). D: Coding properties of $\mathrm{MRO} 2$. The sensory neuron fires during the whole stretching of RM2, and the frequency of firing is maintained during the stretched-position plateau (duration larger than $30 \mathrm{~s}$, shortened on the graph). The firing response ends as soon as RM2 is released. [C and D, from Eyzaguirre and Kuffler, 1955] E: Plot of the firing frequency of the SR2 versus the angle imposed to the abdominal joint in situ, with intact (squares; thick line) or sectioned (triangles; thin line) thick accessory nerve. [From Nja and Walloe, 1973] F: Neurograms from the dorsal nerve roots of $2^{\text {nd }}$ (DN2) and $3^{\text {rd }}$ (DN3) abdominal ganglia. The onset of SR2 activity in DN2 completely inhibits the SR2 activity in DN3 (large spikes), because of the activation of the thick accessory nerve (small spikes). [From Jansen et al., 1970.]

Figure 7: The thoraco-coxal mechanoreceptor (TCMRO). A: Localization within the first leg joint of the TCMRO that codes backward movements of the leg, together with the TC chordotonal organ (TCCO) that codes leg forward movements. B: Coding properties of the non-spiking phasic $(T)$ and tonic $(S)$ fibers. Both are depolarized in response to the TCMRO stretch. [A and B, from Skorupski et al., 1992] C: Detailed drawing of the receptor organ, showing the insertion of both the sensory ( $\mathrm{T}$ - and Sfibers) and motor innervation. The TCMRO motor innervation runs through the promotor motor nerve before branching to the receptor muscle (RM). D: Relation between the T-fiber depolarization and the receptor muscle contraction induced by stimulating its motor nerve. E: Reflex activation of TCMRO receptor muscle by stretching and releasing the CBCO. [D and E, from Cannone and Bush, 1981a]. 
Figure 8: The cuticular stress detector (CSD). A: Localization of the two CSDs (CSD1 and CSD2) in the walking leg. [From Clarac, 1976]. B: Detail structure of CSD2. [From Klärner and Barnes, 1986.] C: Ultrastructure of CSD2 showing the organization of the sensory cells within both the main and accessory strands. [From Wales et al., 1971.] D: Neurograms from both the levator and depressor motor nerves and CSD2 sensory nerve, showing that CSD2 is activated during stance phases (depressor nerve bursts). [From Klärner and Barnes, 1986.]

Figure 9: Neuromodulation of the $\mathrm{CBCO}$ coding. A: Stretch-sensitive $\mathrm{CBCO}$ sensory afferent intracellularly recorded in its terminal. B: Perfusion of serotonin $\left(10^{-6} \mathrm{M}\right)$ onto the $\mathrm{CBCO}$ strand increases the afferent firing frequency for the same stretch of the organ (down movement). [From Rossi-Durand, 1993.]

Figure 10: Resistance reflex activities elicited by abdominal MROs. A: Intracellular recording from a slow extensor motoneuron (Slow Ext. MN) and extracellular recording of a dorsal nerve activity displaying the activities of both the tonic (MRO1, small spikes) and the phasic (MRO2, large spikes) muscle receptor organs. Only the tonic MRO elicits activities in the motoneuron. [From Fields, 1966.] B: Responses to electrical stimulation of SR1, SR2 or both sensory nerves intracellularly recorded from three distinct interneurons within the $6^{\text {th }}$ abdominal ganglion. Some interneurons respond only to either SR1 or SR2, or respond to both. [From Bastiani and Mulloney, 1988.]

Figure 11: Proximal resistance reflexes in leg motor system. A: Drawing of the in vitro preparation used to study the reflexes evoked in protractor and remotor motoneurons by the stretch/release stimulation of both the TCMRO and the TCCO. B: Neurograms from both the promotor and the remotor motor nerves during stretch (S) and release (R) of both the TCMRO and the TCCO. During stretch, new promotor motoneurons are activated, and each is silenced during release. In contrast, remotor motoneurons are activated exclusively during release movement (that mimics leg protraction). C: Instantaneous firing frequency of two identified promotor motoneurons and one remotor motoneuron during stretch and release of both the TCMRO and the TCCO. Data taken from neurograms in B. [A, B and C, from 
Skorupski et al., 1992.] D: Drawing of the in vitro preparation used to study CBCOevoked resistance reflex response in levator and depressor (Dep MN) motoneurons. $\mathrm{E}, \mathrm{F}$ : The two kinds of resistance response recorded intracellularly from depressor motoneuron. In group 1 (Dep MN1), phasic bursts of EPSPs are recorded during release $(R)$ of the CBCO strand (which corresponds to leg levation). In group 2 (Dep MN2), the phasic bursts of EPSPs are superimposed onto a graded membrane depolarization, the amplitude of which is related to the amplitude of the CBCO strand release.

Figure 12: Motoneuronal active properties. A: Extracellular recording from the depressor motor nerve (Dep n) and intracellular recording from a depressor motoneuron (Dep $\mathrm{MN}$ ) in which current is intracellularly injected (i). In control conditions, the motoneuron burst does not outlast the current injection. After perfusion of the muscarinic agonist of acetylcholine, oxotremorine (Oxo), the same current injection elicits a plateau of depolarization in the motoneuron. B: Intracellular recording from a remotor motoneuron (Rem $\mathrm{MN}$ ) displaying pacemaker properties, the frequency of which varies with the holding potential.

Figure 13: State-dependent reflex reversals in TC and CB joints. $A$ Left: Muscarinic activation of the locomotor network induces fictive locomotion that is recorded as alternate bursts of activity between antagonistic motor nerves (protractor, Pro, and remotor, Rem). Fictive forward locomotion is presented, because levator (Lev) activities occur in phase with protractor bursts. In such conditions, T- and S-fibers of the TCMRO are alternately depolarized and hyperpolarized according to the phase of the locomotor cycle. Right: In such a rhythmically active preparation, stretch/release stimulation of the TCMRO evokes assistance reflex activation of protractor and remotor motoneurons. [From Elson et al., 1992.] B: Paired intracellular recordings from various promotor motoneurons (Pro $\mathrm{MN}$ ) and the TCMRO T-fiber in which depolarizing current is injected. Two of the promotor motoneurons are excited while the two others are inhibited by the same Tfiber depolarization. [From Skorupski, 1992.] C Left: Fictive forward walking evoked by muscarinic stimulation of the locomotor network. Right: Stretch/release stimulation of the CBCO strand elicits assistance activation of levator (Lev) and depressor (Dep) motoneurons in such a rhythmic preparation. 
Figure 14: Thoracic coordinating interneurons. A: Coordination of promotor (Pro), Remotor (Rem), levator (Lev) and depressor (Dep) motoneurons into a forward walking activity by injection of depolarizing current $(+8 \mathrm{nA})$ in an interneuron (IN) located within the hemi-ganglion. B: Four kinds of coordinating interneurons have been described in thoracic ganglia to be responsible for swing and stance phases in both forward and backward walking activities.

Figure 15: Proprioceptive control of rami activity. A: Neurograms from swimmeret protractor (Pro), remotor (Rem) and ramus motor nerves during rhythmic activity in unrestrained animal (1), or when the basipodite is maintained in forward (2) or backward (3) position. Activity of ramus motoneurons is largely dependent on sensory information originating form the basipodite. B: Ramus neurogram during forward (up) and backward (down) movements imposed to the basipodite in quiescent preparation. The instantaneous frequency of firing is directly correlated to the angle imposed to the basipodite.

Figure 16: Proprioceptive control of TC joint motoneurons by A: Extracellular recordings from the $\mathrm{CBCO}$ sensory nerve $(\mathrm{CBn})$ and intracellular recordings from both a promotor motoneuron (1) and a remotor motoneuron (2) during imposed stretch (down) and release (up) of the CBCO strand. In quiescent preparation, both stretch and release stimulation evoke an increase in activity recorded from the $\mathrm{CBn}$ and depolarizing responses in promotor and remotor motoneurons. B: In active preparation, the responses evoked in motoneurons that control the TC joint (here a promotor motoneuron) are increased and more complex.

Figure 17: Bilateral synchronization in swimmeret motor system. A: Intracellular recordings from two powerstroke motoneurons (PS MN), one from the right side, the other from the left side. During proctolin-induced swimmeret rhythm, both PS MNs are in phase. B: Addition of tetrodotoxin (TTX) to the perfusion of proctolin completely inhibits the synchronization. [A and B, from Murchison et al., 1993.]

Figure 18: Limb coordination in the thoracic walking system. A: Neurograms from remotor motor nerves (Rem) of the $2^{\text {nd }}, 3^{\text {rd }}$ and $4^{\text {th }}$ right legs. In vitro, 
spontaneous in phase coordination is commonly observed. B: Neurograms from remotor motor nerves of the $3^{\text {rd }}$ and $4^{\text {th }}$ right legs during mechanical stimulation of the TCMRO of the $4^{\text {th }}$ leg at various frequencies. The assistance feedback evoked by TCMRO stimulation spreads to neighbor leg. [A and B, from Sillar et al., 1987.]

Figure 19: Leg coordination by dactyl sensory afferents (DSAs). A: Neurograms from levator (Lev) and depressor (Dep) motor nerves of the $4^{\text {th }}$ leg during stimulation of DSA of either the $4^{\text {th }}$ (left) or the $5^{\text {th }}$ (right) leg of the crab. Conversed reflex responses are evoked. B: DSA electrical stimulation restores inter-leg coordination during free walking in the crab. The activities of the depressor muscles of legs 2, 3 and 4 are represented by filled rectangle in three conditions: when leg 3 is free during walking (left), when leg 3 is blocked in levated position without (center) and with (right) DSA electrical stimulation. [From Libersat et al., 1987b].

Figure 20: Relative and absolute coordination between walking and swimmeret beating. A: In vivo, electromyograms from swimmeret promotor (Pro) and remotor (Rem) muscles, and leg depressor muscle (Dep), during walking activity, display either relative (two swimmeret beating cycles for each walking period) coordination (A1) or absolute coordination (A2). B: In vitro, during a fictive swimmeret beating activity sequence, the electrical stimulation of the $5^{\text {th }}$ leg CBCO sensory nerve entrains the swimmeret beating rhythm in an absolute coordination mode.

Figure 21: Circuits for crayfish escape behavior. On this schema, neural circuits involving giant fibers (GFs) to produce tail flips are shown on the left, and the circuitry that do not use GFs is shown on the right.

GF-MEDIATED REACTIONS are illustrated in the drawings at the bottom of the figure. The dark gray crayfish represents a lateral giant-axon (LG)-mediated response (forward escape in response to mechanical stimulation of the tail of the animal - see dark gray sensory fields at the top of the figure). The light gray crayfish represents a medial giant-axon (MG)-mediated response (backward escape in response to mechanical or visual stimulus - see light gray sensory fields at the top of the figure). The segmental joints at which bending occurs to produce these reactions are indicated by circles above the white crayfish. Circuitry for GF-mediated responses involves primary afferents, sensory interneurons, $L G$ and $M G$, and giant 
motoneurons (MoGs) arranged from top to bottom. LG-associated elements and MGassociated elements are colored in dark gray and light gray, respectively.

NON-GIANT RESPONSE (non-G) circuitry (shown on the right) involves a separate population of fast flexor (FF) motoneurons.

The segmental giant neuron (SG) allows the LG and MG to recruit non-G motor and premotor units. During LG-type tail flips, the activation of the caudal FF is prevented by inhibitory input triggered by LG-associated sensory circuits. [From Edwards et al., 1999].

Figure 22: Locomotor-related primary afferent depolarizations (PADs). A: Neurogram from a depressor motor nerve and intracellular recording from a CBCO sensory terminal. Bursts of PADs are produced in the terminal essentially at the onset of activity of depressor motoneurons. B: During PADs, afferent sensory spikes are reduced in amplitude. C: Paired intracellular recordings from both a CBCO sensory terminal and a postsynaptic levator motoneuron (MN) showing that, when a PAD occurs (traces numbered 2), both the afferent spike in the CBCO terminal and the EPSP in the postsynaptic motoneuron are reduced in amplitude by comparison to control (traces numbered 1). D: The reversal potential of PADs is around $-35 \mathrm{mV}$.

Figure 23: GABA reproduces the effects of spontaneous PADs. A: Drawing of the experimental procedure. GABA is pressure-ejected directly onto the intracellularly recorded CBCO terminal. B: The GABA micro-application induced both a decrease in input resistance (downward deflection of the membrane potential) and a decrease of afferent spike amplitude. C: Superimposed afferent spikes selected from $B$ at the time points indicated by the numbers (1, before 2, during, and 3, after GABA-evoked depolarization). D: Superimposed input resistance measures selected at the same time points as in $\mathrm{C}$.

Figure 24: PAD-mediated inhibition in CBCO terminals. A: Reproduction from a confocal microphotography of a CBCO terminal stained with Lucifer Yellow, showing the localization of GABA receptors stained by immuno-histochemical reaction. Two intracellular recordings of the same afferent spike at two distinct loci are also presented (ME1 and ME2). B: Intracellular recordings of a CBCO terminal (CBT) afferent spikes without (left) and with (center and right) PAD. C: Effects of 
intracellular injection of depolarizing current of increasing intensity on the amplitude of sensory afferent spikes. Inactivation of $\mathrm{Na}^{+}$channels occurs only for high amplitude depolarizations. D: Comparison of $\mathrm{CBCO}$ afferent spike peaks during depolarizing current injection (open circles) and during spontaneous PADs (filled circles). The shunting effect of PADs occurs for low amplitude PADs by comparison to inactivation of $\mathrm{Na}^{+}$channels (that would occur only for very large PADs). $E$ : Superimposition of the spikes showed in A. Note the effect of decremential propagation in the sensory terminal.

Figure 25: Antidromic spikes in CBCO terminals. A: Intracellular recording from a CBCO terminal (CBT) and neurogram of the CBCO sensory nerve (CBn) showing that spikes that are produced on large PADs are conducted antidromically in the nerve. B: Paired intracellular recordings from a CBT and a postsynaptic motoneuron $(\mathrm{MN})$, together with a neurogram from the $\mathrm{CBn}$, demonstrating that antidromic spikes (right) never elicit any EPSP in the MN, while orthodromic spikes (left) do.

Figure 26: Mechanisms of presynaptic inhibition in CBCO terminals. Schematic drawing of a CBCO sensory terminal (left) locating the GABAergic inhibitory synapses by comparison with both zones of active and passive propagation of the afferent spike (separation between both zones is signaled by the asterisk). A postsynaptic motoneuron is also symbolized (right). A: Normal propagation of an afferent spike, and response evoked in the postsynaptic motoneuron. B: Shunting of an afferent spike by the occurrence of a GABA-mediated PAD, and decrease of the postsynaptic response. C: Propagation of a large PAD-evoked antidromic spike, and lack of postsynaptic response.

Figure 27: Glutamate-mediated presynaptic inhibition in CBCO terminals. A: During pharmacologically induced fictive locomotion (see alternate bursts of activity in levator (Lev $\mathrm{n}$ ) and depressor (Dep $\mathrm{n}$ ) neurograms), an intracellular recording from a CBCO sensory terminal (CBT) may display two kinds of spontaneous depolarizations. Large GABAergic PADs occur at phase transitions between Dep $n$ and Lev $n$, and glutamatergic slow developing PADs (sdPADs) occur during highfrequency motor bursts (see the levator instantaneous frequency histograms, Lev $n$ Inst. Freq.). B: Perfusion of the $\mathrm{GABA}_{A}$-associated chloride channel blocker 
picrotoxin synchronizes motor activities, and elicits in the CBT large summations of sdPADs. C: Diagram of the glutamate-induced presynaptic inhibition, and effect on sensory-motor transmission. Glutamate released in a retrograde manner from the postsynaptic motoneuron (MN) excites an ionotropic glutamate receptor located on the terminal part of the sensory afferent. It activates a mixed $\mathrm{Na}^{+} / \mathrm{K}^{+}$conductance that performs a powerful shunt of the afferent spike and, therefore, reduces the efficacy of the sensory-motor connection.

Figure 28: Lateral inhibition in DSAs. A: Drawing of the experimental organization. Sensory hairs of the dactyl are mechanically stimulated while the afferent volley is recorded from the DSA nerves, and intracellular recordings are performed from identified DSA terminals within the ipsilateral hemi-ganglion. B: Superimposed intracellular recordings from a DSA terminal (DSA-t) showing the occurrence of coupled afferent spikes, and PADs. C: PADs and coupled spikes originate from another DSA that is identified on the DSA nerve neurogram. D: Diagram of interrelations between DSA afferents. Both electrical coupling and disynaptic lateral inhibition occur.

Figure 29: Protective presynaptic inhibition in abdominal circuitry. Schematic drawing of the circuitry responsible for the escape reaction (in the $5^{\text {th }}$ abdominal ganglion, AG5) and its proprioceptive control (in the $6^{\text {th }}$ ganglion, AG6). The lateral giant fiber (LG) activates the escape network and excites also, through the corollary discharge interneuron (CDI), an interneuron specialized in the production of PADs that presynaptically inhibit the mechanosensory afferents (MSA) before they excite the mechanosensory interneurons (MSI). [From Kirk, 1985.]

Figure 30: Mechanisms of reflex reversal in crayfish. A: Organization of the resistance reflex pathway. Upward movements of the leg (left) excite releasesensitive CBCO afferents that monosynaptically connect depressor motoneurons (DEP MNs). Leg downward movements (right) excite levator motoneurons (LEV MNs), through the activation of their presynaptic stretch-sensitive CBCO afferents. B: Organization of the assistance reflex. When the CPG is active, the monosynaptic connections between CBCO sensory afferents and motoneurons are cut by the activation of the PAD-producing interneurons (PADIs). In the same time, strong 
reciprocal inhibition between antagonistic motoneurons helps to the inhibition of resistance reflexes. Reversed reflex is allowed by assistance reflex interneurons (ARINs) being activated and conveying sensory information to agonistic motoneurons. This latter pathway is locally controlled by assistance reflex controlling interneurons (ARCINs).

Figure 31: Mechanism of habituation in the escape circuitry. A: Simplified diagram of the escape reaction circuitry. The lateral giant interneuron (LG) integrates both monosynaptic (a) and disynaptic (b), through mechanosensory interneurons (MSIs), tactile afferent inputs and activates abdominal giant motoneurons (MoGs). Inset shows the result of the sensory integration in LG. B: Successive responses of a LG and a presynaptic MSI to electrical stimulation of a tactile sensory nerve demonstrating that habituation results from a decrease in the activity of the presynaptic MSI. No changes were found in the early (monosynaptic) response of LG, while the late component decreases with the firing in MSI. [From Zucker, 1972a,b.]

Figure 32: Plasticity at crayfish neuromuscular junctions. A: Intracellular recordings from a unit fiber of the claw opener muscle and quantal analysis of the EPSP amplitude performed before (left) and after (right) tetanizing the excitor motor axon. LTP results from an increase in both the quantal content and the number of quanta. [From Baxter et al., 1985.] B: Plot of the excitatory junction potential (EJP) amplitude recorded in a unit fiber of the closer muscle before (depression), during (stronger depression) and after (facilitation) a conditioning stimulation (5 Hz, $30 \mathrm{~min}$ ) was applied to the fast motor axon. Facilitation results from a slight potentiation of the EJP and a complete loss in depression properties. [From Lnenicka and Atwood, 1985.]

Figure 33: LTP at crayfish sensory-motor synapses. A: Plot of the normalized EPSP amplitude showing a large and long-lasting potentiation of the EPSP that develops slowly after the sole postsynaptic motoneuron activity (MN St). B: Paired intracellular recordings from both a CBCO sensory terminal (CBT) and a postsynaptic motoneuron (MN), and quantal analysis of the unitary EPSP before (left) and after (right) postsynaptic motoneuron activation (in the absence of presynaptic activity). 
LTP results from the sole increase in the number of quanta released by the CBT. C: Schematic representation of the cellular mechanisms involved in sensory-motor LTP. When the postsynaptic MN remains silent for a long period of time (1), the CBT release a small quantity of acetylcholine (ACh) for each afferent spike. The onset of motor activity induces a central, retrograde release of glutamate (Glu) from the postsynaptic MN onto its own presynaptic CBTs, which activates a metabotropic glutamate receptor (mGluR) located on the terminal part of the CBT (2). After such a MN activation occurred, the presynaptic CBT releases larger quantities of acetylcholine for each afferent spike (3). 
FIG 01

A
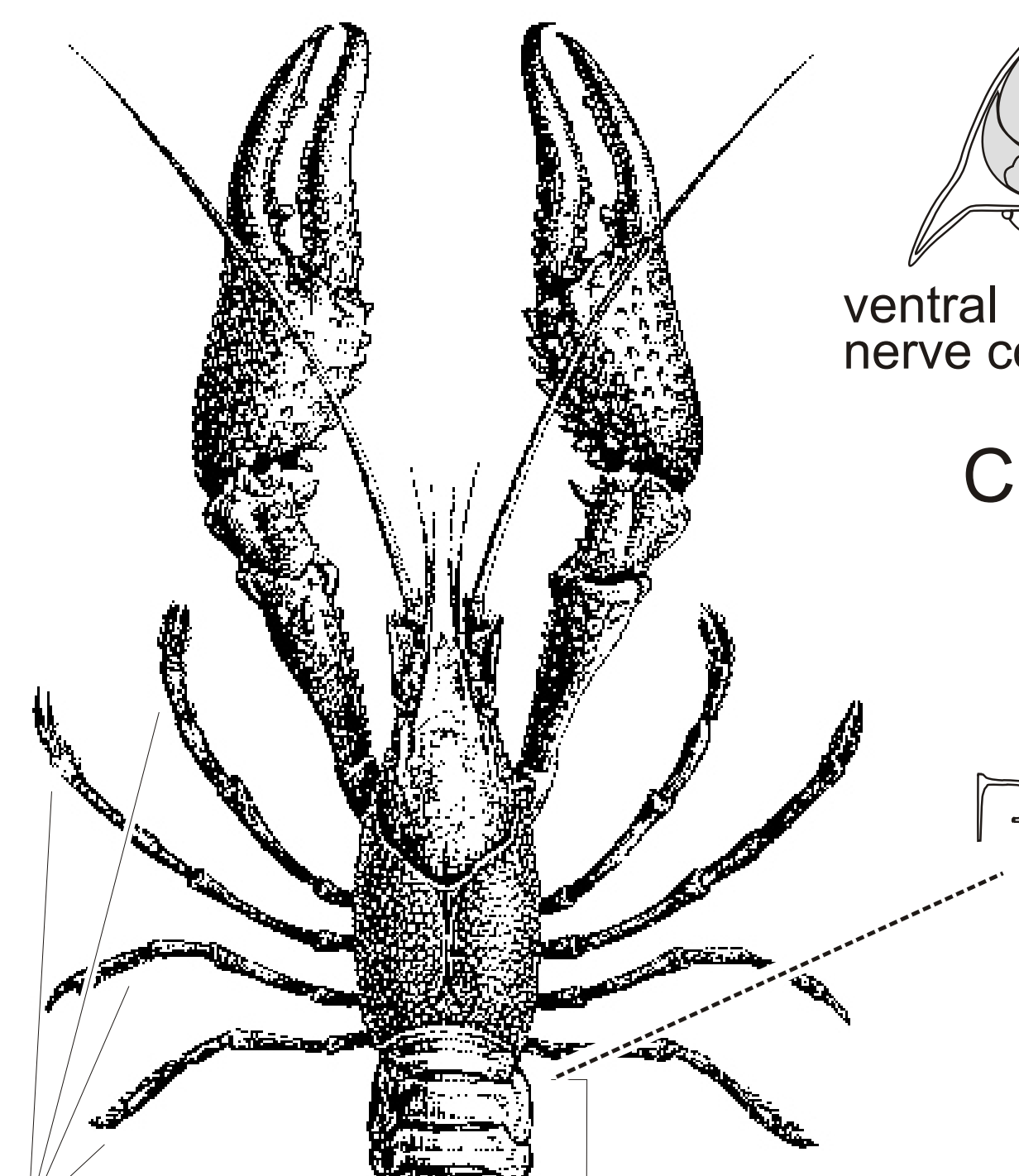

Abdomen

walking legs

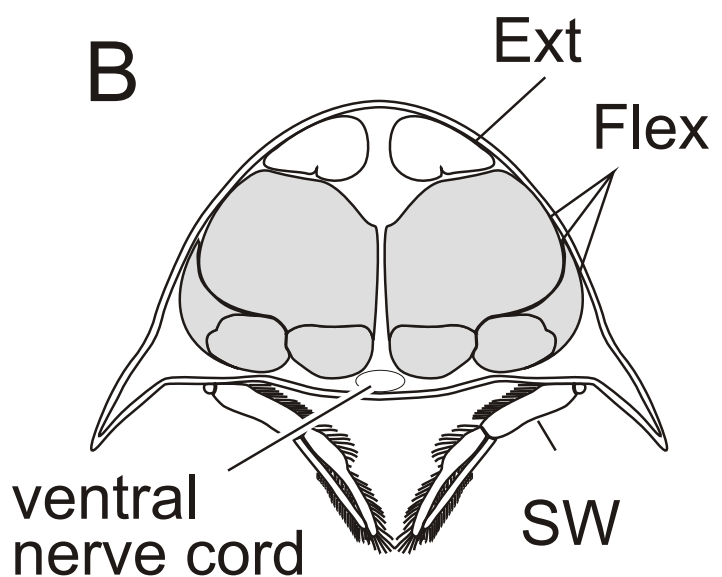

nerve cord SW

C

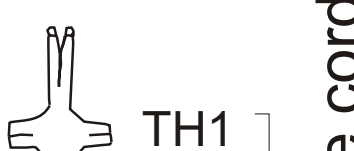

응

(1)

$\xi$ TH2

TH3

包

인

(2)

은
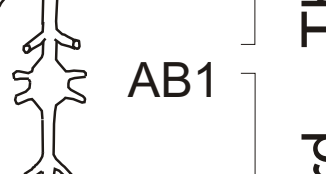

잉

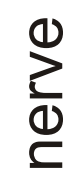

을

Uropods Telson

Tailfan 
A

B

FIG 02

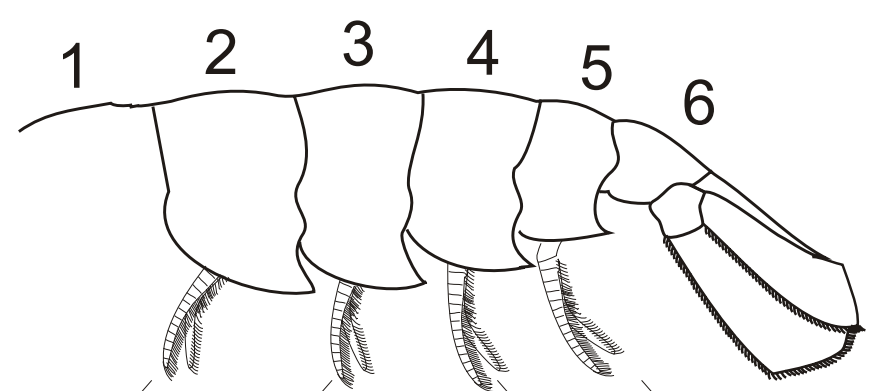

Promotor Remotor

SW2 SW3 SW4 SW5 Basipodite Exopodite Endopodite

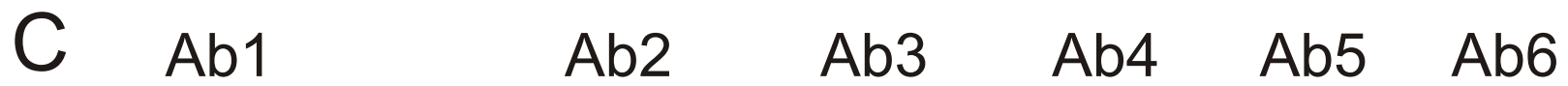
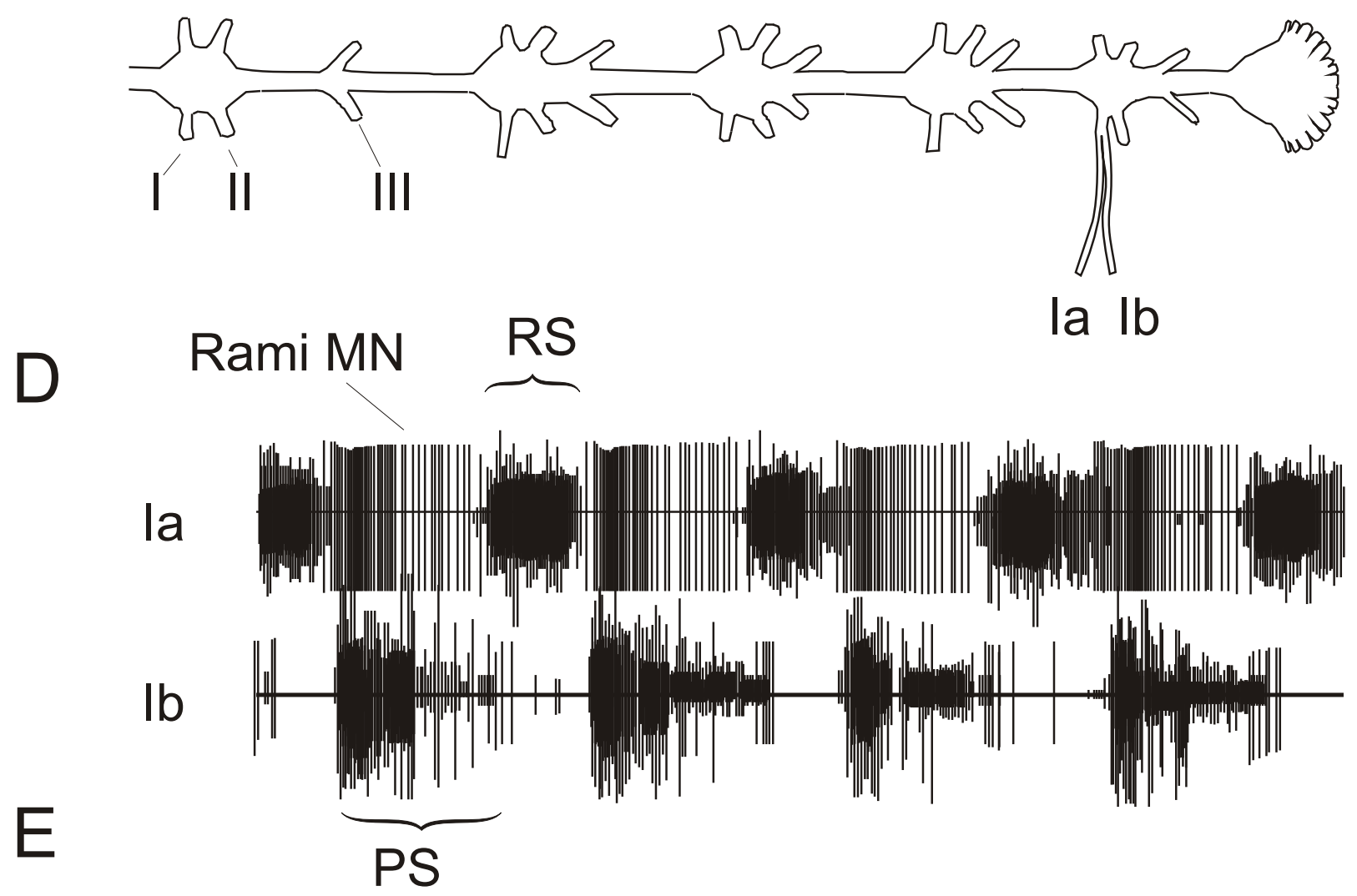

SW2 SW3 W...W

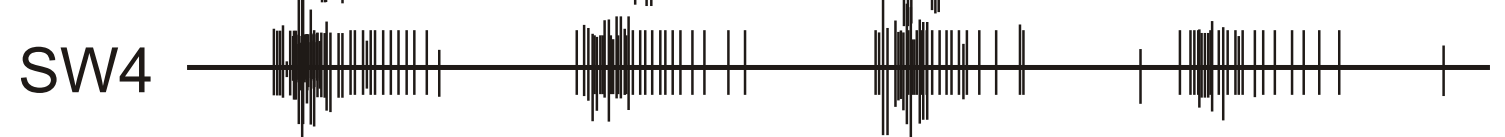
SW5 $1 \mathrm{~s}$ 

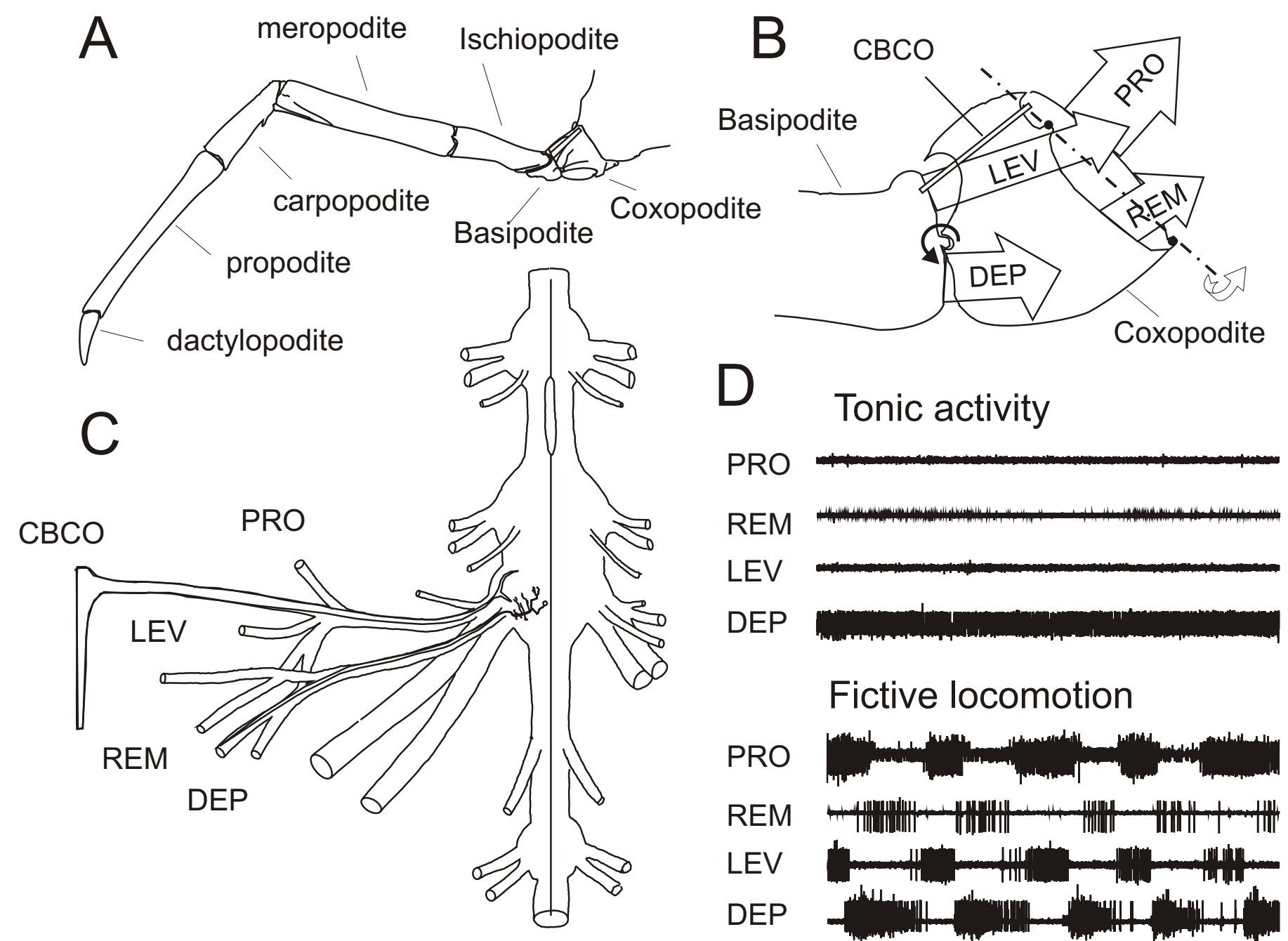

Fictive locomotion

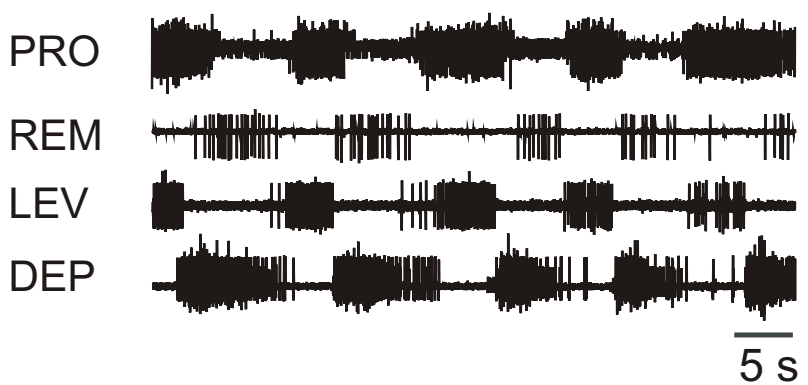




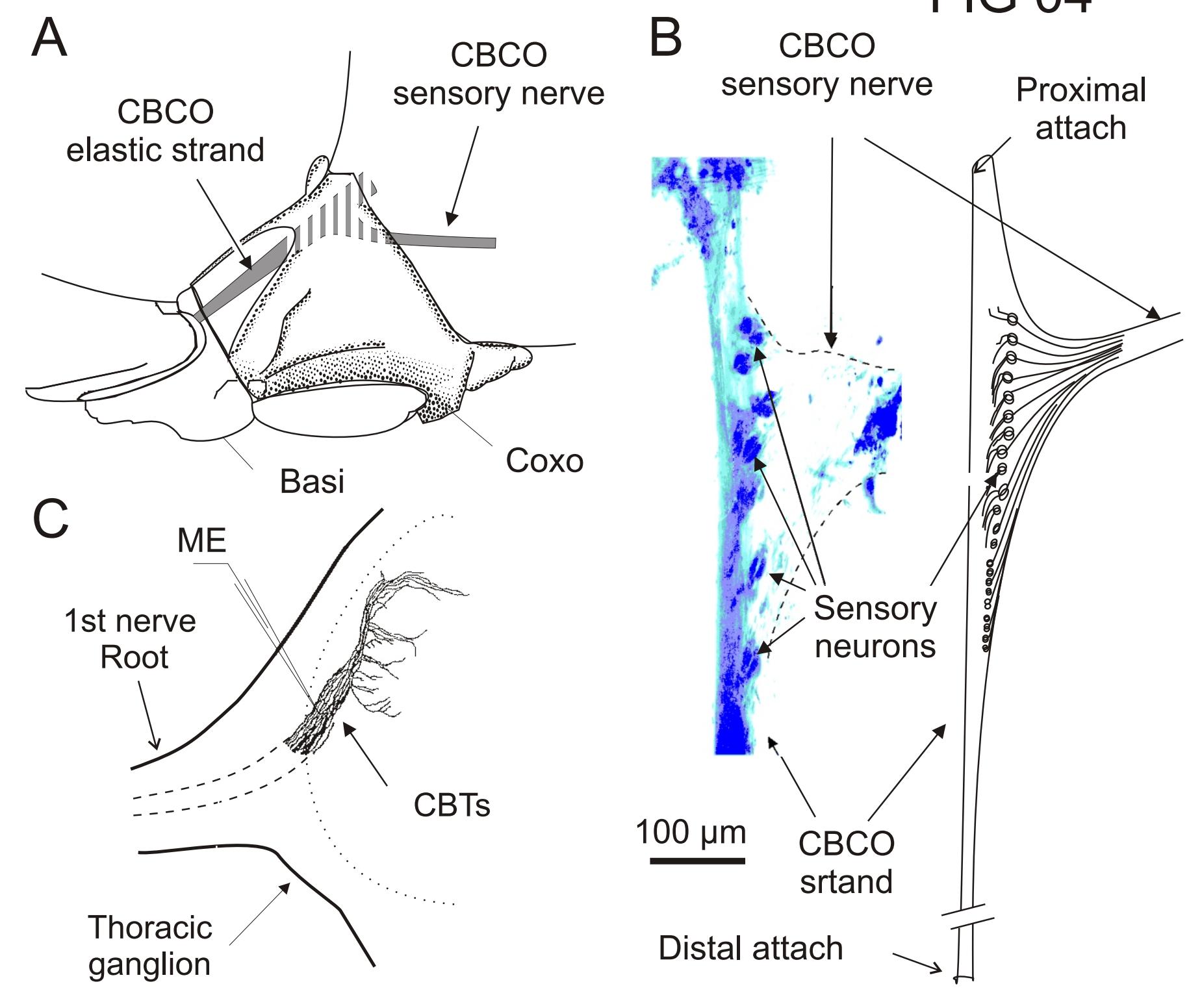

FIG 04

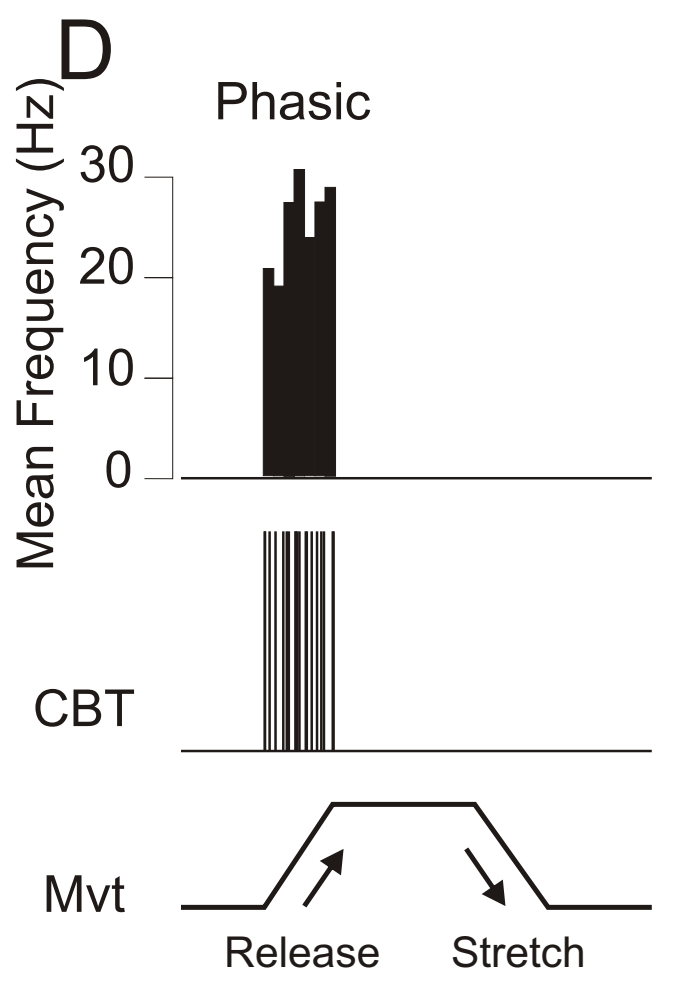

Phaso-tonic

Continuous
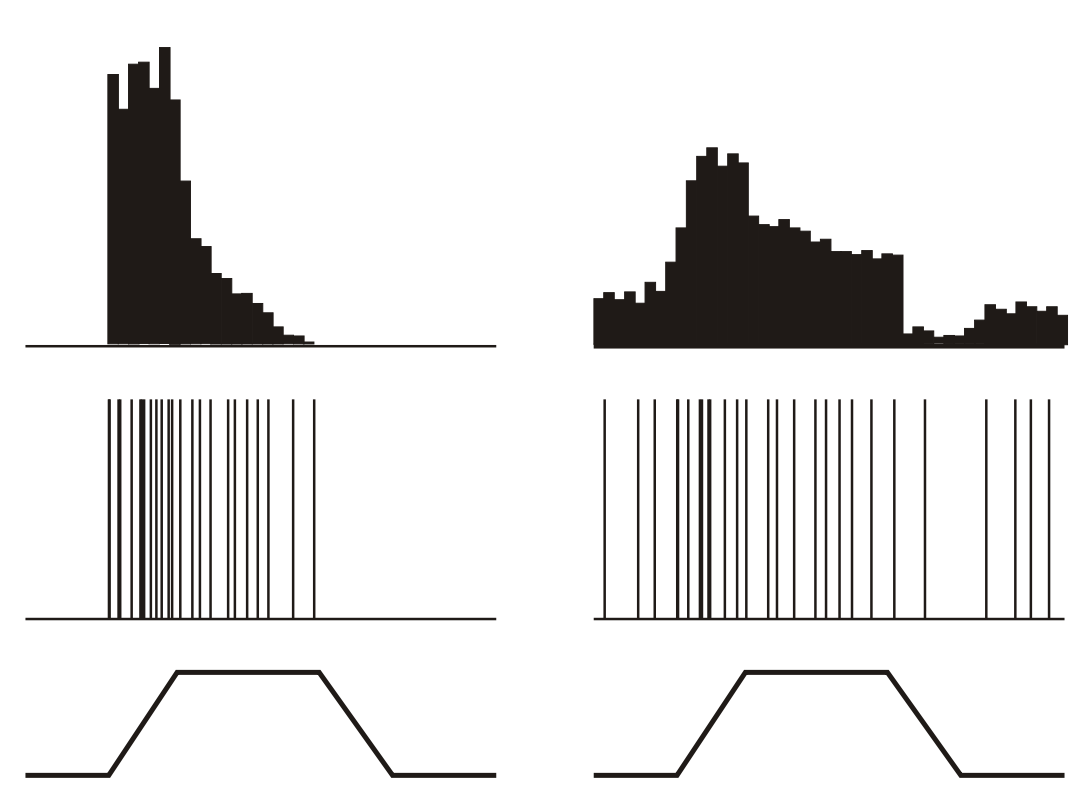
A

Basipodite

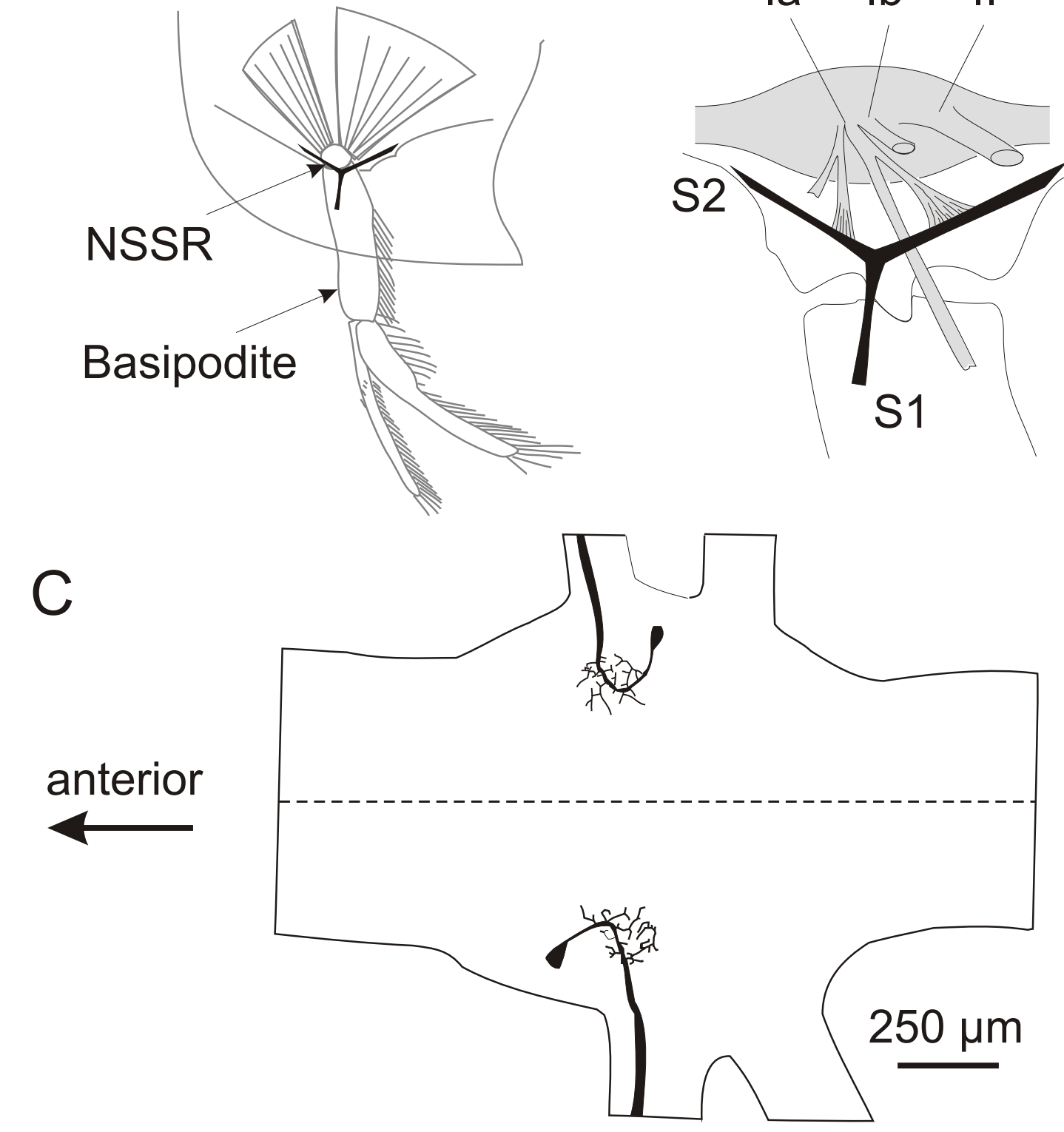

B la Ib II

FIG 05

D

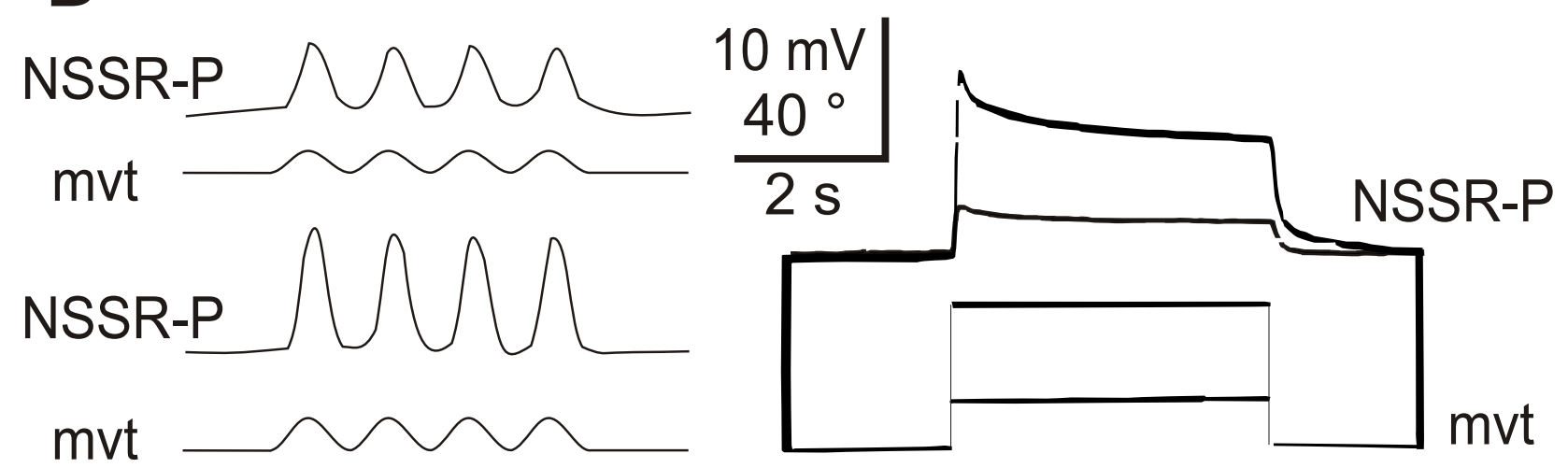


A

B

RM1

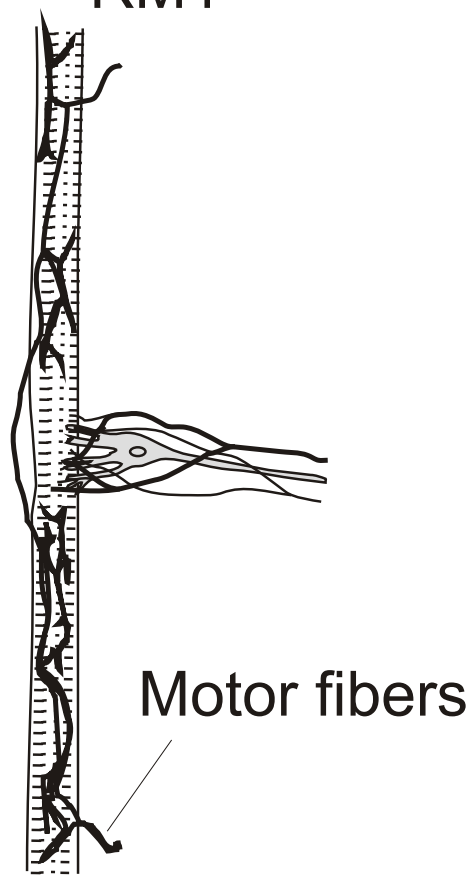

RM2

FIG 06

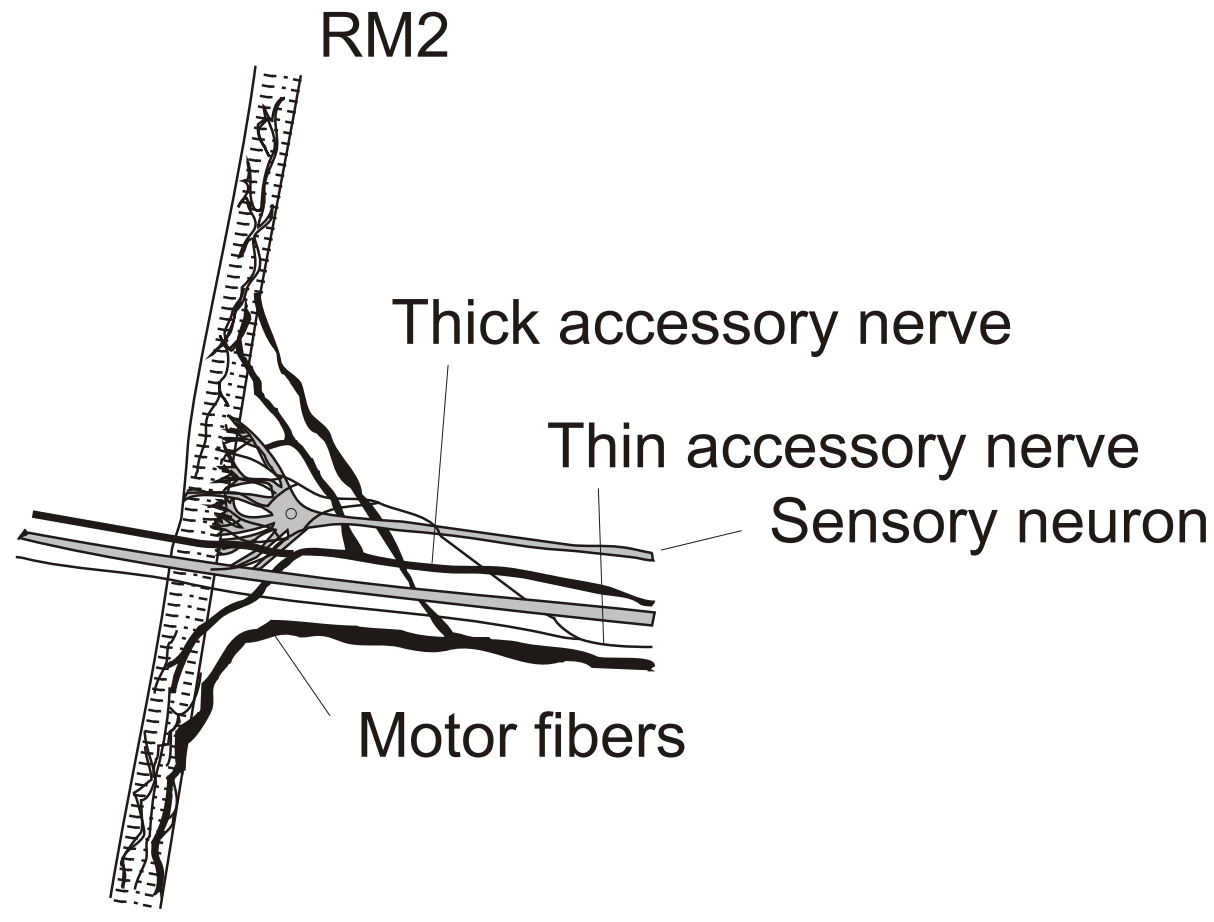

C fast adapting SR

(SR1)
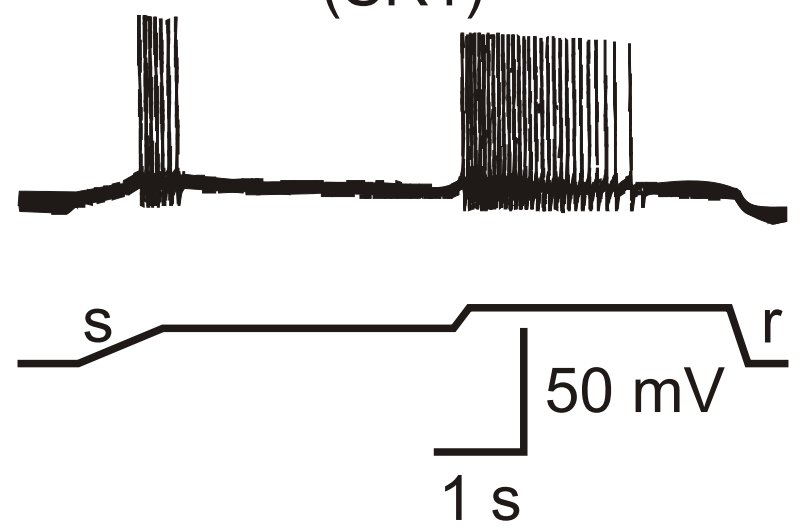

E

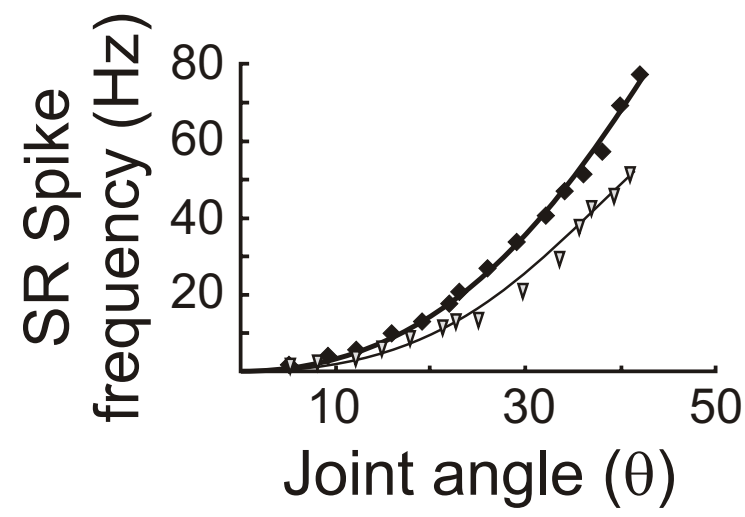

F slow adapting SR (SR2)
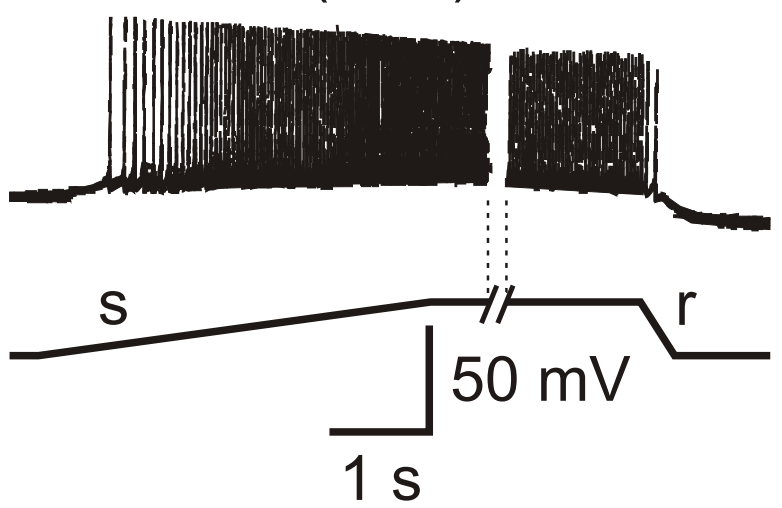

DN2

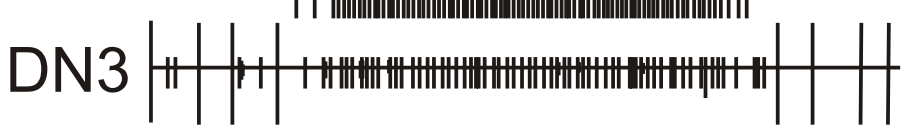

$1 \mathrm{~s}$ 
A

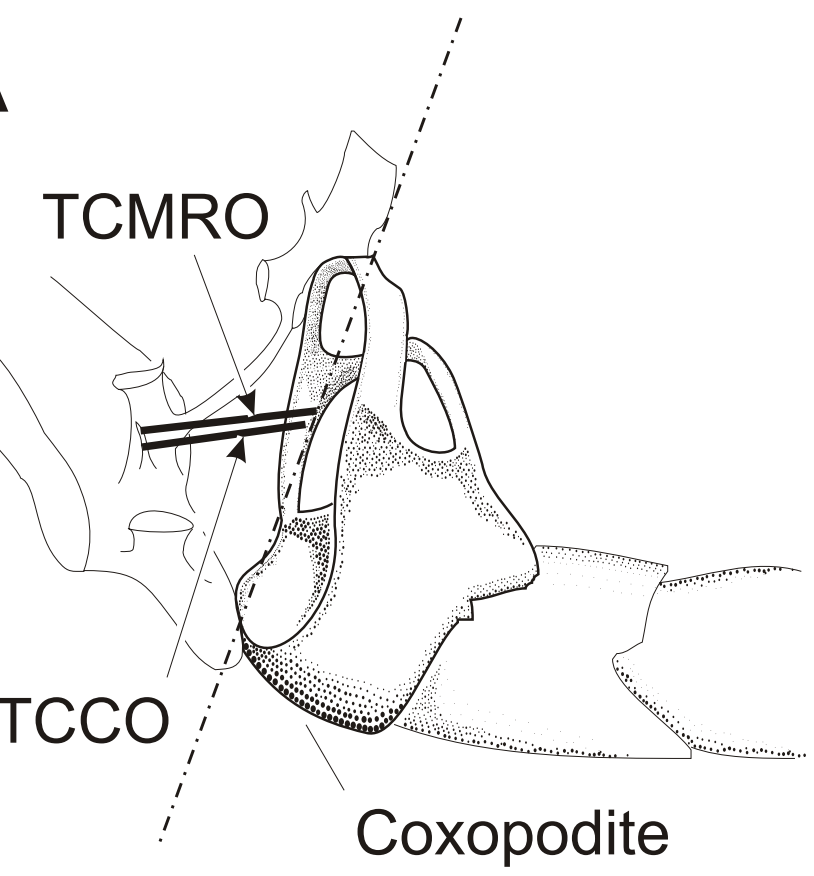

C

Promotor nerve
B

FIG 07

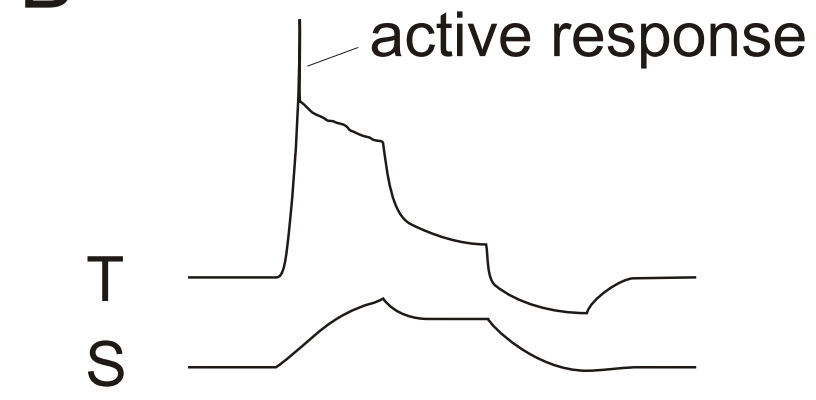

TCMRO

$\mathrm{mvt}$

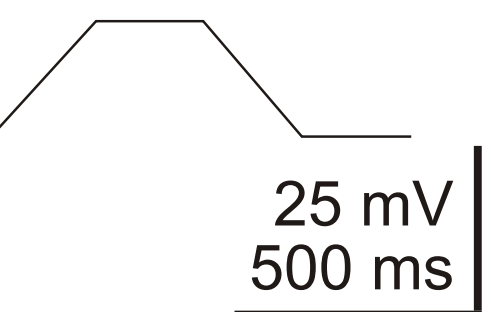

Receptor motor nerve

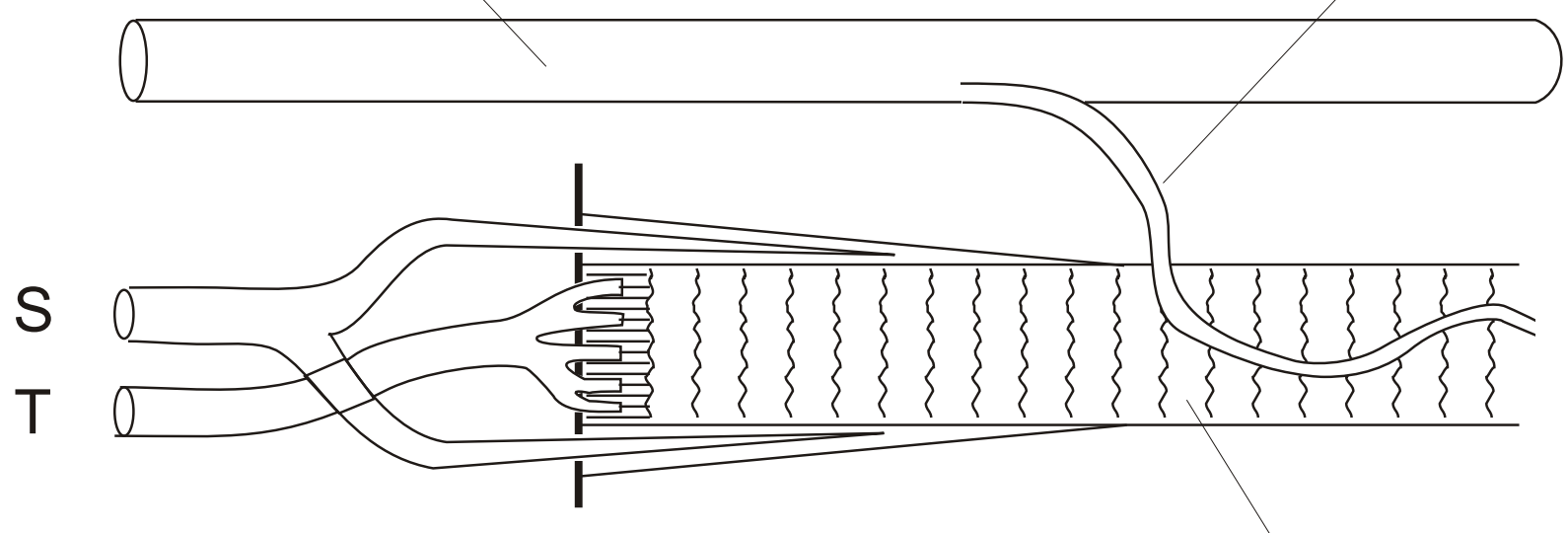

RM

D

E

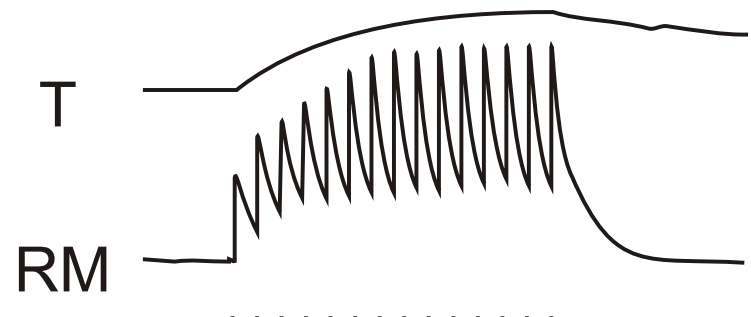

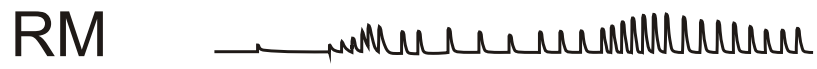

CBCO mvt

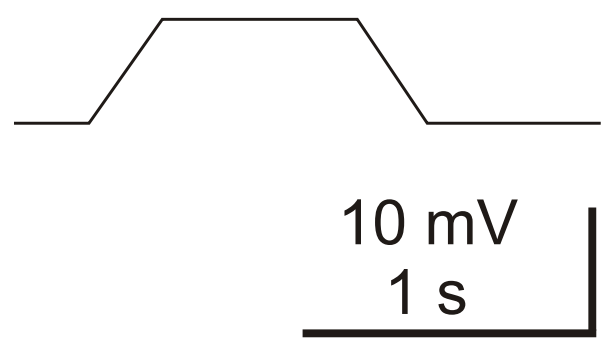

Receptor

motor nerve

stimulation 
A

FIG. 08

Coxopodite Ischiopodite

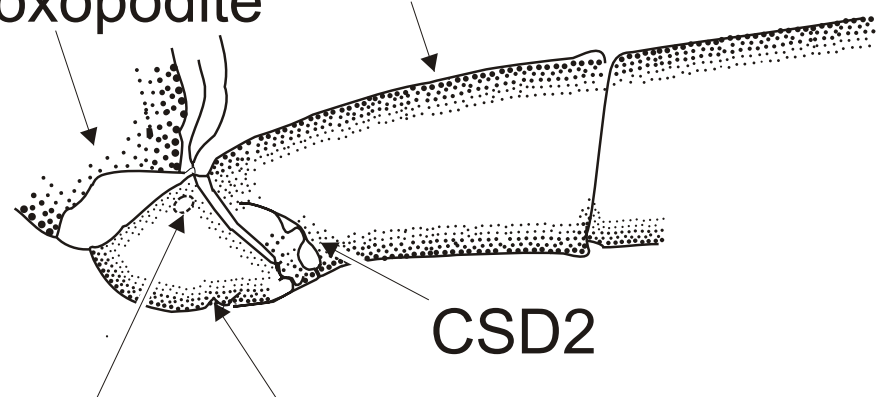

CSD1 Basipodite

C

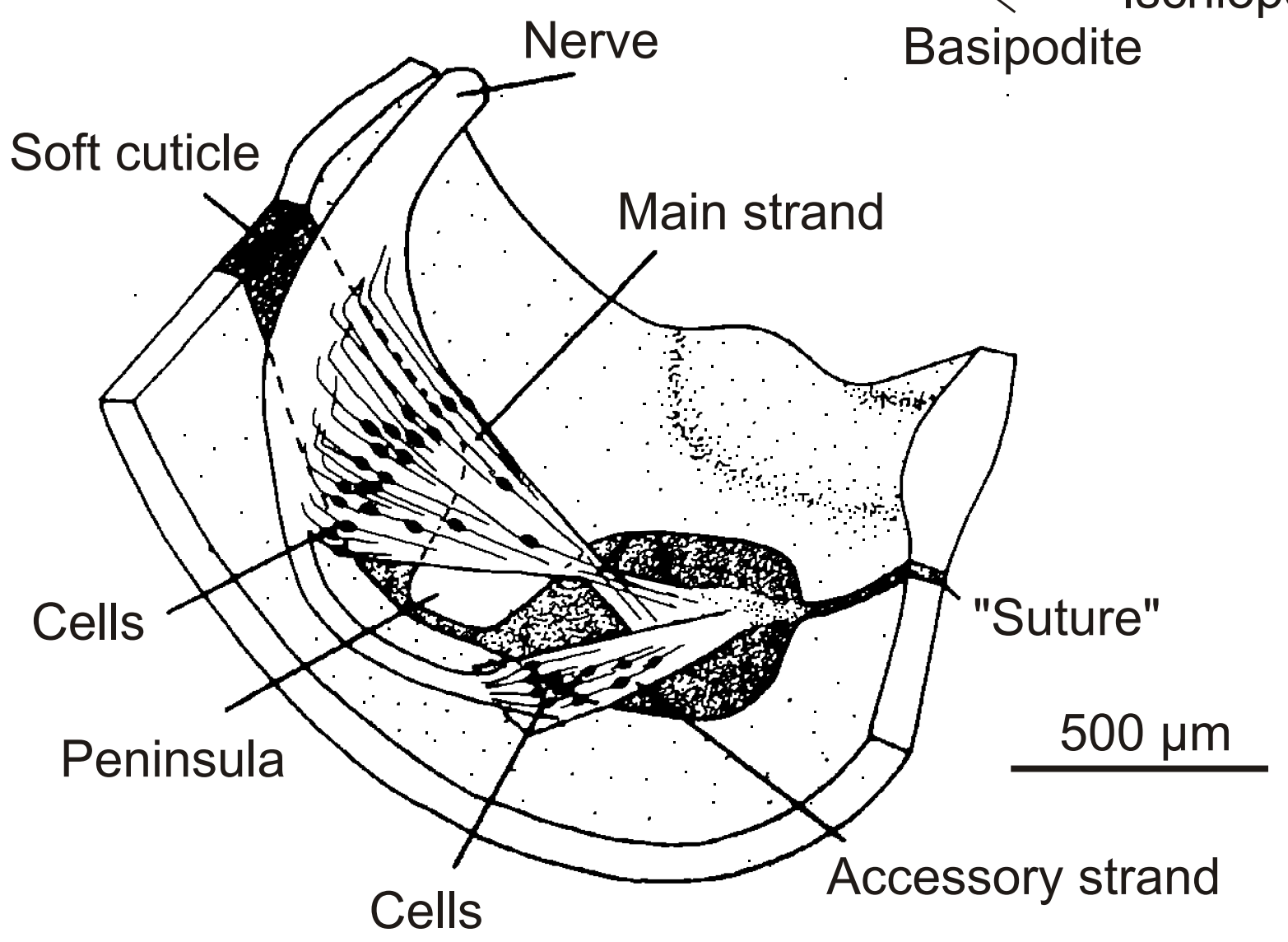

D

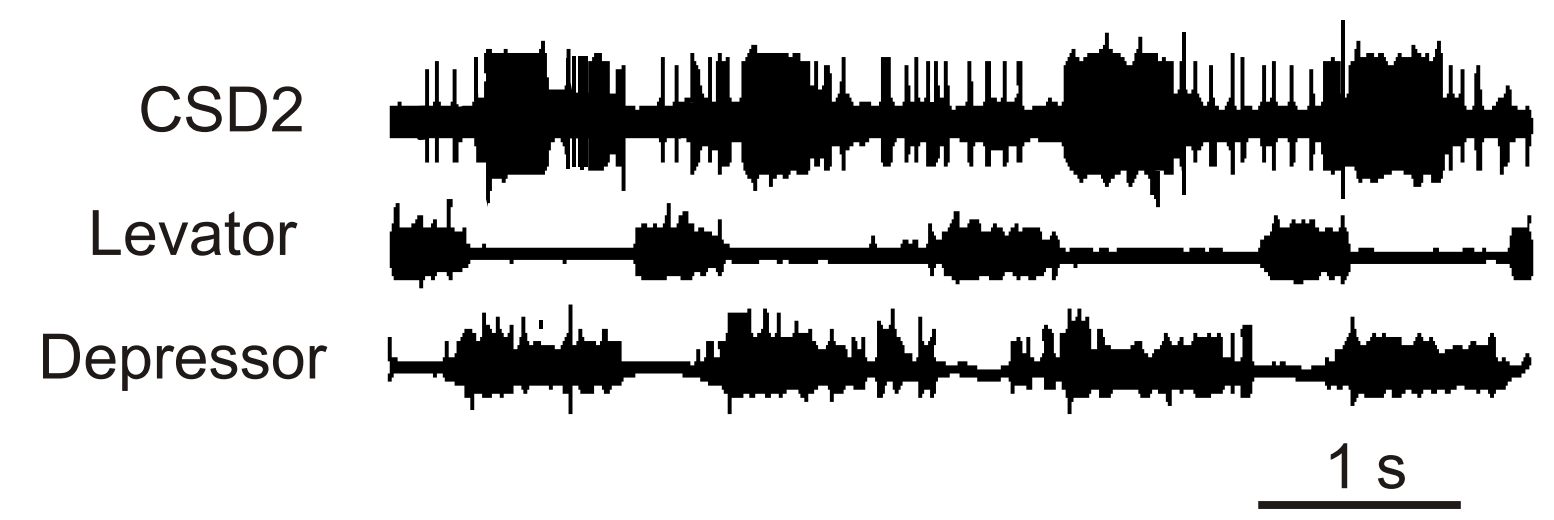


FIG. 09

A

Control

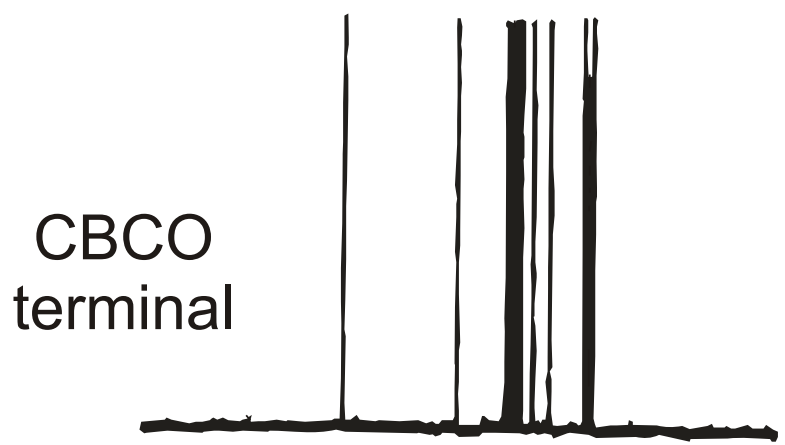

B Serotonin $10^{-6} \mathrm{M}$

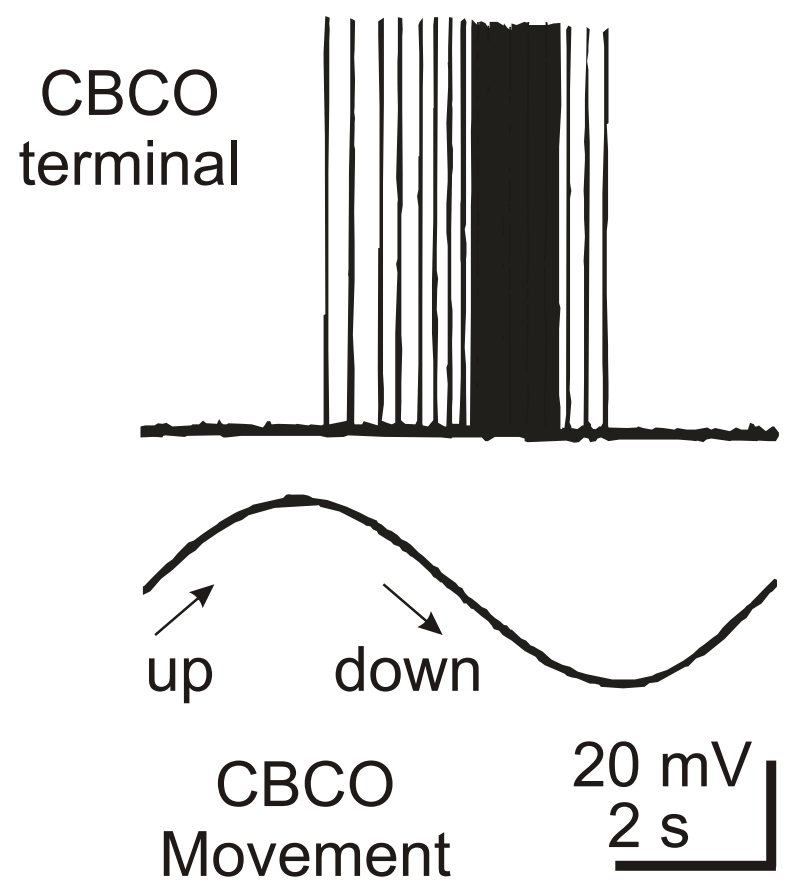


FIG 10

A

Slow Ext.

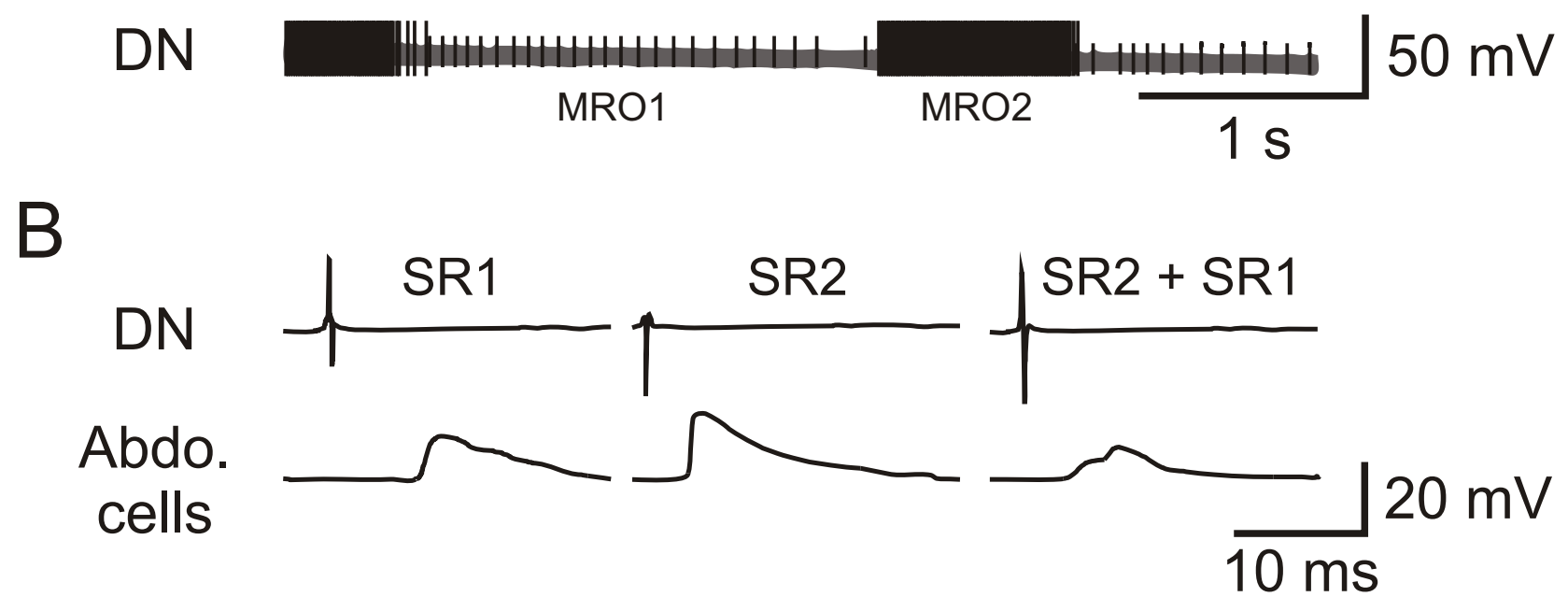


A

TCMRO

FIG 11

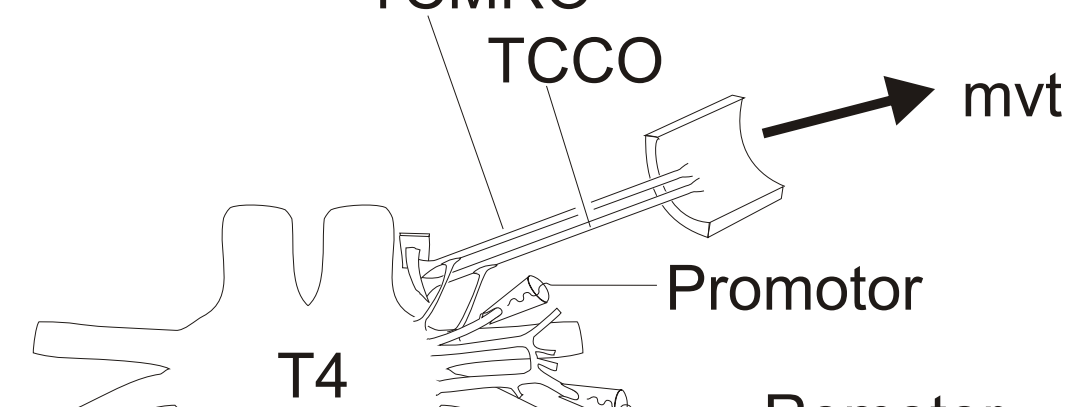

B

Résistance reflex

Remotor

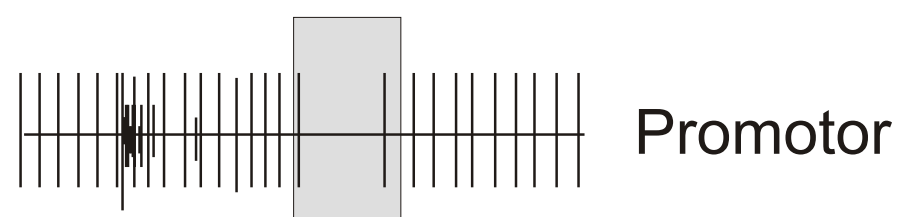

C

50

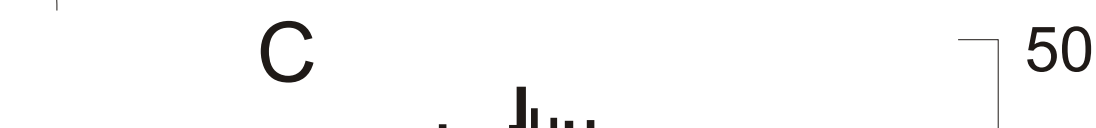

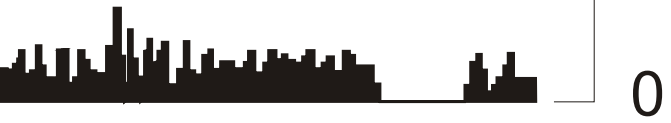

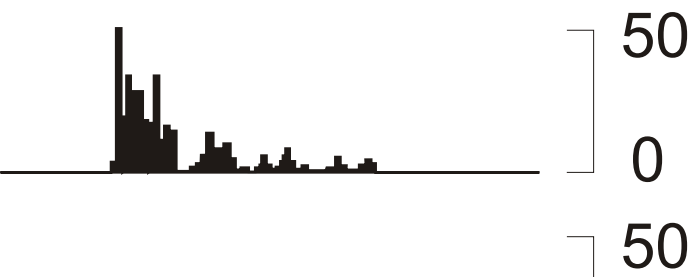

Remotor

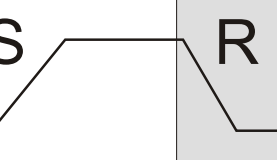

mvt

$\mathrm{R}<=>$ Leg Forward

D

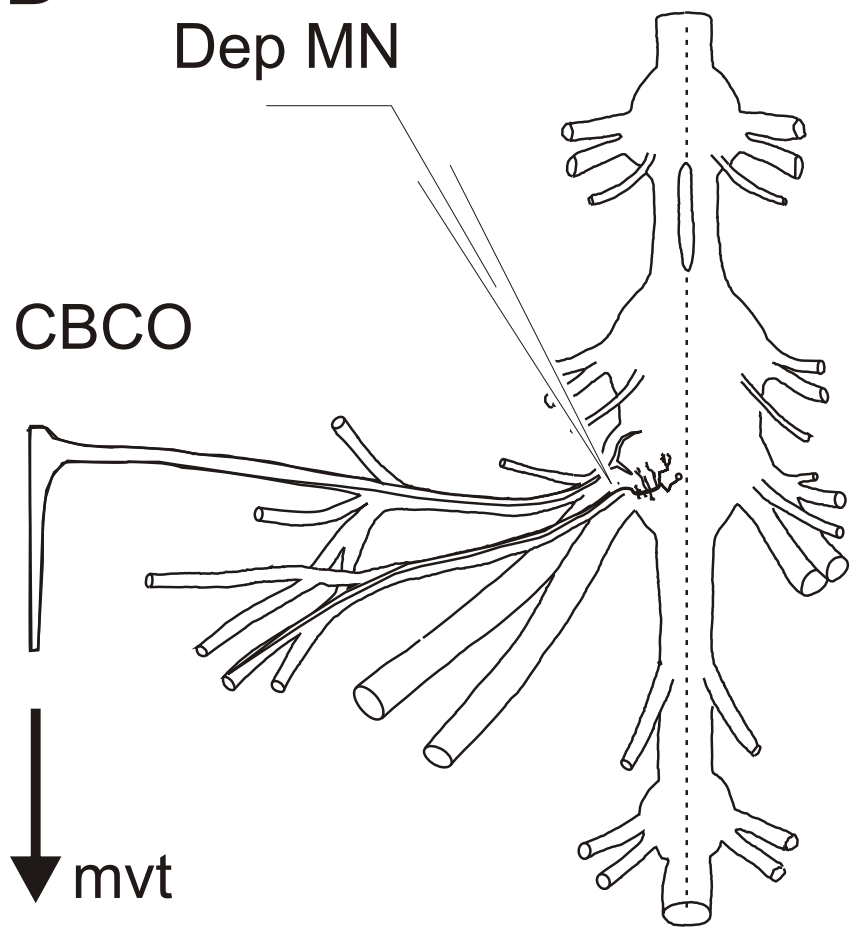

E

Résistance reflex
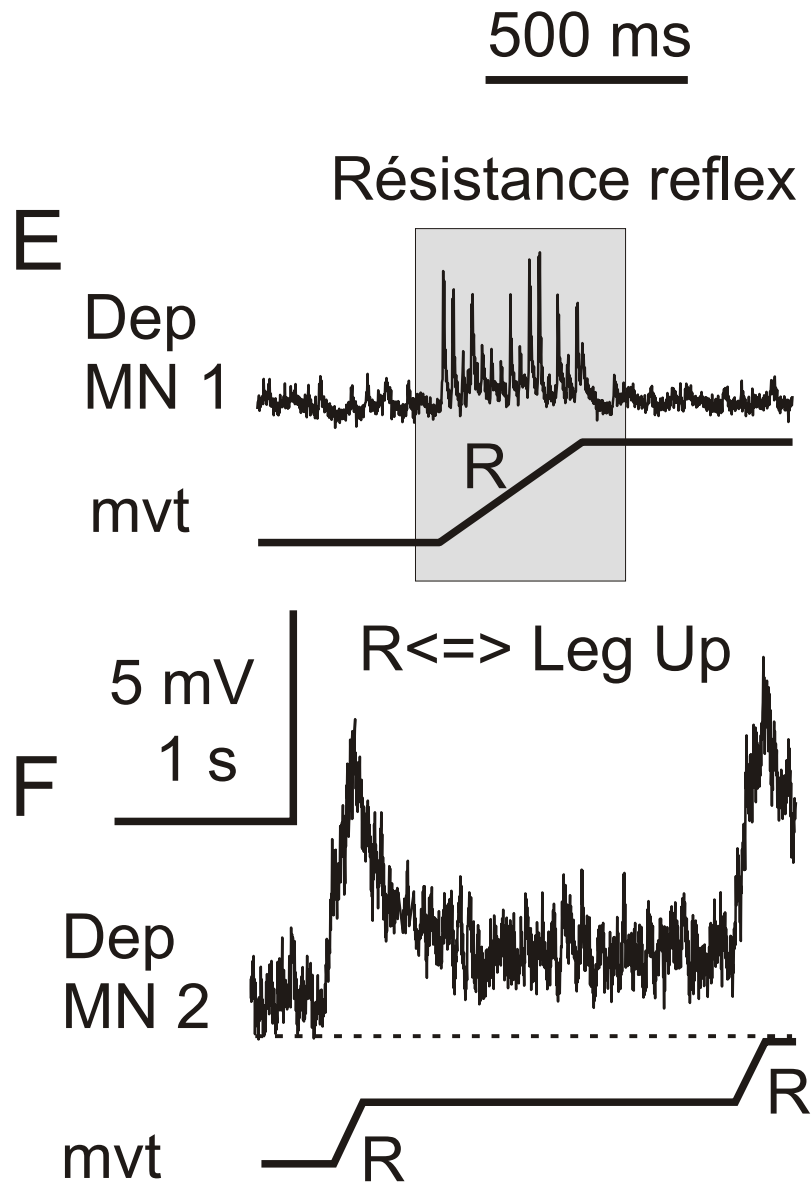
FIG 12

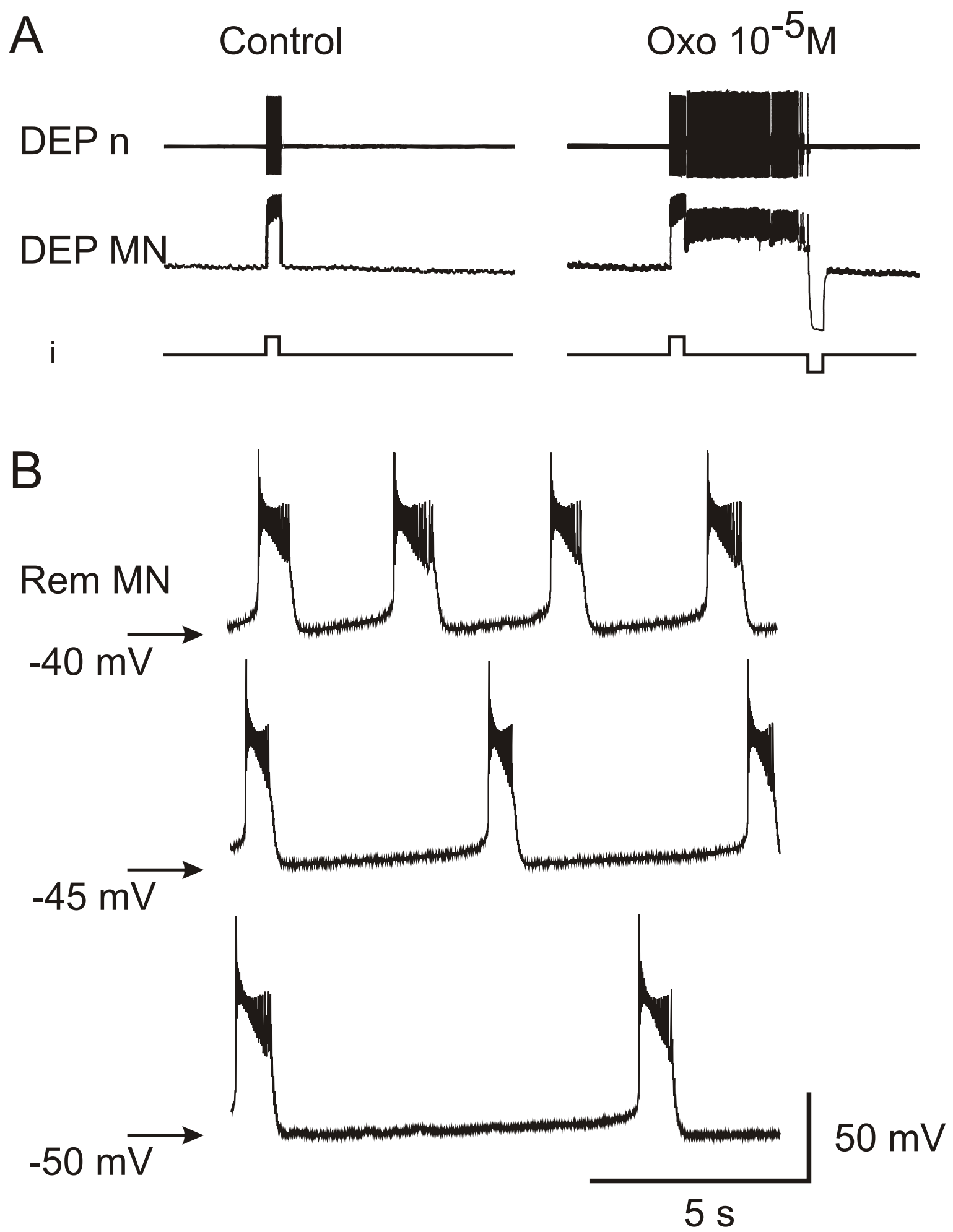




\section{A TCMRO}

Fictive locomotion

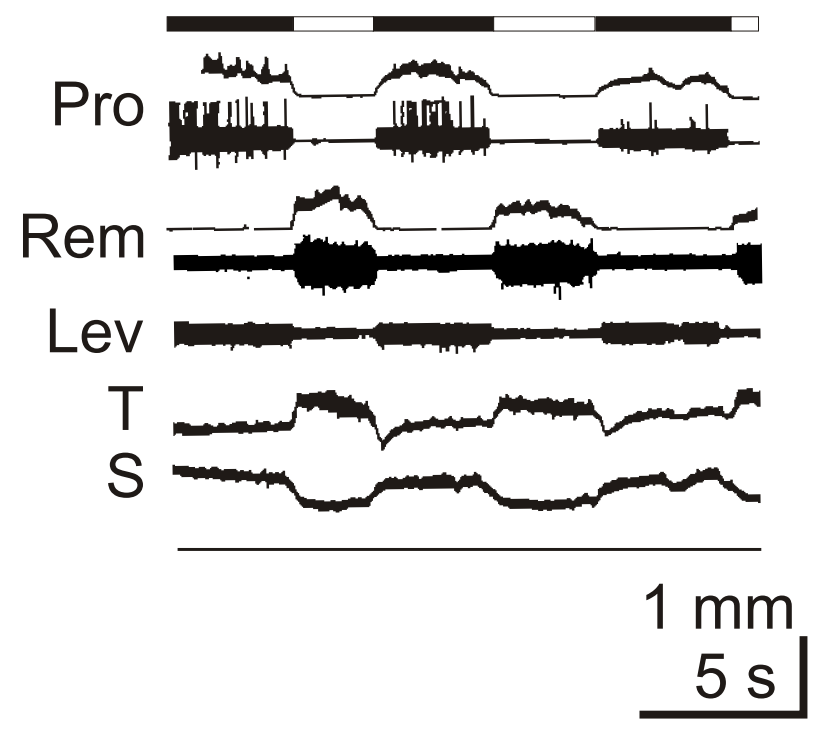

FIG 13

Assistance reflex

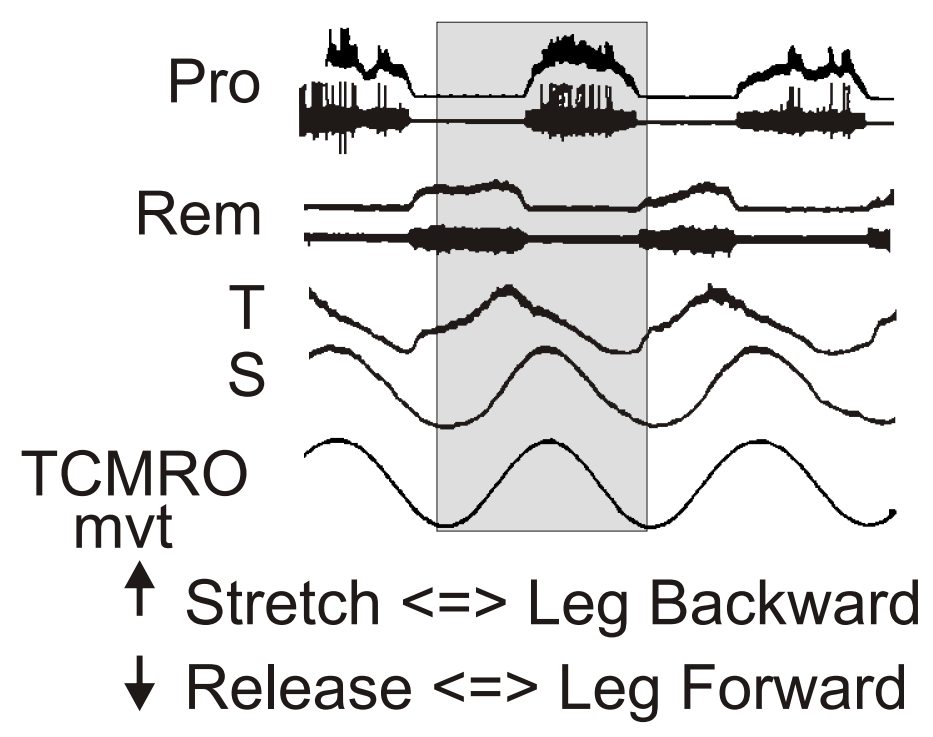

B

Pro MN $-65 \mathrm{mV}$
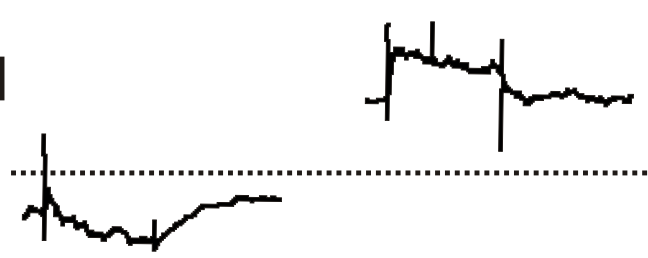
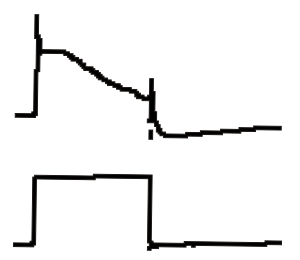

C CBCO

Fictive locomotion

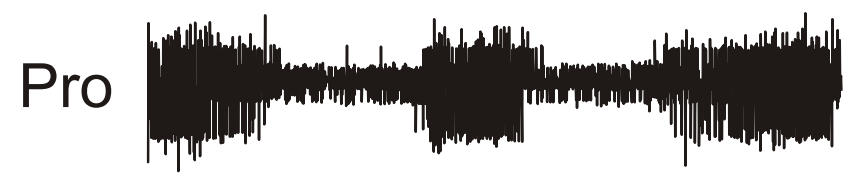

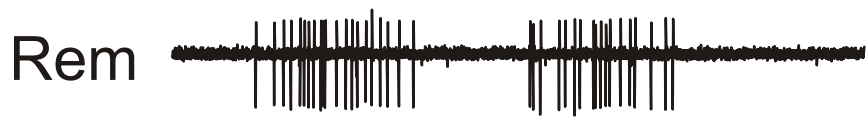

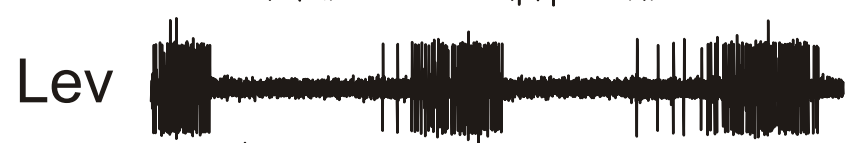

Dep - ل-

$1 \mathrm{~mm}$

$5 \mathrm{~s}$
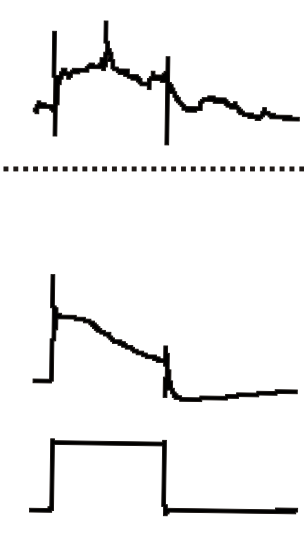

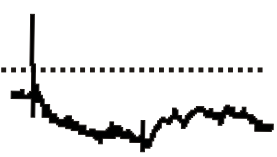

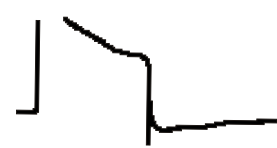

$25 \mathrm{mV}$

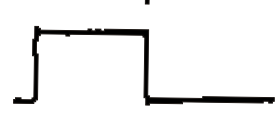

$20 \mathrm{nA}$

Assistance reflex

CBCO mvt

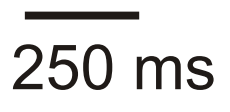

$\uparrow$ Release <=> Leg Up

$\downarrow$ Stretch <=> Leg Down 
A
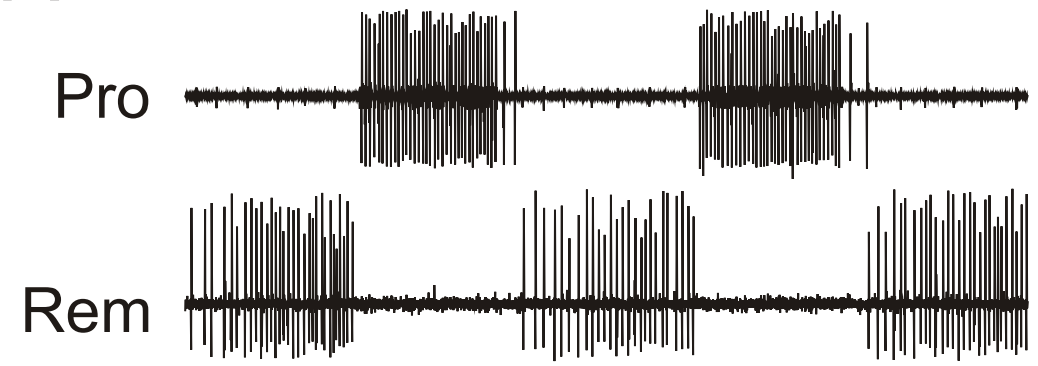

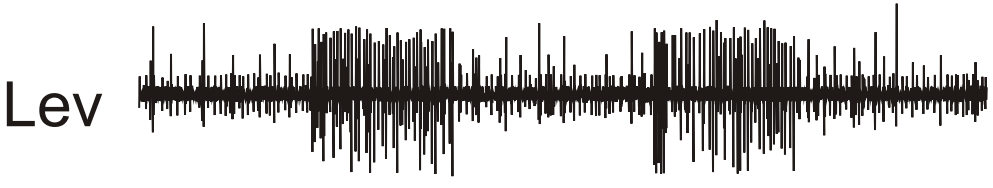
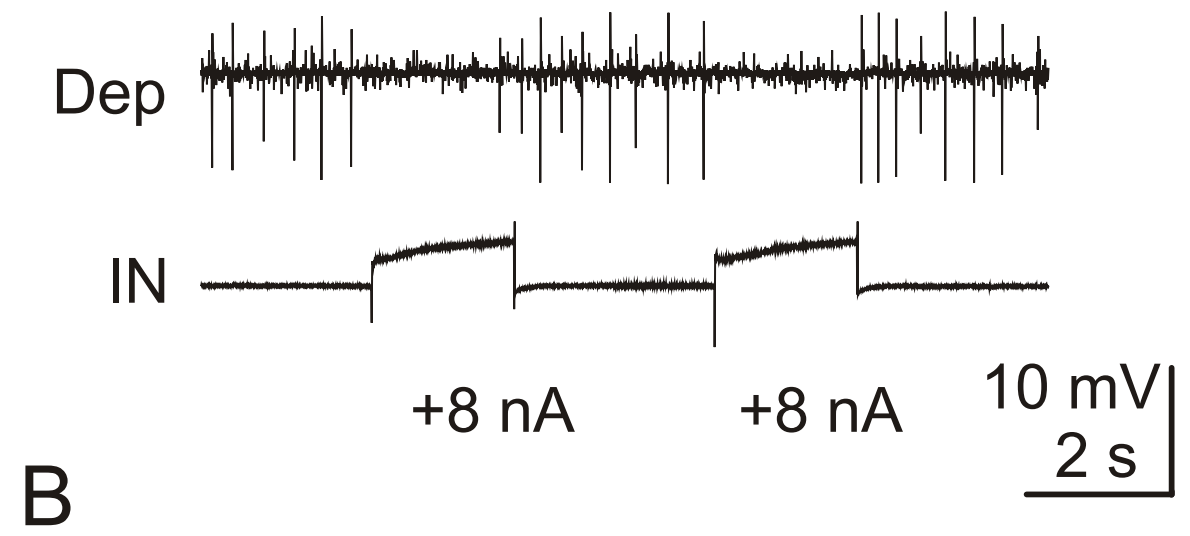

SWING

STANCE

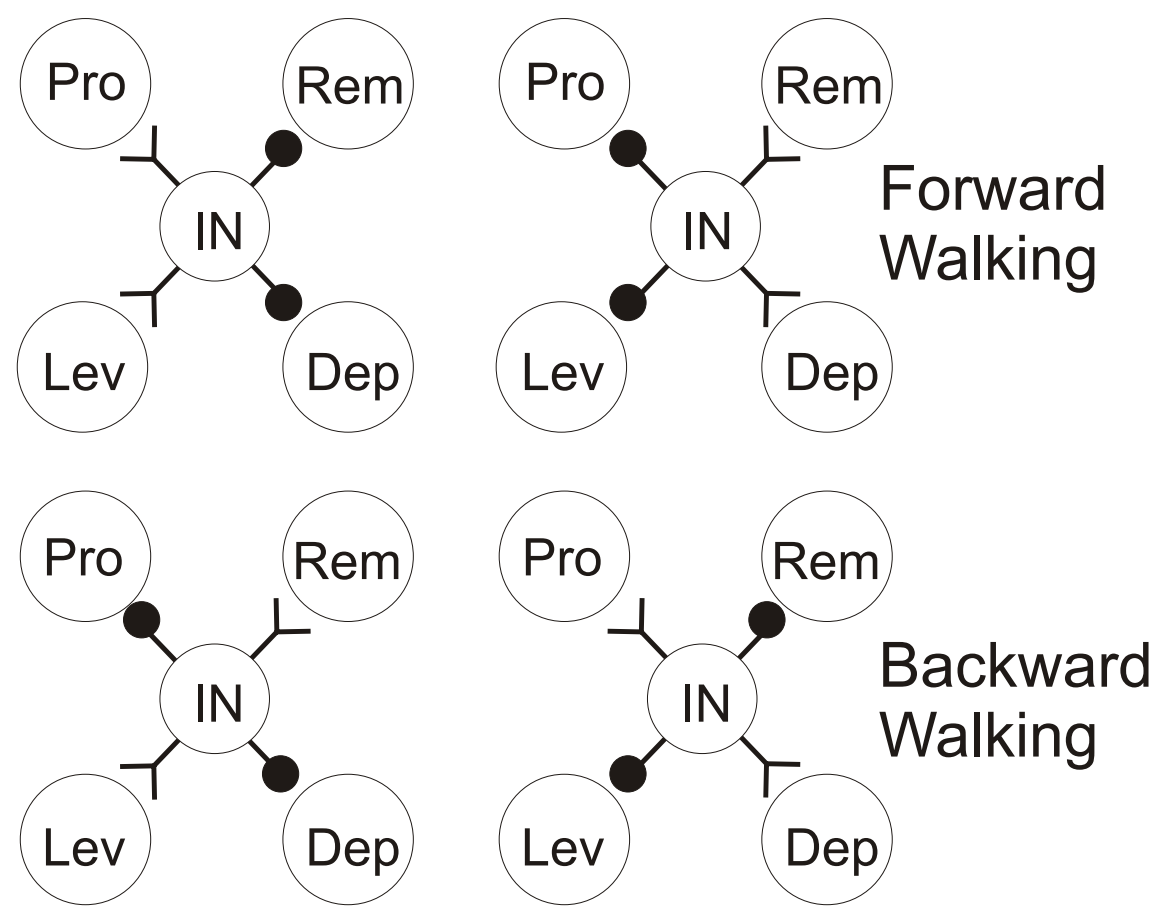


FIG 15

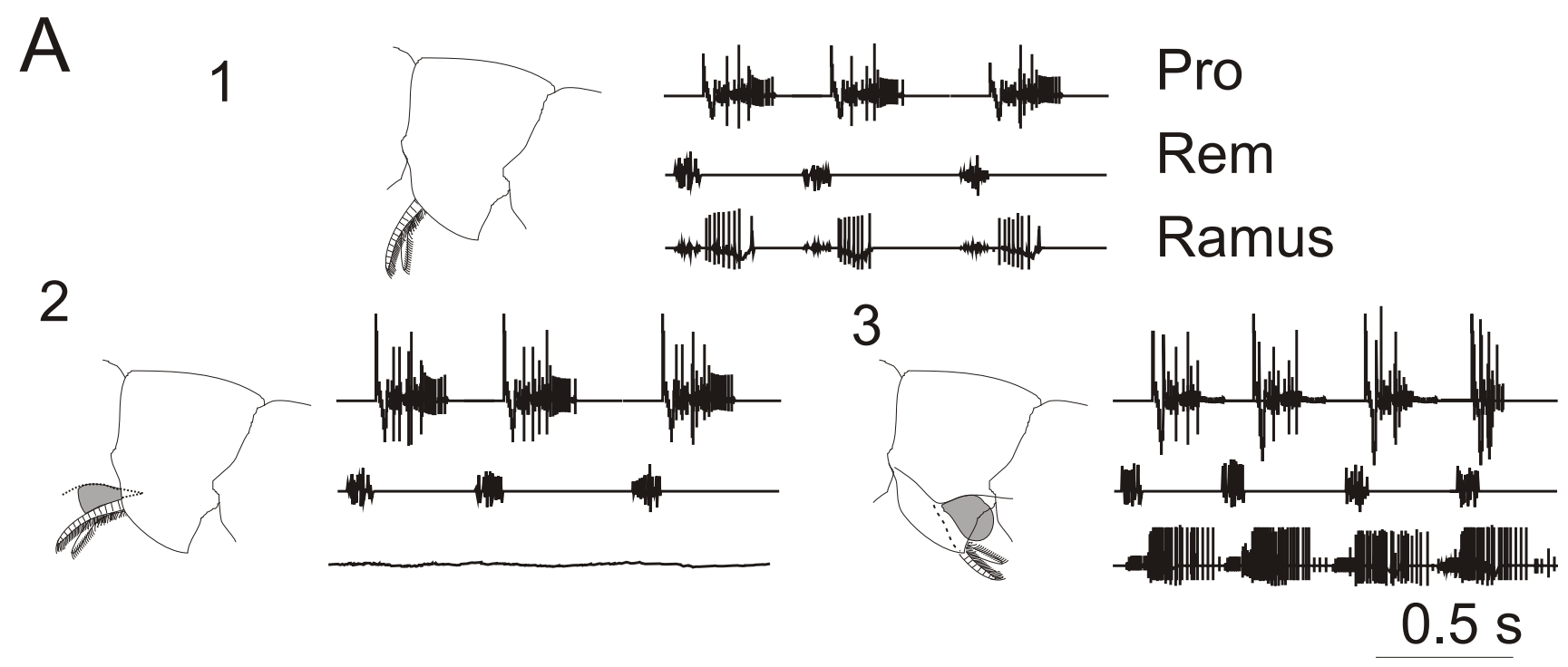

B Ramus
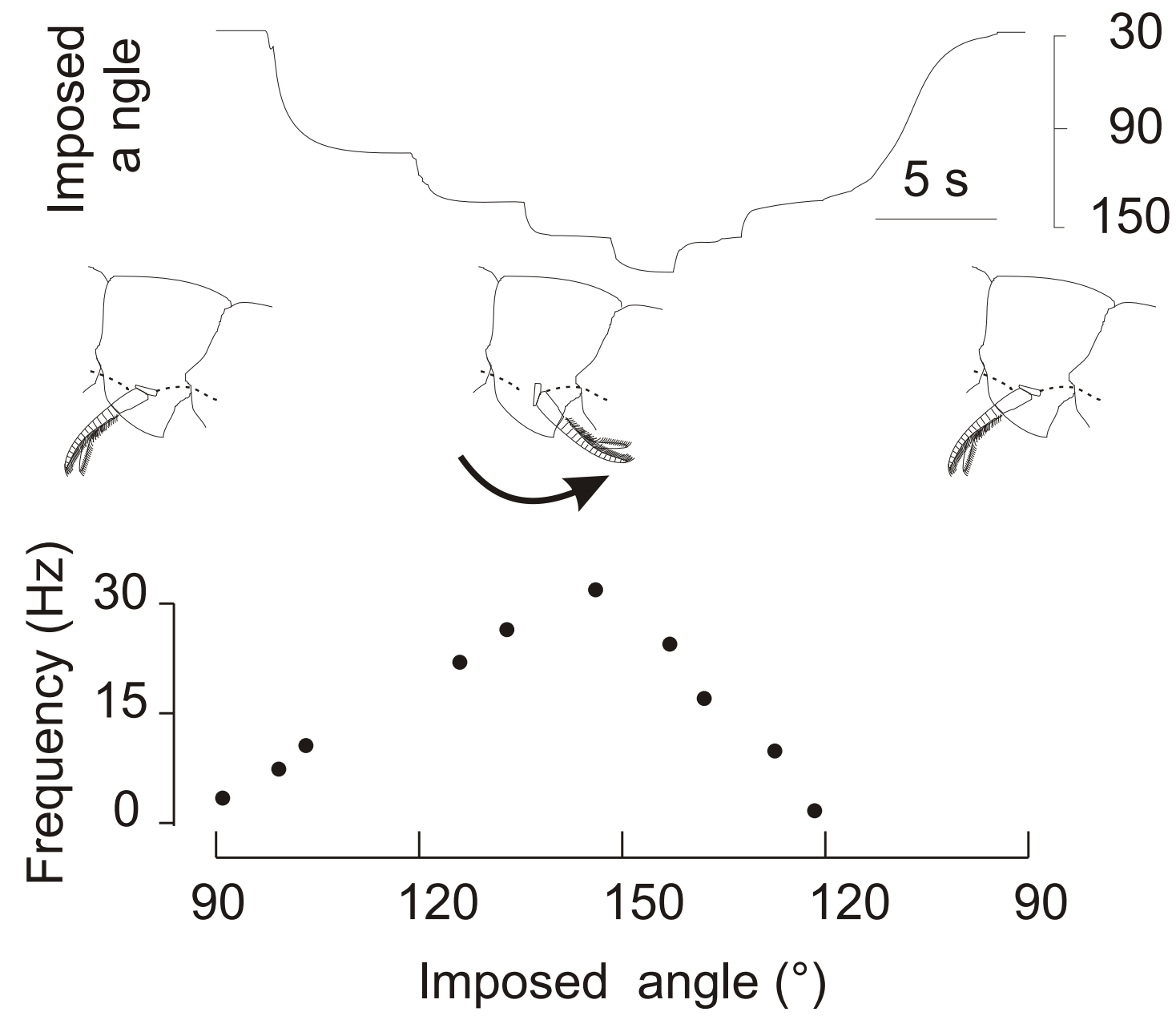
A

1

Promotor

MN

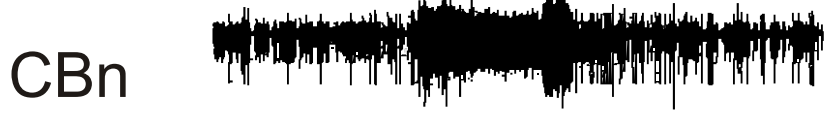
CBCO mvt down

2

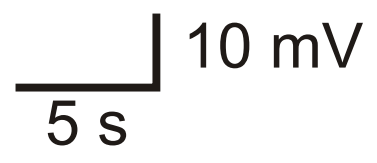

Remotor

MN

$\mathrm{CBn}$

$\mathrm{CBCO}$ mvt downt
B

FIG. 16
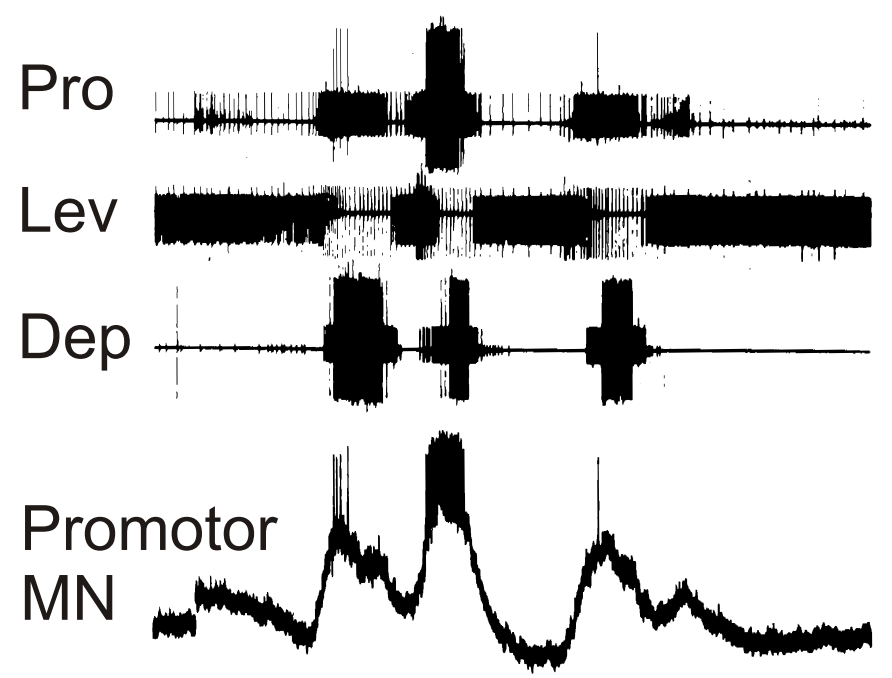

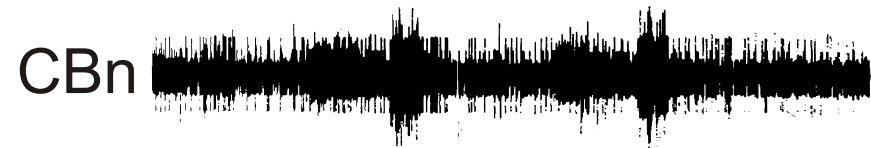
CBCO $\mathrm{mvt}$

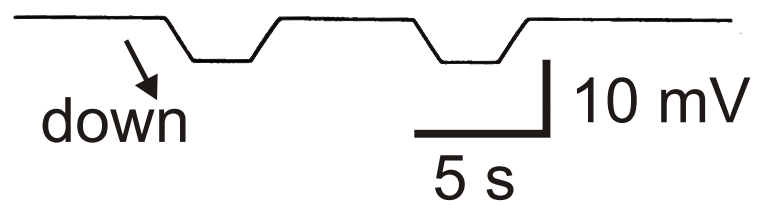


FIG. 17

A Proctolin

PS MN Right

PS MN

Left

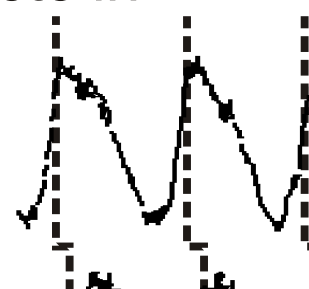<smiles>[AlH2]</smiles><smiles>[AlH2]</smiles>

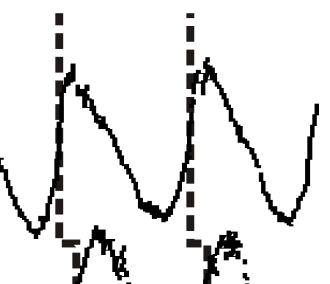

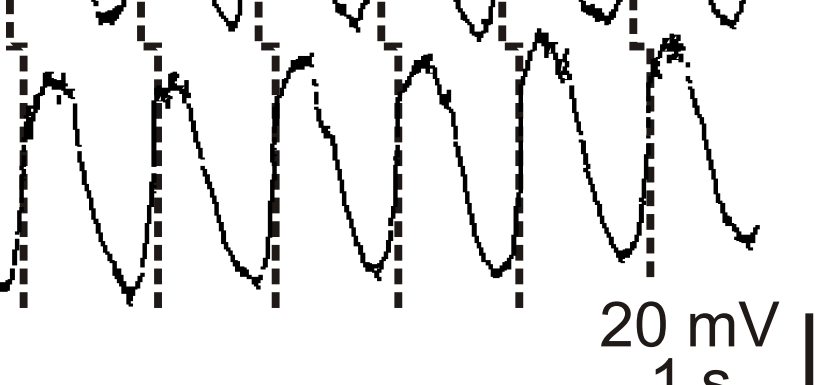

B Proctolin + TTX

PS MN

Right

PS MN

Left

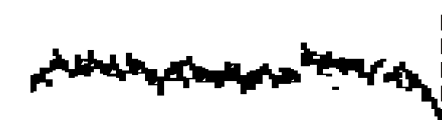


FIG. 18

A

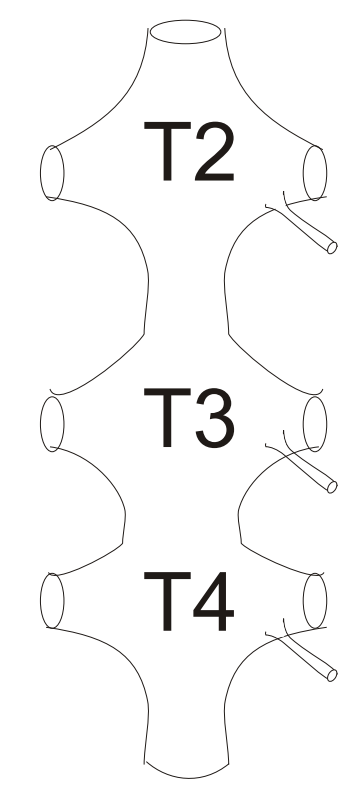

Rem 2

Rem 3

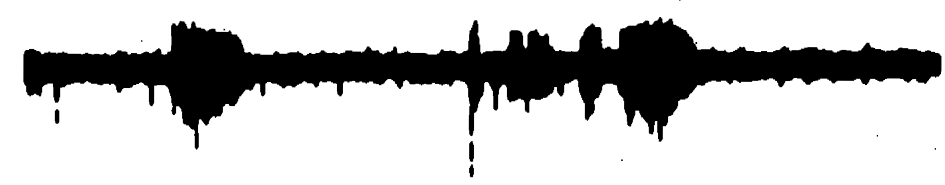
Rem 3 Rem 4 S

B

Rem 4 Rem 3

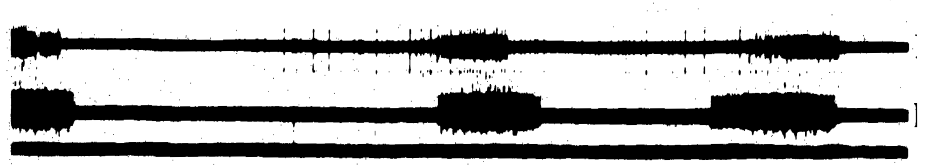

T2

Rem 4
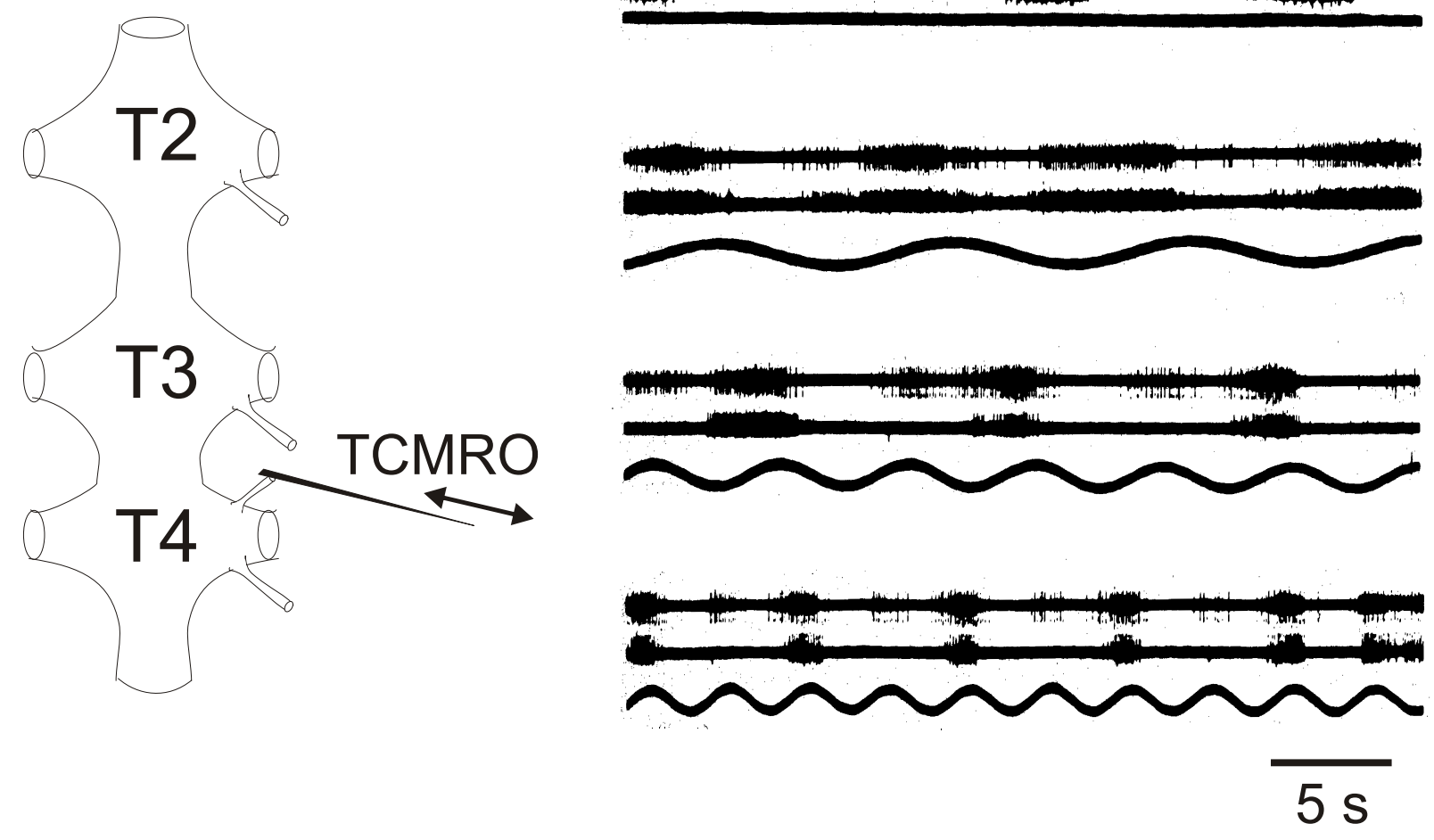
FIG. 19

A

Lev 4
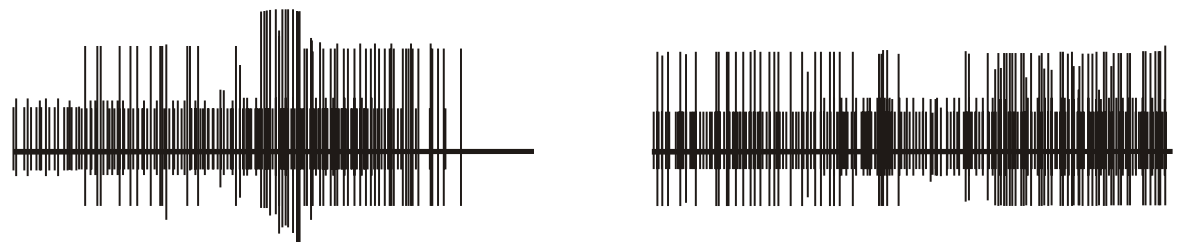

Dep 4
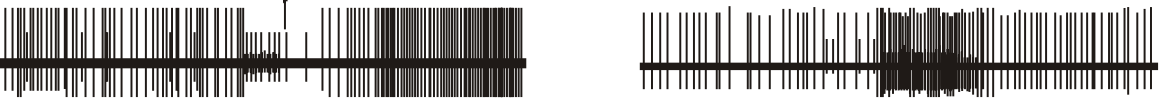

DSA4 stim

DSA5 stim

B

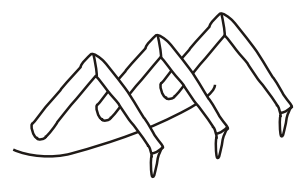

P3 Free

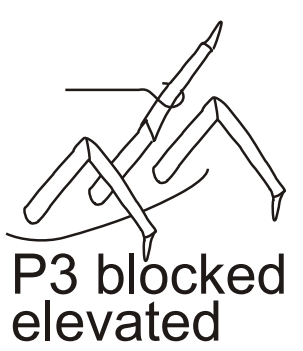

elevated

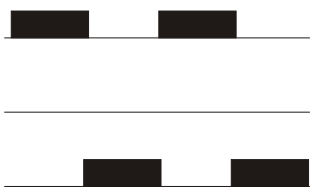

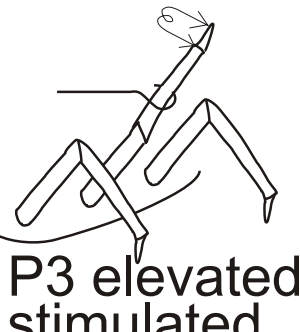

Dep 2

Dep 3

Dep 4

DSA3 stim

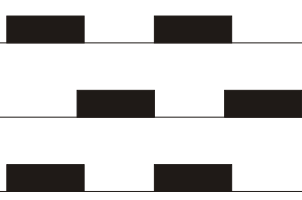


A

FIG. 20

1 Relative coordination

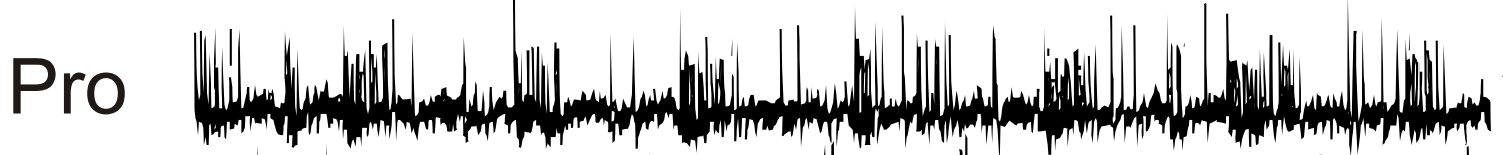

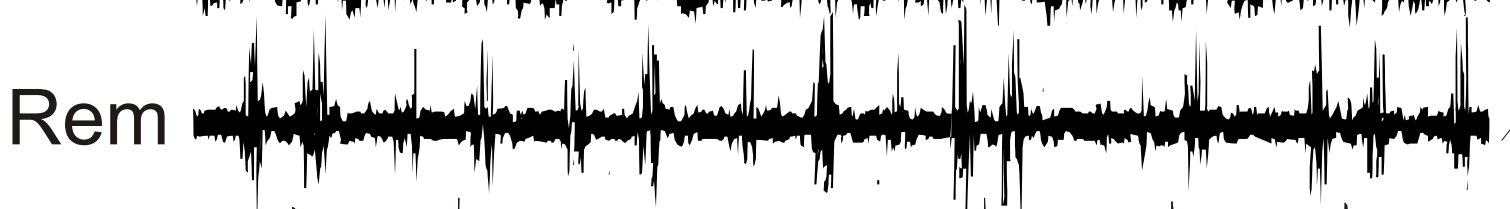

SW5

Dep - leg 5

2 Absolute coordination

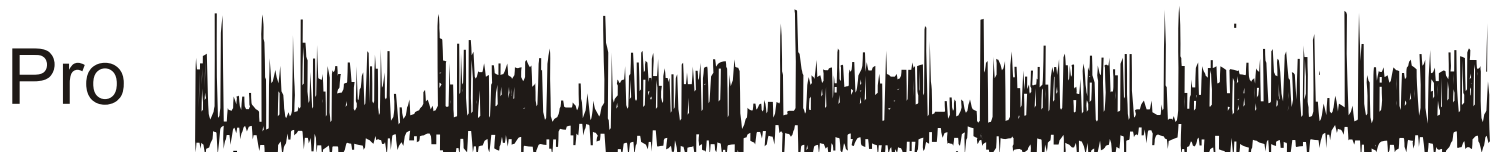

Dep Leg 5

B

Rem - NW

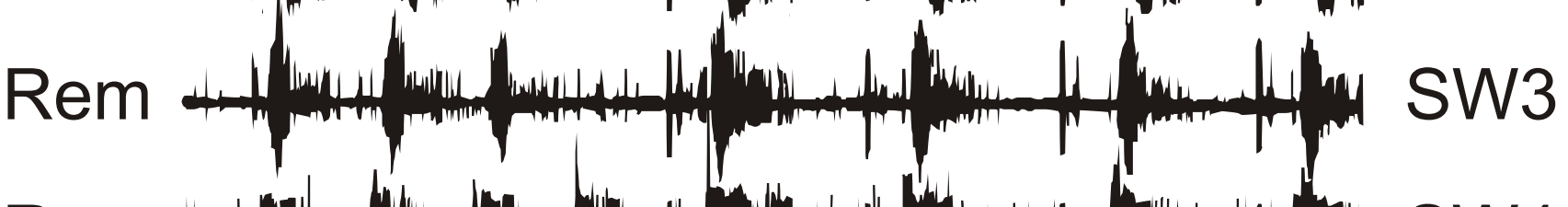
Rem $H$

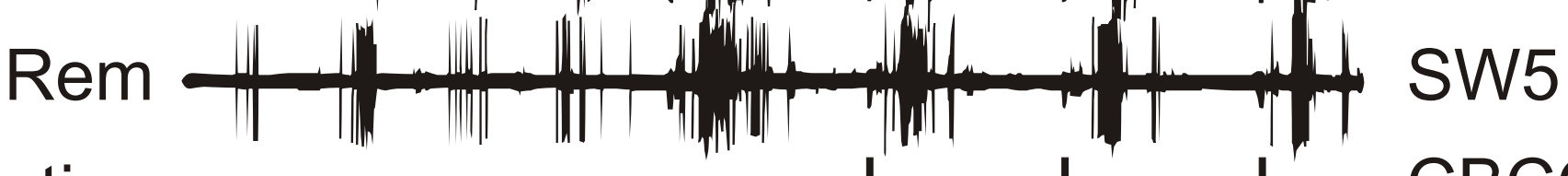
stim

CBCO 

FIG. 21

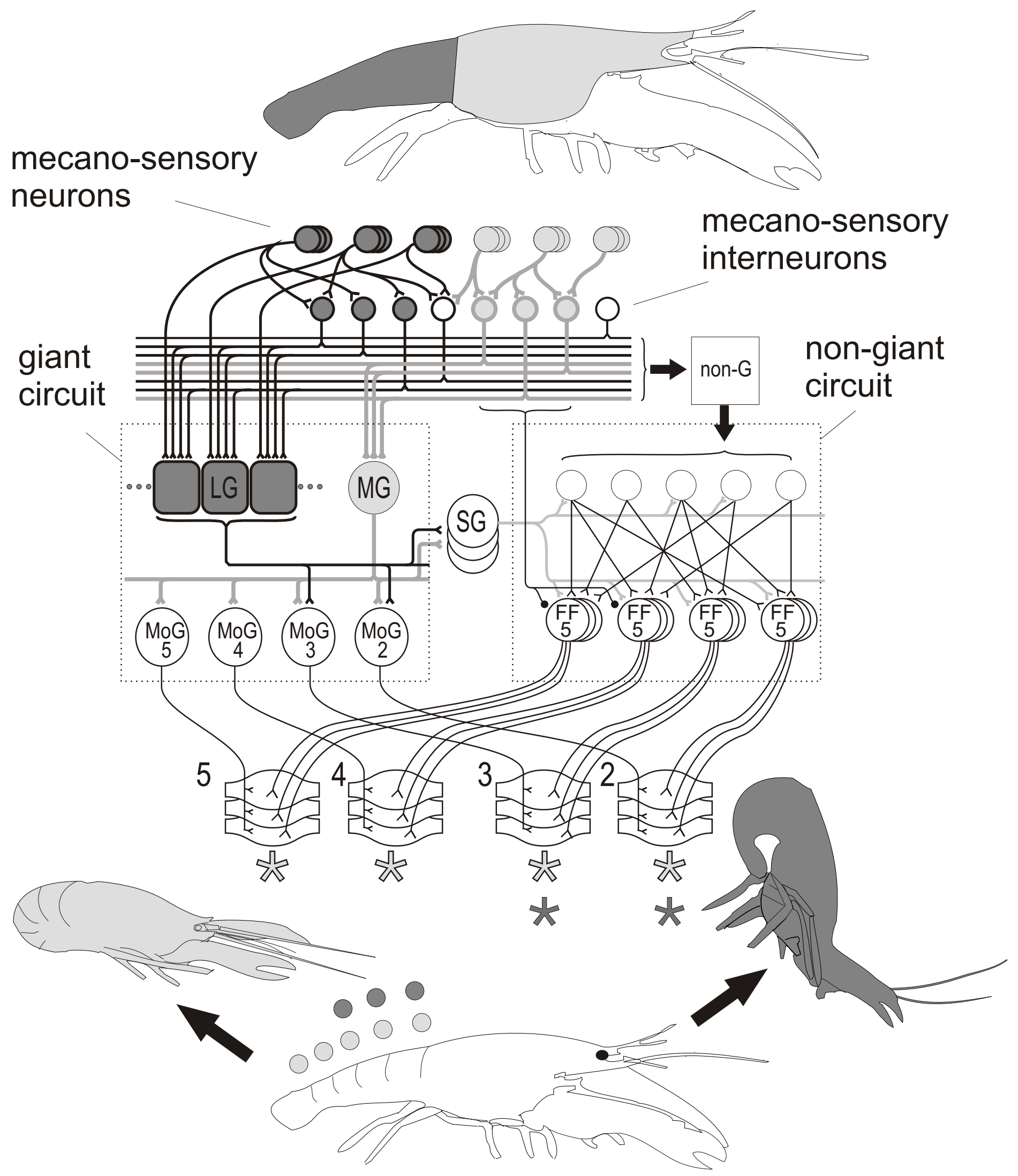

DH Edwards, WJ Heitler and FB Krasne (1999) TINS 22 (4) 133-161 (Fig. 1) 
FIG. 22

A

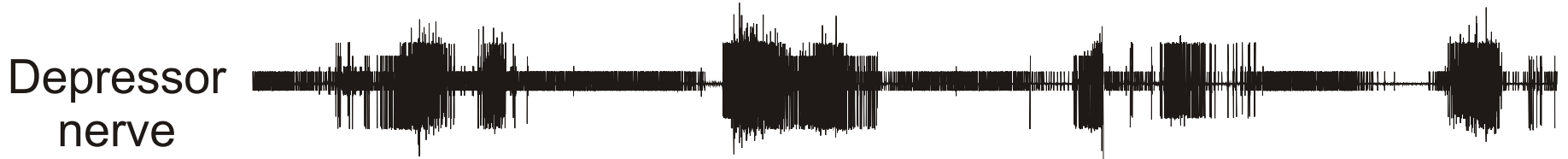

CBCO

terminal

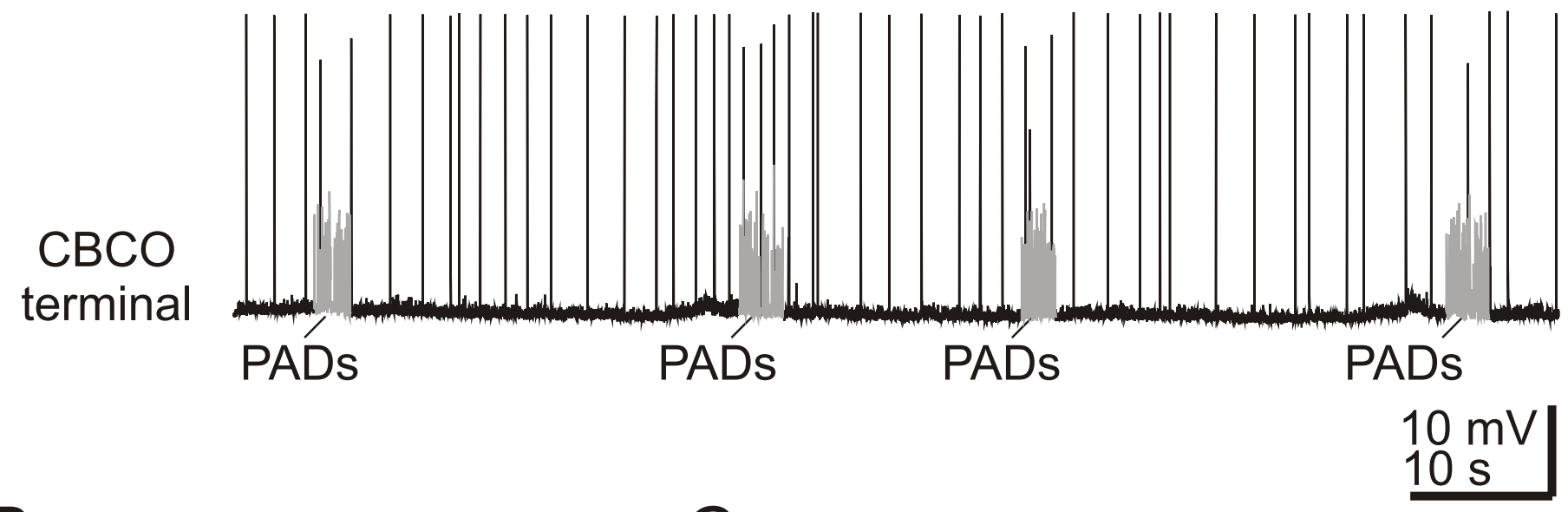

B

CBCO terminal

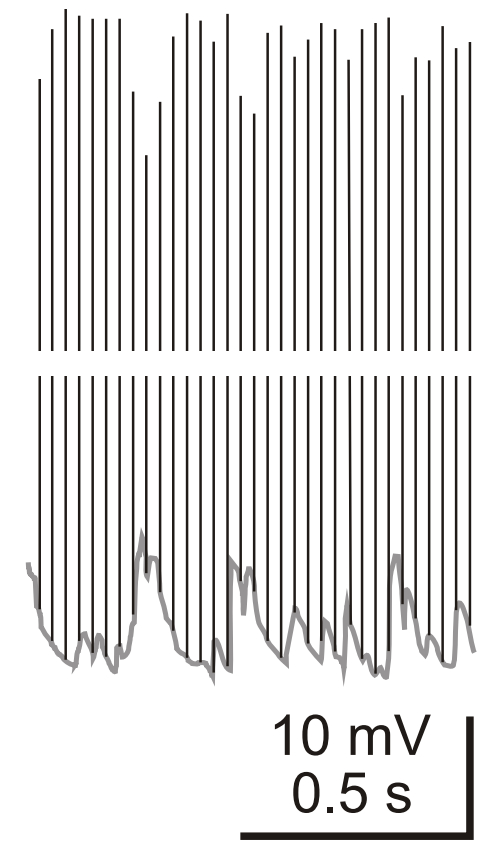

C

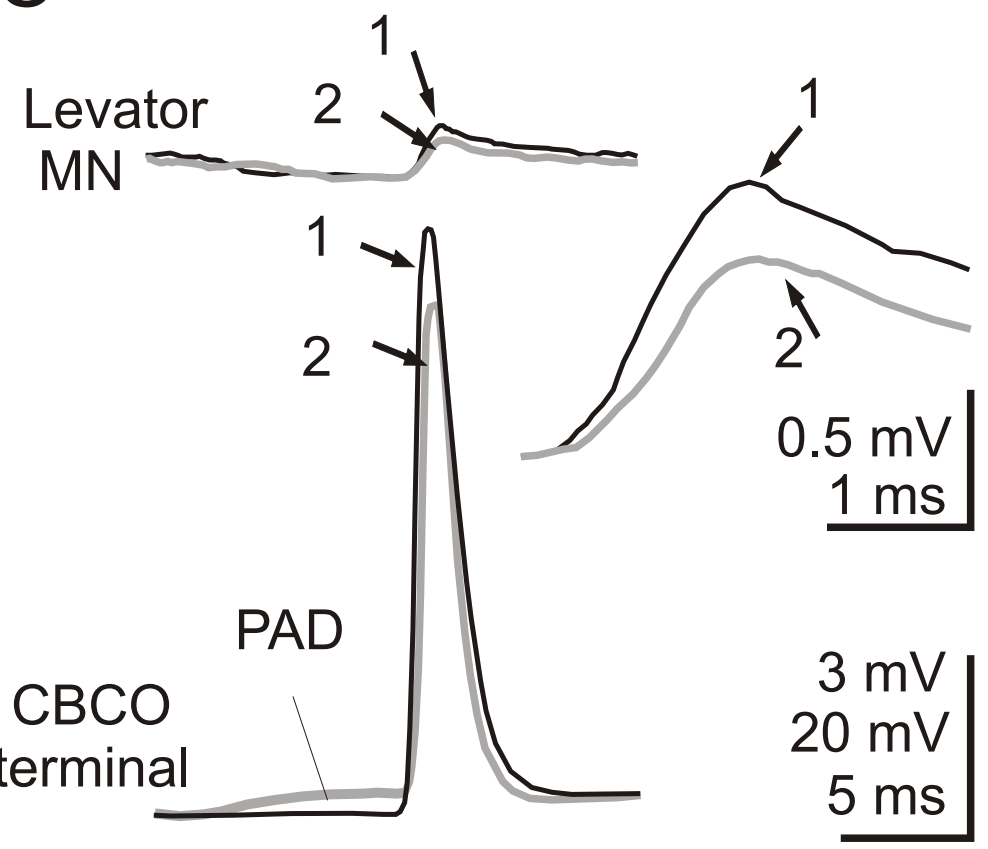

D

CBCO terminal

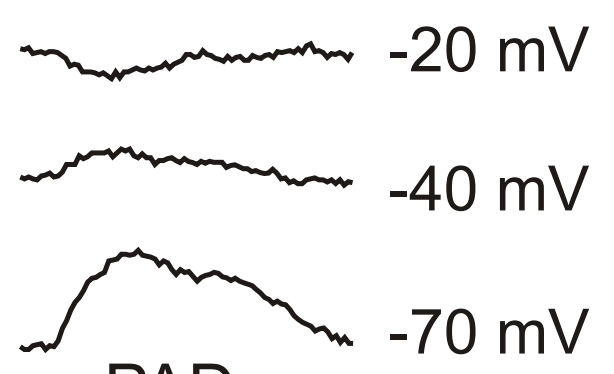

PAD

$5 \mathrm{mV}$

$10 \mathrm{~ms}$ 
A

B

FIG. 23

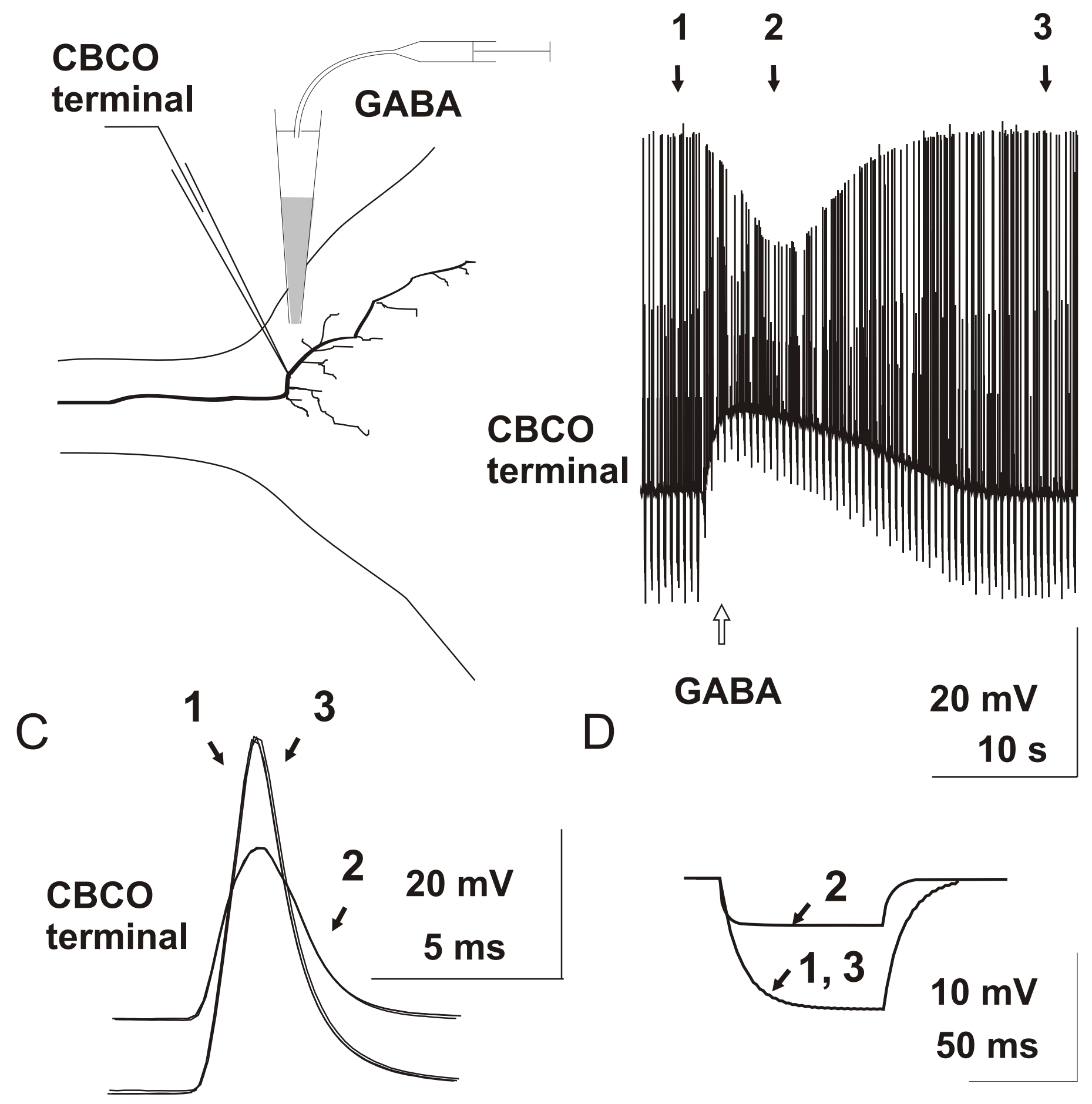


A

FIG. 24

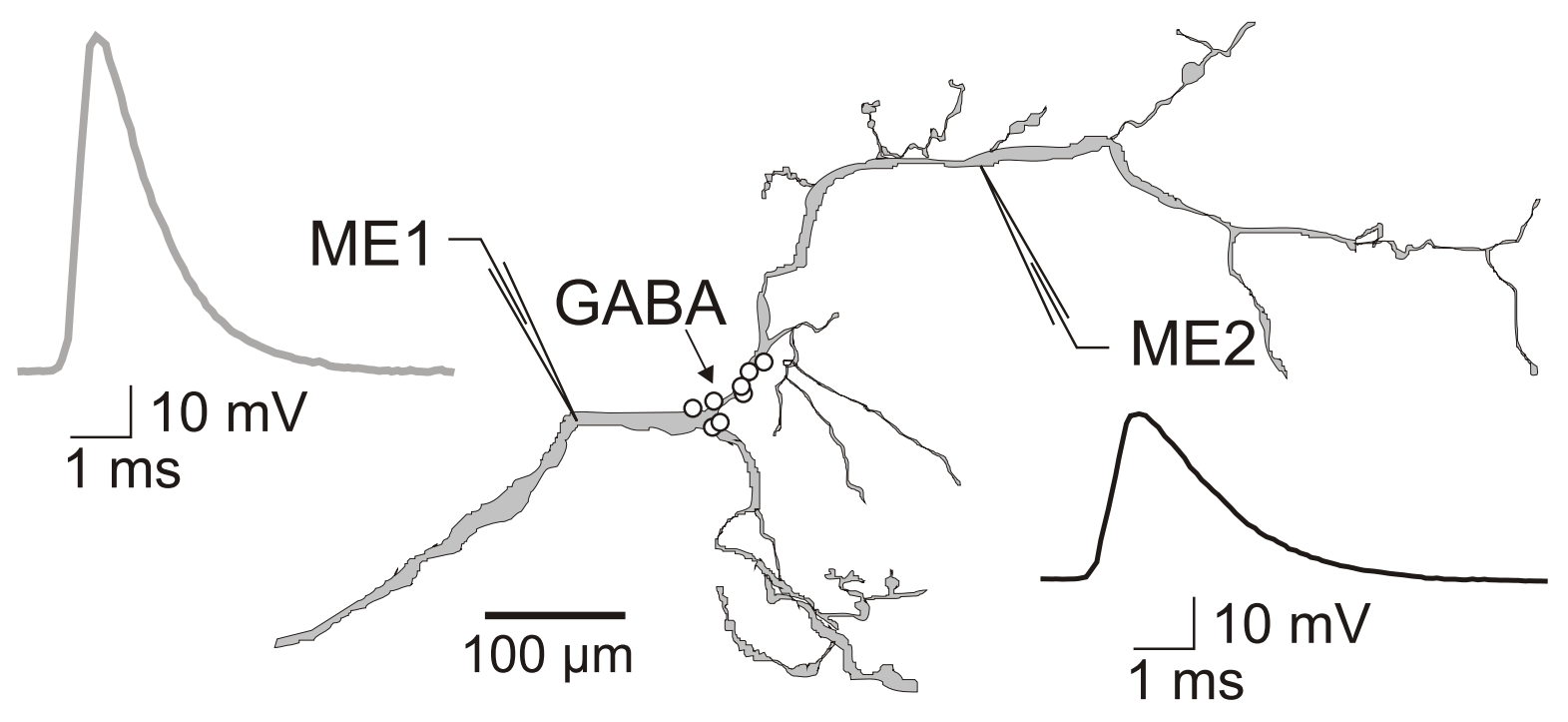

B

C

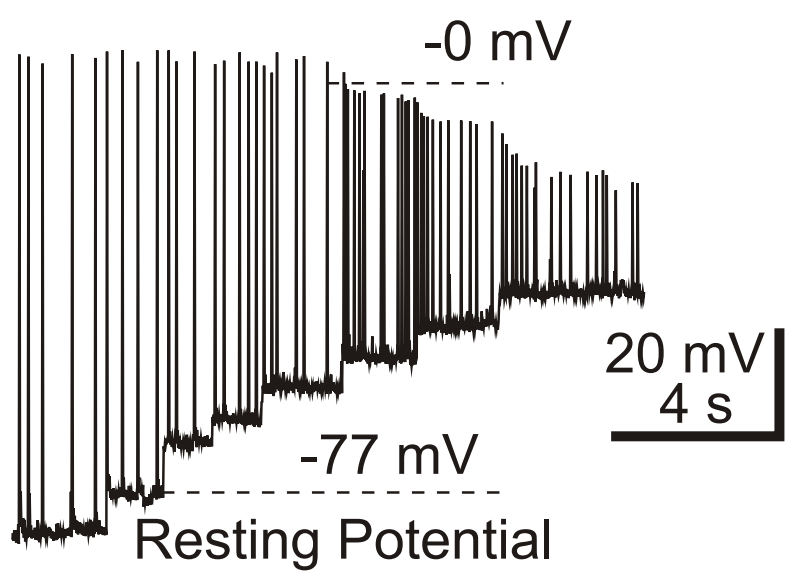

D

o. Current injection

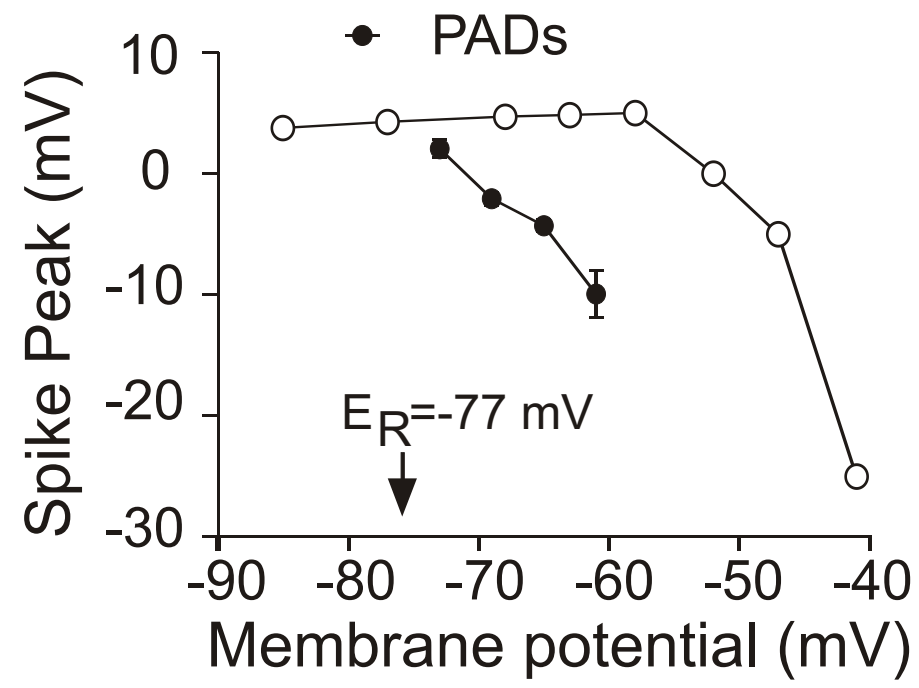

E

ME1

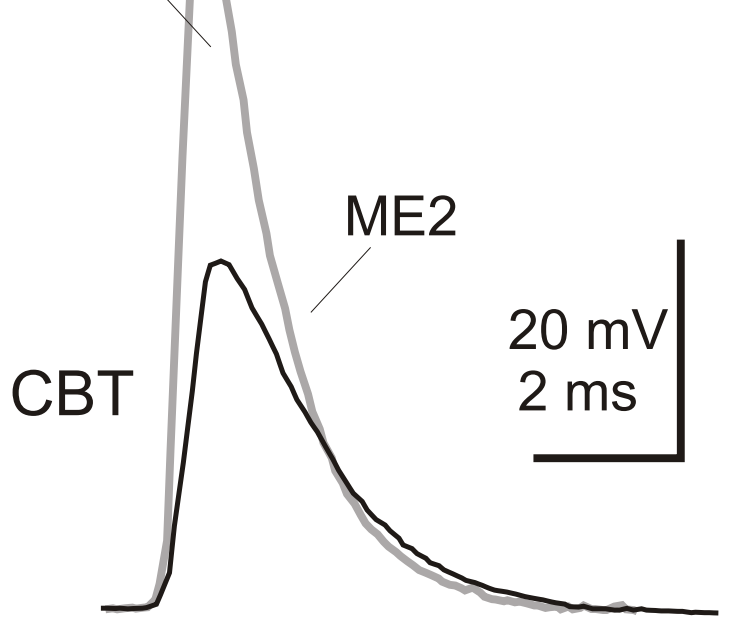


FIG. 25

A

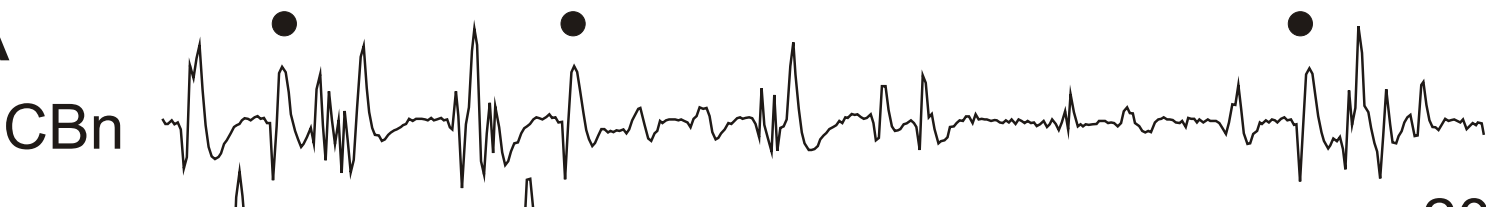

CBT

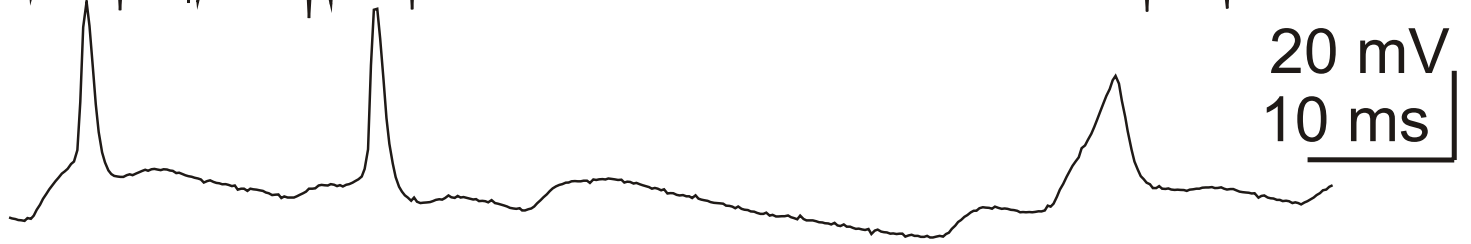

B

Orthodromic spike EPSP

Antidromic spike

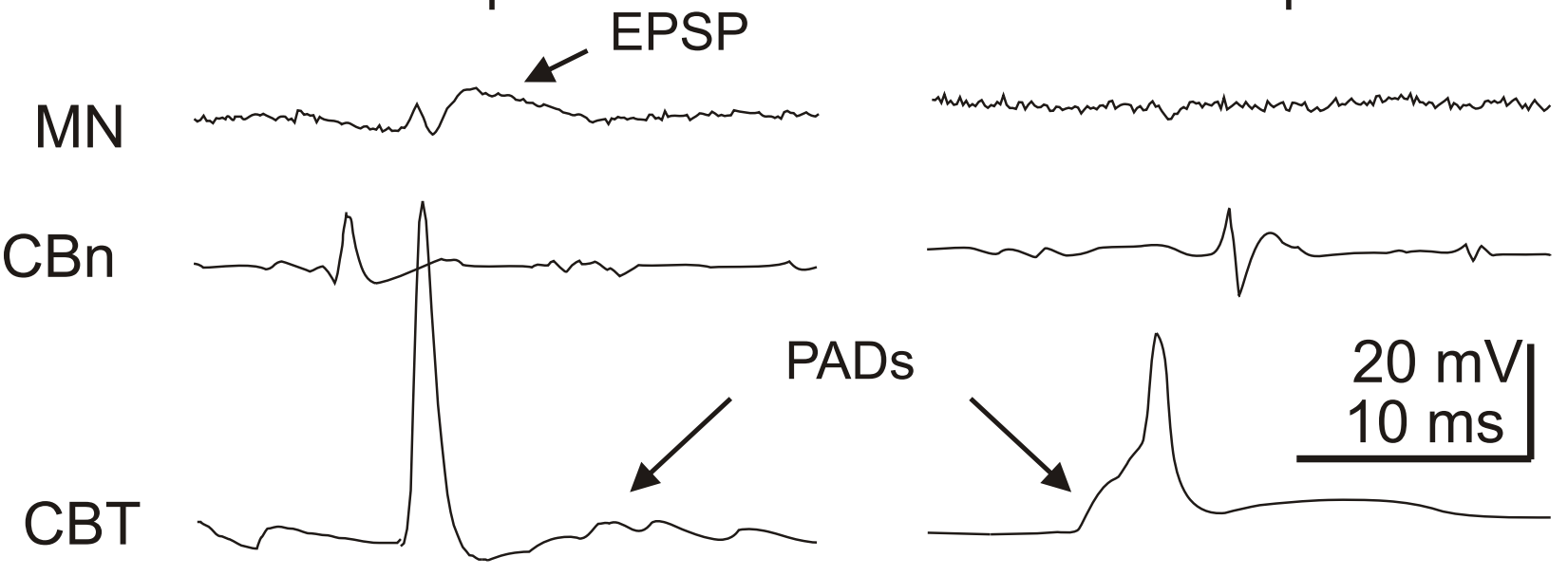


FIG. 26

\section{PRESYNAPTIC}

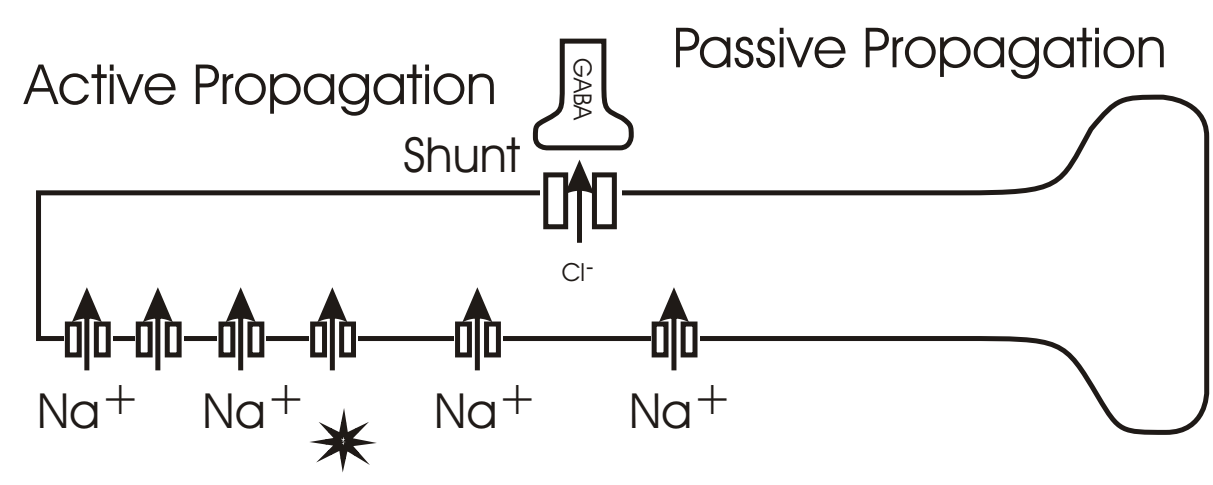

Orthodromic spike
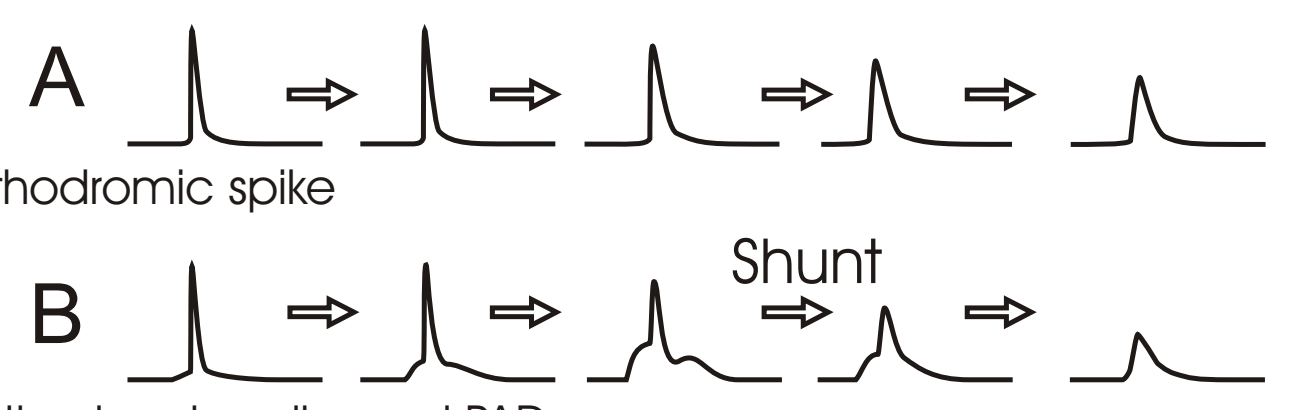

Orthodromic spike and PAD

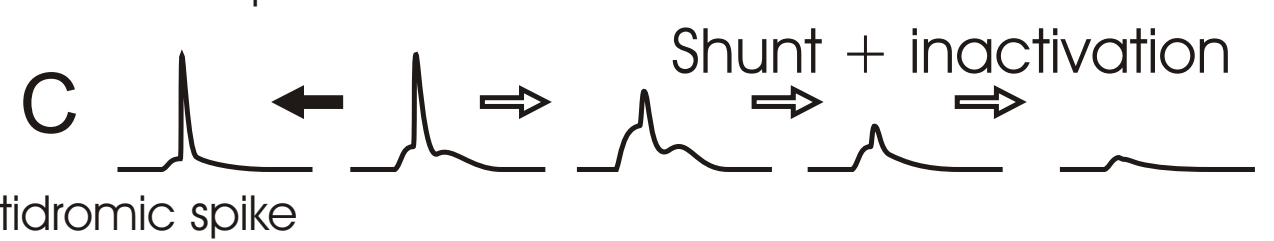


A

PADs

FIG. 27

sd PADs

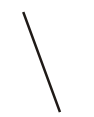

CBT

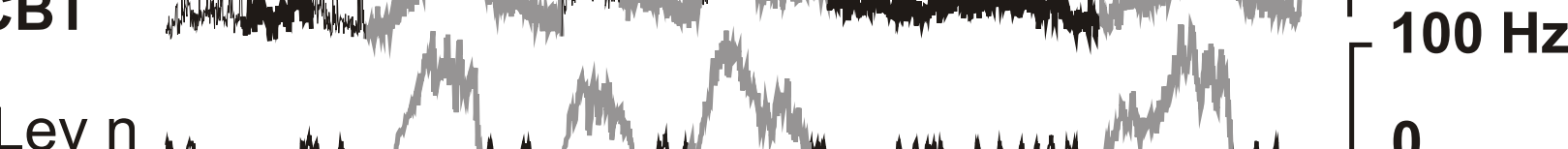
inst. Freq.

Lev $n$

sd PADs

Dep $n$

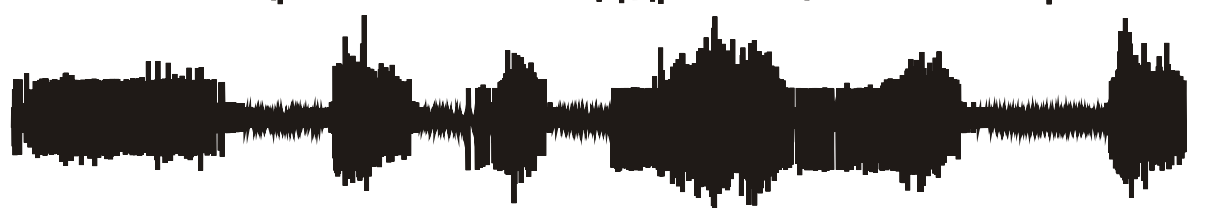

B Picrotoxin $10^{-4} \mathrm{M}$

CBT

Pro $n-m_{m}$

Lev $n$

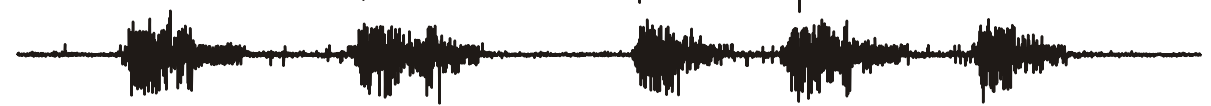

Dep $n$
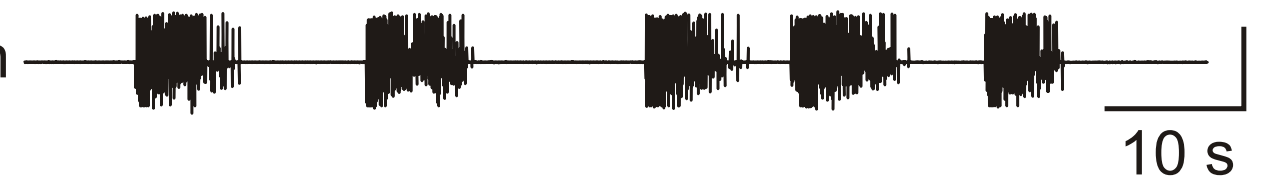

C

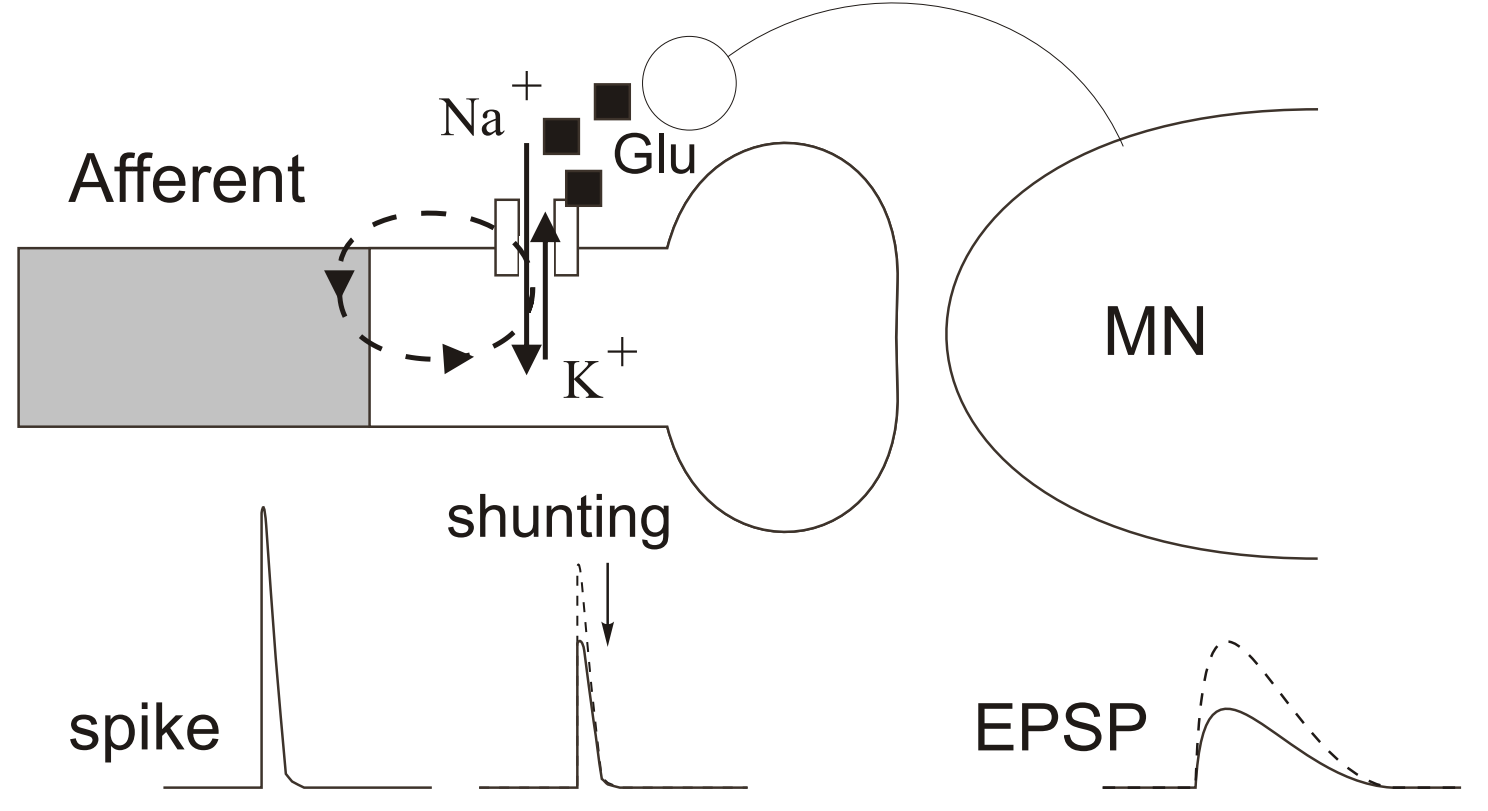


A

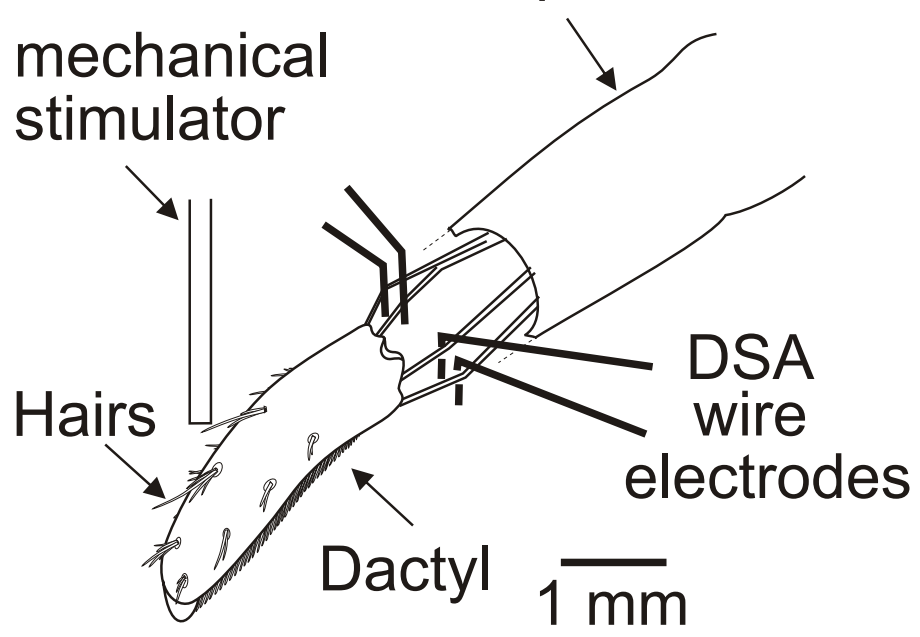

C
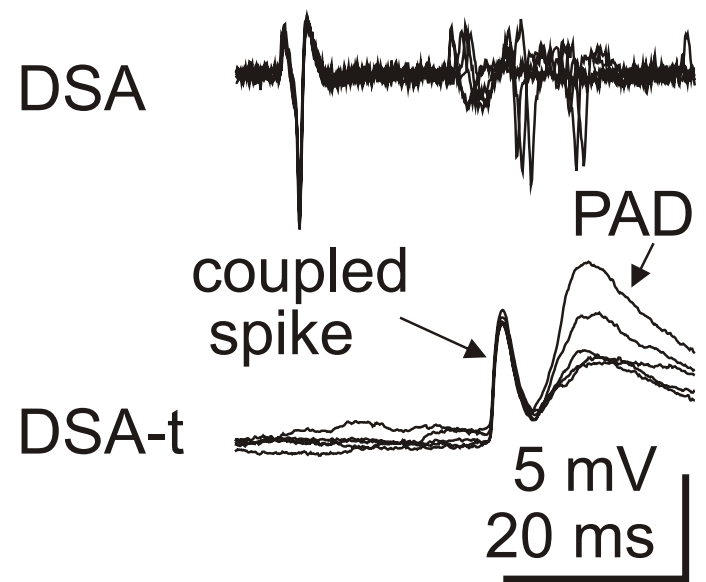

D
FIG. 28

B afferent

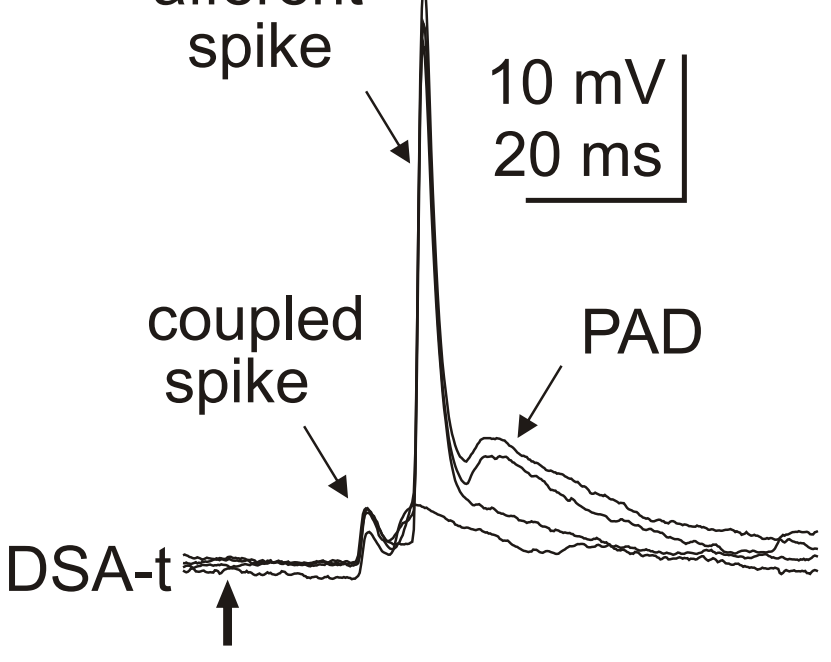

stim. microelectrode

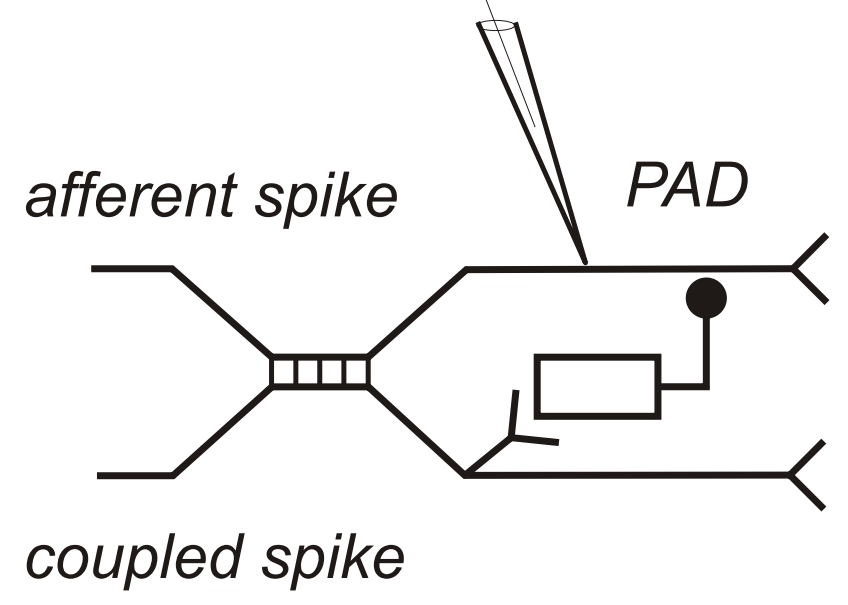


FIG.29

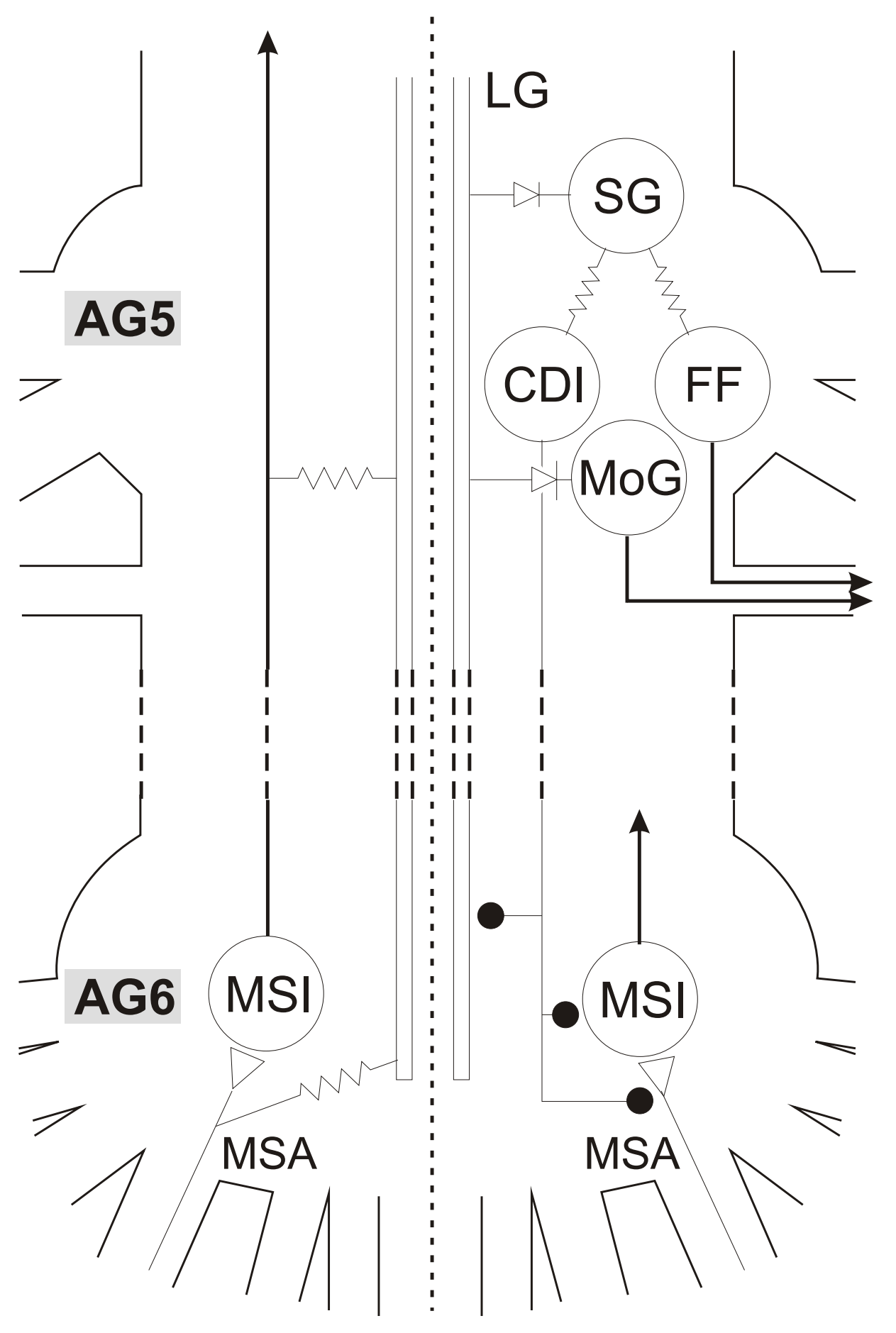



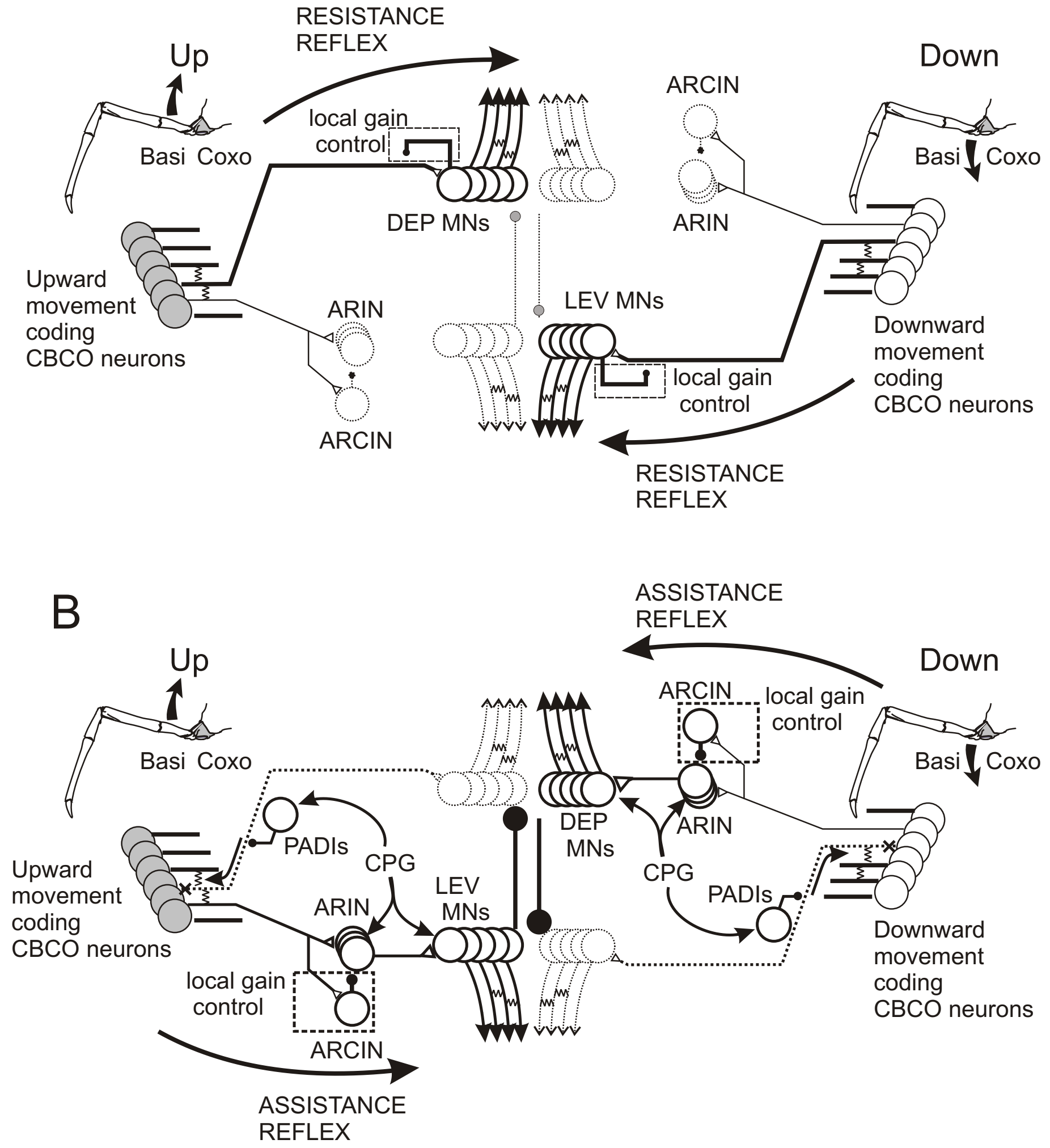
FIG. 31

A

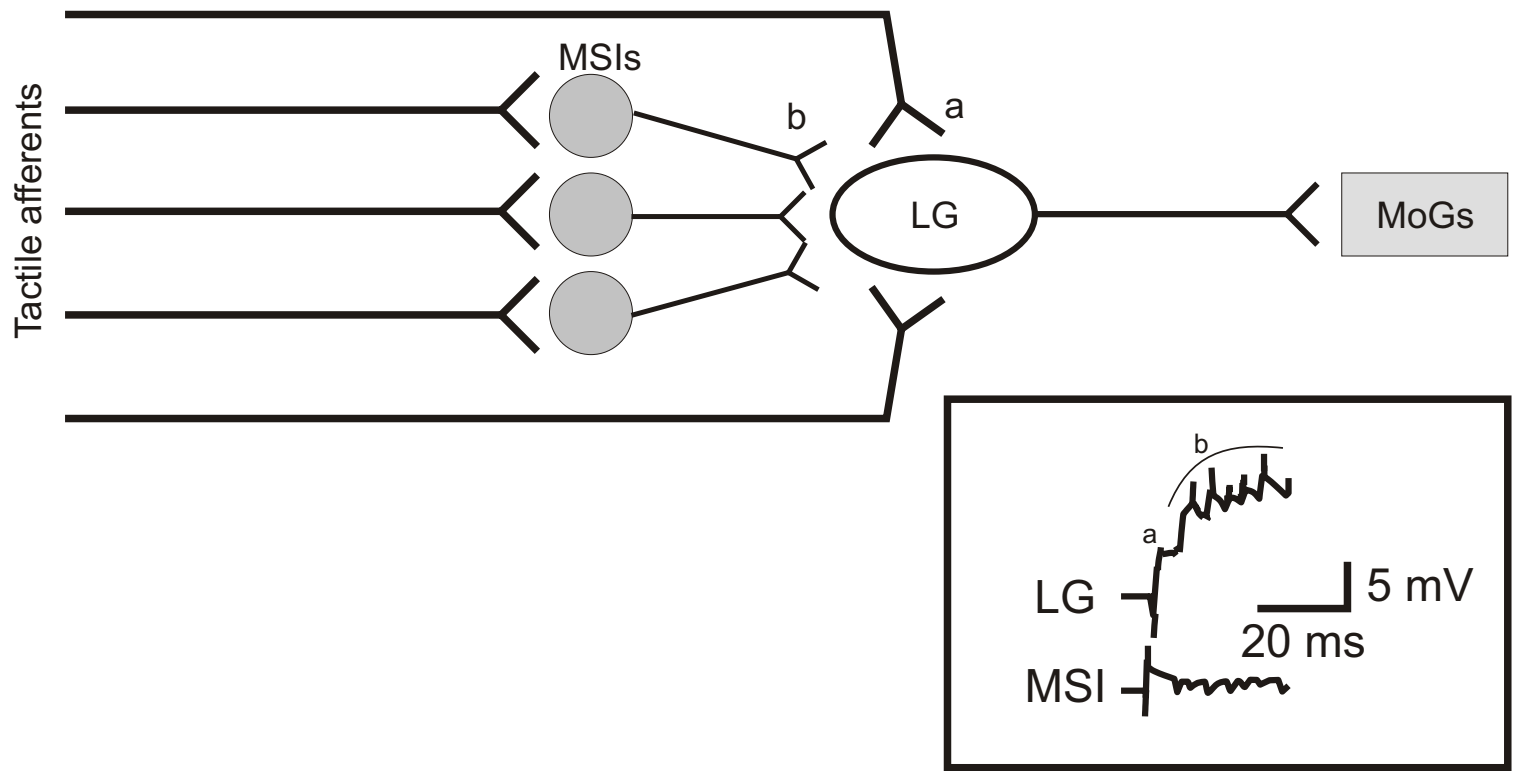

B

(2)

(3)

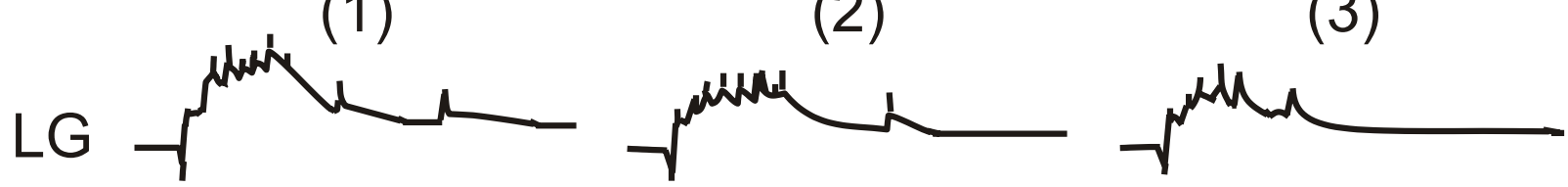

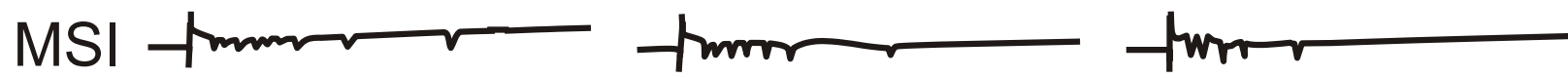

(4)

(10)

(30)

$\mathrm{LG} \sqrt{\mu \mu}$
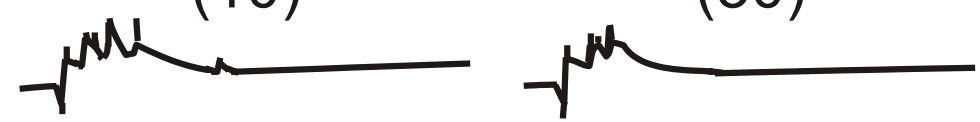

MSI -tw

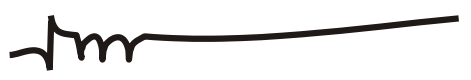

tro

$25 \mathrm{~ms}$ 
FIG. 32

A

Control

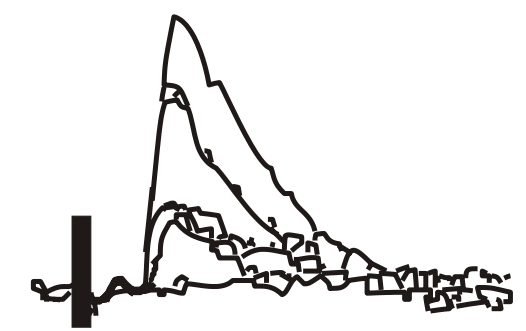

Motor

nerve St

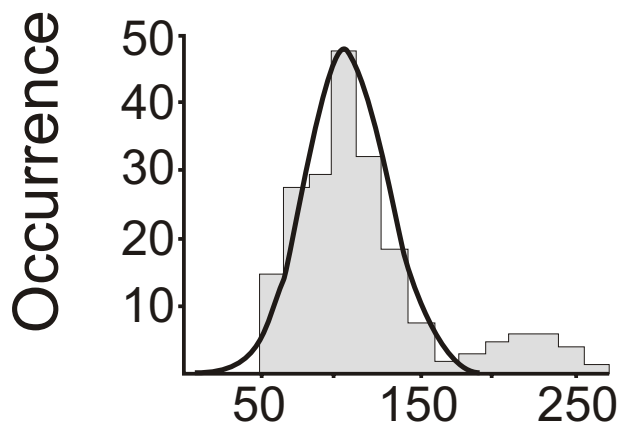

Amplitude $(\mu \mathrm{V})$
Posttetanus
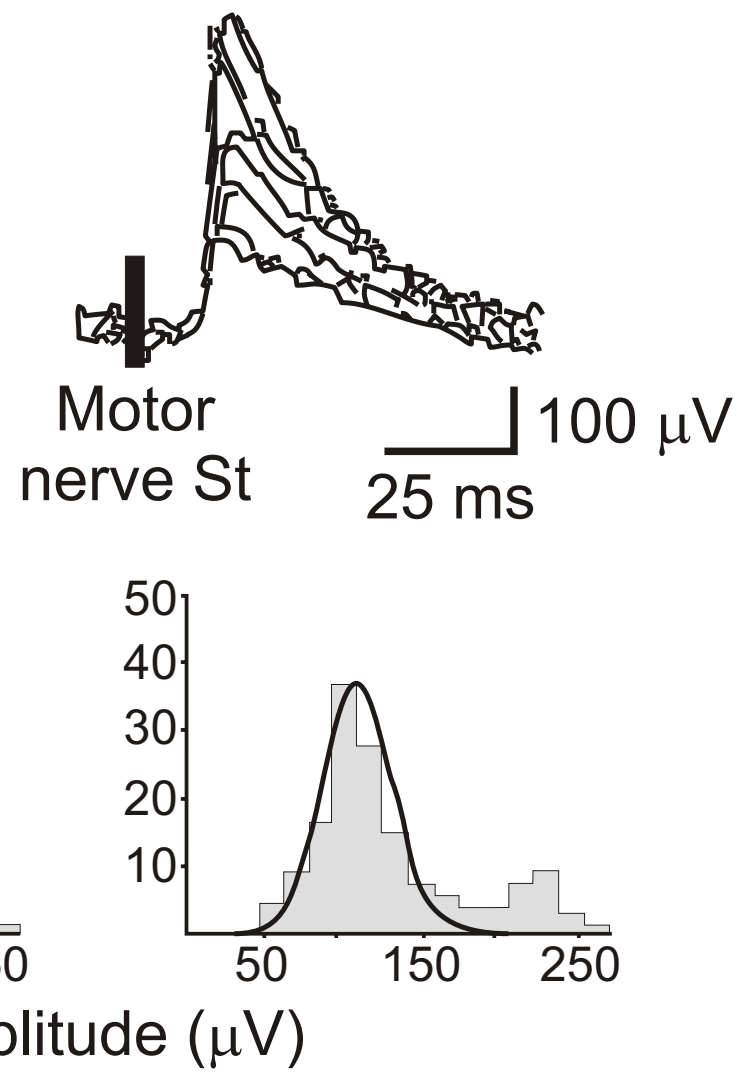

B

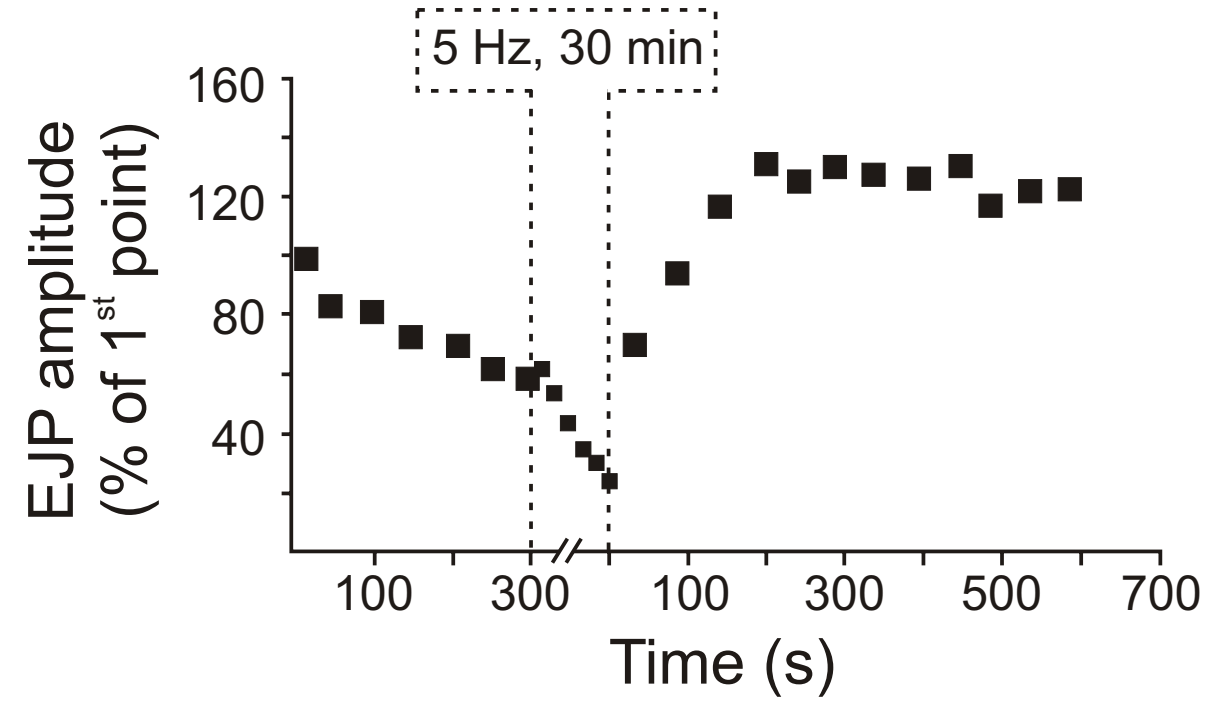


FIG.33
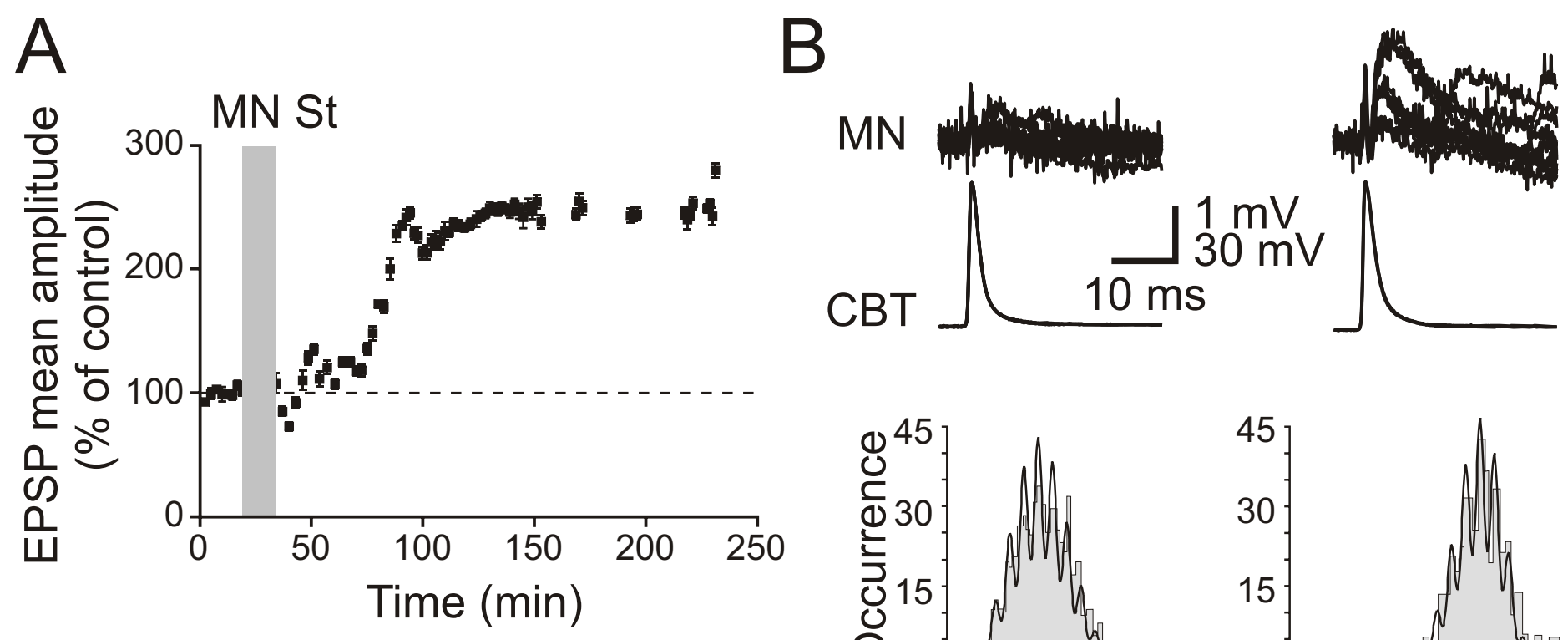

C

1 Silent MN Active afferent

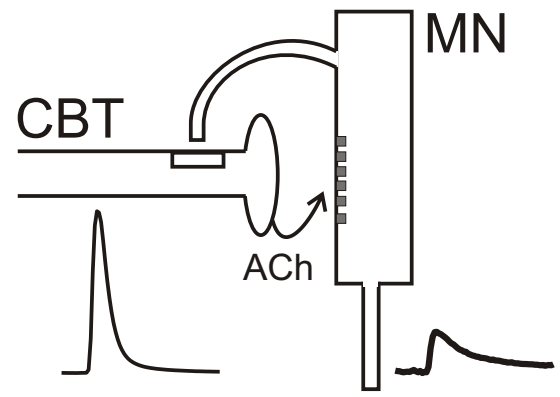

2 Active MN Silent afferent

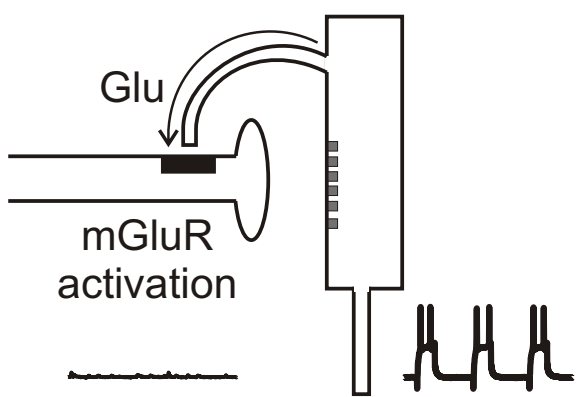

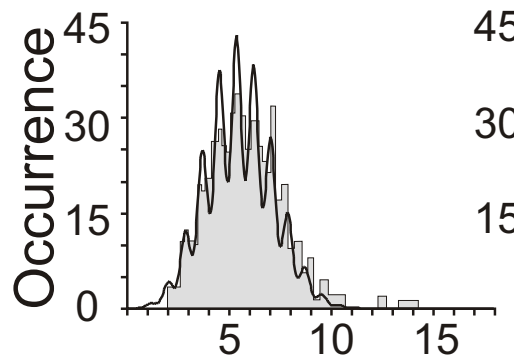

Quanta number

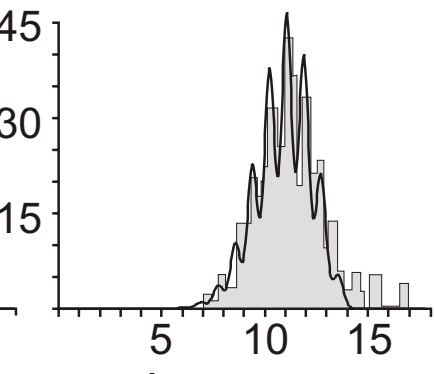

3 Potentiated

Synapse

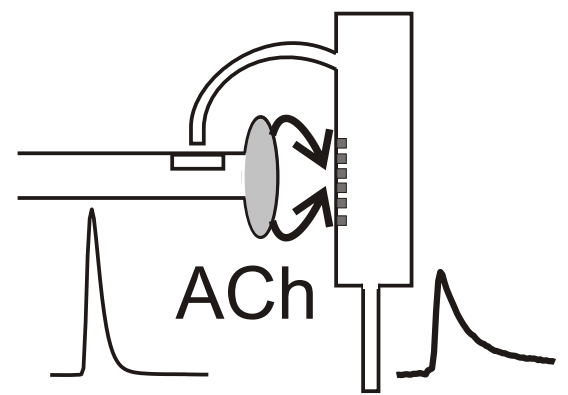

